\title{
MODELAGEM DE CAMPO ACÚSTICO GERADO POR TRANSDUTORES
}

\section{ULTRA-SÔNICOS RETANGULARES}

Dissertação apresentada à Escola Politécnica da Universidade de São Paulo para obtenção do

Título de Mestre em Engenharia

Área de Concentração:

Engenharia Mecatrônica

Orientador:

Prof. Dr. Flávio Buiochi 
Este exemplar foi revisado e alterado em relação à versão original, sob responsabilidade única do autor e com a anuência de seu orientador.

São Paulo, 21 de dezembro de 2007.

Assinatura do autor

Assinatura do orientador

\section{FICHA CATALOGRÁFICA}

Guglielmo Benítez, Juan Carlos

Modelagem de campo acústico gerado por transdutores ultra-sônicos retangulares / J.C. Guglielmo Benítez. -- São Paulo, 2007.

85 p.

Dissertação (Mestrado) - Escola Politécnica da Universidade de São Paulo. Departamento de Engenharia Mecatrônica e de Sistemas Mecânicos.

1.Acústica 2.Sensores biomédicos 3.Modelagem matemática I.Universidade de São Paulo. Escola Politécnica. Departamento de Engenharia Mecatrônica e de Sistemas Mecânicos Il.t. 
Dedico, humildemente, este trabalho ao Supremo Engenheiro, o grande Criador; a meus queridos antepassados, minhas raízes;

a meus queridos pais (in memoriam), Emílio e Josefa, que me deram a vida e amor;

a meus queridos irmãos, Mirtha e Manuel, firmes companheiros de longa caminhada;

a meus queridos filhos, Florência, Jorge (in memoriam) e Pedro, flores e frutos da minha vida;

e a meus queridos amigos (in memoriam), Eduardo Juan Jensen Arias e Jorge Juan Escribano, que trouxeram luz em minha vida. 


\section{AGRADECIMENTOS}

Ao meu orientador, Prof. Dr. Flávio Buiochi, que graciosamente compartilhou seus profundos conhecimentos do assunto, pela recepção amistosa e sem restrições e especialmente por ter acreditado em mim, apesar das condições menos favoráveis;

à Universidade de São Paulo, na pessoa do Prof. Dr. Júlio C. Adamoswki, do Laboratório de UltraSom desta universidade, sem cuja existência esta dissertação não teria sido possível, extensiva a todos os professores e funcionários desta prestigiosa instituição; aos meus colegas, especialmente aos Mestres, Marco Aurélio Brizzotti Andrade, por sua inestimável colaboração no desenvolvimento prático e teórico desta dissertação, Maro Jinbo, inseparável companheiro de tantas peripécias desde a longínqua Santa Catarina até a USP e David Julio da Costa, pela dedicada ajuda para finalizar este trabalho;

ao Prof. Werner José Bertoldi, atual Reitor da Universidade do Contestado (SC), pela expedita ajuda sempre prestada para a concretização do meus projetos, extensiva a todos os docentes e funcionários do campus de Curitibanos, pela ajuda prestada ao meu projeto de mestrado; a todas as outras pessoas que, de uma ou outra maneira, permitiram a conclusão deste trabalho e, por último e especialmente, à minha querida esposa Cristina por me oferecer sua infindável alegria, incentivadora desta feliz caminhada. 


\section{RESUMO}

A modelagem do campo acústico gerado por um transdutor ultra-sônico retangular é importante porque sua geometria é usada freqüentemente por transdutores multielementos (arrays). O conhecimento do campo acústico pode otimizar alguns parâmetros de projeto de transdutores ultra-sônicos, tais como: a sua geometria, a profundidade de foco, a largura do feixe acústico, bem como os parâmetros de focalização de um array (leis de retardos e de apodização). O modelo implementado neste trabalho calcula a pressão acústica e o potencial de velocidade gerados por transdutores de geometria retangular em um conjunto de pontos do espaço. A abordagem usa o método da integral de convolução e da resposta espacial impulsiva, cuja solução computacional do problema é exata e relativamente simples, o que normalmente não ocorre com outros métodos que apresentam um alto custo computacional (tempo de processamento). A resposta em pressão do transdutor em cada ponto do espaço é obtida com o modelo implementado em Matlab e é verificada experimentalmente. São realizadas medidas experimentais do campo de pressão gerado por transdutores retangulares monoelementos na faixa de freqüências de $400 \mathrm{kHz}$ a 2,2 MHz e um array na freqüência de $1 \mathrm{MHz}$, em um tanque de imersão, utilizando um hidrofone pontual e um sistema computadorizado de varredura de campo. A comparação entre os resultados simulados e experimentais mostra uma boa concordância, bem como as suas limitações.

Palavras-chave: campo acústico, transdutor ultra-sônico, modelagem. 


\begin{abstract}
The simulation of the acoustic field generated by a rectangular ultrasonic transducer is important because its geometry is frequently used in arrays. The knowledge of the acoustic field can optimize some design parameters of ultrasonic transducers, such as: geometry, focus depth, acoustic beam width, as well as the delay laws and the apodization of an array. Such simulation is implemented in this work, using a model that calculates the acoustic pressure in a space point. The approach uses the convolution integral and the spatial impulsive response methods. This computational solution is exact and relatively simple. That does not usually happen to other methods with a higher computational time. The acoustic field simulations obtained with the model implemented in Matlab are verified experimentally. Measurements of the pressure field generated by rectangular transducers in $400 \mathrm{kHz}$ to $2.2 \mathrm{MHz}$ and by an $1 \mathrm{MHz}$ array were made in an immersion tank, using a punctual hidrophone and a computerized system for acoustic field measurements. The comparison between the simulated and experimental results shows good agreement.
\end{abstract}

Keywords: acoustic field, ultrasonic transducer, simulation. 


\section{LISTA DE ILUSTRAÇÕES}

Figura 1.1. Sistema de diagnóstico ou medida ultra-sônico.

Figura 2.1. Pistão plano de geometria arbitrária.

Figura 2.2. Pistão plano de geometria arbitrária e arco ativo L.

Figura 2.3. Campo próximo e campo distante de um transdutor.

Figura 2.4. Geometria para cálculo de $\mathrm{R}_{\min }$.

Figura 2.5. Geometria do pistão retangular.

Figura 2.6. Pistão plano de geometria retangular e arco ativo L.

Figura 2.7. Regiões usadas para calcular o valor de $\Omega\left(\boldsymbol{R}^{\prime \prime}, t\right)$.

Figura 2.8. Variáveis usadas para calcular o valor de $\Omega\left(\boldsymbol{R}^{\prime \prime}, t\right)$.

Figura 3.1. Focalização sem deflexão do feixe acústico de um array linear.

Figura 3.2. Focalização com deflexão do feixe acústico de um array linear.

Figura 3.3. Lóbulos principal e secundários do campo acústico gerado por um array linear.

Figura 3.4. Lóbulos de espaçamento do campo acústico gerado por um array linear.

Figura 3.5. Geometria de um array linear de $\mathrm{N}$ elementos.

Figura 4.1. Fluxograma da simulação da resposta espacial impulsiva.

Figura 4.2. Protótipo do transdutor \#1 (monoelemento).

Figura 4.3. Geometria do array usado na simulação e verificação experimental.

Figura 4.4. Protótipo do transdutor matricial linear.

Figura 4.5. Geometria das coordenadas das simulações.

Figura 4.6. Geometria da focalização sem deflexão.

Figura 4.7. Geometria da deflexão sem focalização.

Figura 4.8. Geometria da deflexão com focalização.

Figura 4.9. Sinal de excitação do transdutor \# 1 de 2,2 MHz. 
Figura 4.10. Sinal de excitação do transdutor \#2 de $400 \mathrm{kHz}$.

Figura 4.11. Sinal de excitação do transdutor \#3 de $400 \mathrm{kHz}$.

Figura 4.12. Sinal de excitação do transdutor \#4 de $400 \mathrm{kHz}$.

Figura 4.13. Sinal de excitação do array de $1 \mathrm{MHz}$.

Figura 4.14. Diagrama de blocos do sistema computadorizado de medição do campo acústico.

Figura 4.15. Varredura do mapeamento do campo acústico.

Figura 4.16. Fotografia do hidrofone pontual de $\varnothing=0,6 \mathrm{~mm}$.

Figura 4.17. Sistema computadorizado de medição do campo acústico.

Figura 5.1. Pressão acústica em função do tempo obtida na posição $(x=0 \mathrm{~mm}, \mathrm{y}=10 \mathrm{~mm}$ e $\mathrm{z}=10$ $\mathrm{mm}$ ): (a) pressão teórica; (b) pressão experimental.

Figura 5.2. Comparação entre o campo acústico teórico e experimental no plano $x z$ sendo $y=0$ : (a) teórico; (b) experimental.

Figura 5.3. Comparação entre o campo acústico teórico e experimental no plano $y z$ sendo $x=0$ : (a) teórico; (b) experimental.

Figura 5.4. Comparação entre o campo acústico teórico e experimental no plano $x z$ sendo $y=0$ : (a) teórico; (b) experimental. (Transdutor \#2 de $400 \mathrm{kHz}$ ).

Figura 5.5. Comparação entre o campo acústico teórico e experimental no plano $y z$ sendo $x=0$ : (a) teórico; (b) experimental. (Transdutor \#2 de $400 \mathrm{kHz}$ ).

Figura 5.6. Comparação entre o campo acústico teórico e experimental no plano $x z$ sendo $y=0$ : (a) teórico; (b) experimental. (Transdutor \#3 de $400 \mathrm{kHz}$ ).

Figura 5.7. Comparação entre o campo acústico teórico e experimental no plano $y z$ sendo $x=0$ : (a) teórico; (b) experimental. (Transdutor \#3 de $400 \mathrm{kHz}$ ).

Figura 5.8. Comparação entre o campo acústico teórico e experimental no plano $x z$ sendo $y=0$ : (a) teórico; (b) experimental. (Transdutor \#4 de $400 \mathrm{kHz}$ ).

Figura 5.9. Comparação entre o campo acústico teórico e experimental no plano $y z$ sendo $x=0$ : (a) teórico; (b) experimental. (Transdutor \#4 de $400 \mathrm{kHz}$ ).

Figura 5.11. Pressão acústica em função do tempo obtida na posição dos pontos $M_{1}(0,0,30 \mathrm{~mm}$, vermelho), $M_{2}(0,5 \mathrm{~mm}, 30 \mathrm{~mm}$, verde $)$ e $M_{3}(0,10 \mathrm{~mm}, 30 \mathrm{~mm}$, azul), sem deflexão e sem focalização: (a) pressão teórica; (b) pressão experimental no ponto $M_{1}$.

Figura 5.12. Pressão acústica em função do tempo obtida na posição dos pontos $M_{1}(0,0,30 \mathrm{~mm}$, vermelho), $M_{2}(0,5 \mathrm{~mm}, 30 \mathrm{~mm}$, verde $)$ e $M_{3}(0,10 \mathrm{~mm}, 30 \mathrm{~mm}$, azul), sem deflexão e com focalização no eixo acústico, em $z=30 \mathrm{~mm}$ : (a) pressão teórica; (b) pressão experimental no ponto $M_{1}$. 
Figura 5.13. Pressão acústica em função do tempo obtida na posição dos pontos $M_{1}(0,0,30 \mathrm{~mm}$, vermelho), $M_{2}(0,5 \mathrm{~mm}, 30 \mathrm{~mm}$, verde $)$ e $M_{3}(0,10 \mathrm{~mm}, 30 \mathrm{~mm}$, azul), com deflexão e sem focalização: (a) pressão teórica; (b) pressão experimental no ponto $M_{1}$.

Figura 5.14. Pressão acústica teórica em função do tempo obtida na posição dos pontos $M_{1}(0,0,30$ $\mathrm{mm}$, vermelho), $M_{2}\left(0,5 \mathrm{~mm}, 30 \mathrm{~mm}\right.$, verde) e $M_{3}(0,10 \mathrm{~mm}, 30 \mathrm{~mm}$, azul $)$, com deflexão e com focalização no eixo acústico, em $z=30 \mathrm{~mm}$. (a) pressão teórica; (b) pressão experimental no ponto $M_{1}$.

Figura 5.15. Comparação entre o campo acústico teórico e experimental gerado pela excitação isolada de um único elemento: (a) teórico; (b) experimental. (Array de $1 \mathrm{MHz}$ ).

Figura 5.16. Campo acústico teórico gerado pela excitação simultánea dos elemento do array (Array de $1 \mathrm{MHz}$ ).

Figura 5.17. Campo acústico experimental gerado pela excitação simultánea dos elemento do array (Array de $1 \mathrm{MHz}$ ).

Figura 5.18. Campo acústico teórico, sem deflexão e com focalização no eixo acústico, em $z=30$ $m m$.

Figura 5.19. Campo acústico teórico, com deflexão de $10^{\circ}$ e com focalização em $z=30 \mathrm{~mm}$. 


\section{LISTA DE TABELAS}

Tabela 4.1. Dimensões dos transdutores construídos.

Tabela 4.2. Características acústicas dos transdutores construídos.

Tabela 4.3. Atrasos dos elementos do array em focalização sem deflexão.

Tabela 4.4. Atrasos dos elementos do array com deflexão e sem focalização.

Tabela 4.5. Ordenadas e atrasos dos elementos do array com deflexão e com focalização. 


\section{LISTA DE SÍMBOLOS}

$\boldsymbol{R}$ vetor posição do ponto

$p(\boldsymbol{R}, t)$ pressão acústica

$\boldsymbol{v}$ velocidade

$\rho$ densidade do fluido

$\phi$ potencial de velocidade

$\delta$ função delta de Dirac

$\phi_{i}(\mathbf{R}, t)$ resposta impulsiva do potencial de velocidade

$\phi(\boldsymbol{R}, t)$ potencial de velocidade

$\Omega(c t)$ ângulo dos arcos concêntricos ao ponto

$\boldsymbol{L}$ arco ativo

$p_{i}(\boldsymbol{R}, t)$ resposta impulsiva da pressão

$p(\boldsymbol{R}, t)$ pressão acústica

$v(t)$ velocidade de vibração do pistão

$\lambda$ comprimento de onda

$\Delta z$ resolução axial

$2 a$ lado menor do retângulo

$2 b$ lado maior do retângulo

$t_{A}$ tempo de chegada ao vértice $A$

$t_{B}$ tempo de chegada ao vértice $B$

$t_{C}$ tempo de chegada ao vértice $C$

$t_{D}$ tempo de chegada ao vértice $D$

$t_{1}$ tempo de chegada ao lado 1 
$t_{2}$ tempo de chegada ao lado 2

$t_{3}$ tempo de chegada ao lado 3

$t_{4}$ tempo de chegada ao lado 4

$t_{0}$ tempo para alcançar o ponto 


\section{SUMÁRIO}

\section{CAPÍTULO 1}

INTRODUÇÃO

1.1 Justificativa 3

1.2 Objetivos 3

$\begin{array}{ll}1.3 \text { Organização } & 4\end{array}$

1.4 Revisão Bibliográfica 4

CAPÍTULO 2

MODELO TEÓRICO PARA O CÁLCULO DO CAMPO ACÚSTICO

2.1 Campo acústico produzido por um pistão plano de geometria arbitrária.

Método da resposta impulsiva (RI)

2.2 Campo próximo e campo distante

2.3 Campo acústico produzido por um transdutor retangular.

\section{CAPÍTULO 3}

TRANSDUTORES MULTIELEMENTOS (ARRAYS) 22

$\begin{array}{ll}3.1 \text { Parâmetros dos feixes acústicos } & 23\end{array}$

3.2 Campo acústico gerado por arrays lineares $\quad 24$

$\begin{array}{ll}3.3 \text { Projeto de arrays lineares } & 27\end{array}$

CAPÍTULO 4

MATERIAIS E MÉTODOS 29

4.1 Modelos implementados $\quad 29$

4.2 Transdutores monoelementos 33

4.3 Transdutores array lineares $\quad 35$

4.4 Funções de excitação 42

4.5 Sistema computadorizado de medição 
CAPÍTULO 5

RESULTADOS TEÓRICOS E EXPERIMENTAIS 48

5.1 Transdutores monoelementos retangulares $\quad 48$

5.2 Transdutores multielementos (array lineares) 56

CAPÍTULO 6

CONCLUSÕES E PRÓXIMAS ATIVIDADES 67

REFERÊNCIAS BIBLIOGRÁFICAS $\quad 68$

APÊNDICE A - Arquivo “m” da resposta espacial impulsiva. $\quad 72$ 


\section{CAPÍTULO 1}

\section{INTRODUÇÃO}

As ondas de ultra-som são ondas mecânicas que se propagam nos materiais pelo movimento harmônico das moléculas do meio. São chamadas de ondas ultra-sônicas porque sua freqüência de vibração é superior às freqüências audíveis. A energia das ondas ultra-sônicas pode ser empregada para modificar o meio onde se propaga, para fins terapêuticos (aquecimento) ou industriais (limpeza de peças), por exemplo. Tais aplicações são chamadas de alta intensidade em razão da potência envolvida, da ordem de centenas ou milhares de watts. Outro tipo de aplicação é para ensaios nãodestrutivos, o que possibilita a detecção de falhas em peças mecânicas. As mudanças produzidas nas ondas durante a propagação por um material permitem medir as características físicas ou geométricas do mesmo (ADAMOWSKI, 1993 e BUIOCHI, 1994). Também pode ser aplicado na área médica com a finalidade de diagnóstico por imagens. Essas aplicações são de baixa intensidade por envolverem, geralmente, potências na ordem de miliwatts.

Em um meio físico podem existir dois tipos de ondas, a longitudinal e a de cisalhamento, dependendo se ele é sólido ou fluido. Se durante a propagação de uma onda, as partículas do meio se deslocarem na direção de propagação da mesma, trata-se de uma onda longitudinal. Para o caso da onda de cisalhamento, as partículas se deslocam na direção perpendicular à propagação. Nos sólidos podem existir ondas longitudinais e de cisalhamento. Já num fluido não viscoso, só podem existir ondas longitudinais. Neste trabalho, é feito um estudo do campo acústico emitido por transdutores retangulares em fluidos não viscosos.

Um sistema de diagnóstico ou medida ultra-sônico consta dos componentes básicos apresentados na figura 1.1: o emissor, que introduz as ondas no meio, o próprio meio a ser examinado e o receptor, que converte as ondas de ultra-som em sinais elétricos. Eventualmente, o 
receptor pode ser o mesmo transdutor que produz a emissão das ondas ultra-sônicas. Nesse caso, tem-se o modo de operação pulso-eco.

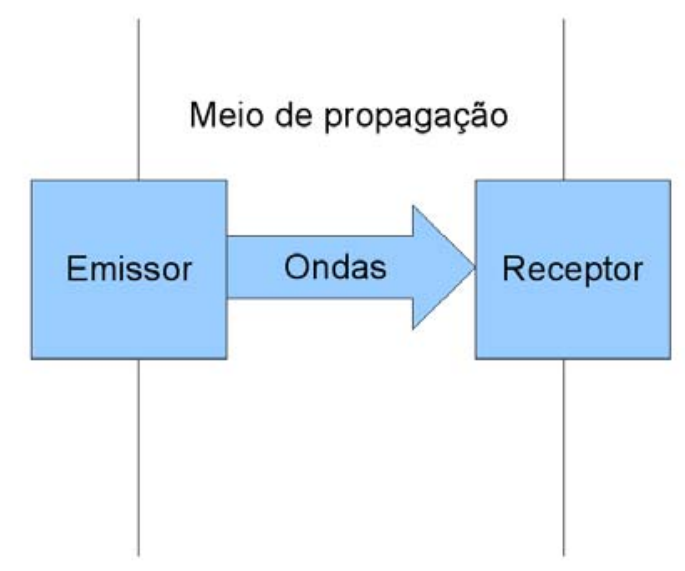

Figura 1.1. Sistema de diagnóstico ou medida ultra-sônico.

Num sistema de visualização por ultra-som, um aspecto importante é a focalização, que resulta da convergência do feixe de ultra-som em um dado ponto de interesse (o chamado ponto focal), melhorando a resolução lateral e a relação sinal/ruído. Existem dois tipos de focalização, a óptica e a eletrônica. Um sistema eletrônico pode focalizar e/ou defletir o feixe ultra-sônico, por meio da defasagem aplicada aos sinais emitidos ou recebidos dos diferentes elementos de um array. Assim, a focalização eletrônica oferece mais versatilidade e flexibilidade, uma vez que a focalização óptica utiliza lentes fixas. Outros parâmetros importantes são a resolução lateral e a profundidade de foco. A resolução lateral é determinada pela largura do feixe e pode ser especificada pelo ângulo de abertura do mesmo ou pela distância entre os pontos extremos. Já a profundidade do foco é determinada pelo intervalo no qual as características do campo são semelhantes às características do foco.

Geralmente, a modelagem de transdutores ultra-sônicos com geometria complexas é feita 
através de métodos numéricos, por meio de uma seqüência finita de passos (o algoritmo), sendo possível transformar um modelo matemático em um problema numérico. Como esse problema envolve o cálculo de integrais complexas, é difícil encontrar uma solução analítica, seja porque o cálculo da função primitiva não é trivial ou porque a expressão analítica da função integrando não é conhecida. Entretanto, utilizando geometrias simples, como por exemplo, a retangular, algumas integrais podem ser simplificadas gerando soluções analíticas.

Por meio da resposta impulsiva, que é a reação de um sistema a uma entrada de pulso delta de Dirac e das propriedades dos sistemas lineares invariantes no tempo, o campo acústico gerado pelo transdutor pode ser calculado como a convolução entre a resposta impulsiva e o sinal de excitação do transdutor.

\subsection{Justificativa}

Modelar a resposta de um transdutor ultra-sônico é fundamental em aplicações como imagens para uso médico e ensaios não destrutivos. Sendo usados cada vez mais transdutores multielementos (array), é necessário adequar os mesmos, diminuindo os lóbulos laterais e aumentando a profundidade do campo, por exemplo. Baseados numa adequada modelagem do campo acústico produzido pelos transdutores, os mesmos podem ser caracterizados e otimizados.

\subsection{Objetivos}

Este trabalho tem como objetivo modelar e medir o campo acústico gerado por transdutores ultra-sônicos retangulares, na faixa de alguns $\mathrm{MHz}$, por meio de modelos matemáticos e verificações experimentais. Apresenta-se um cálculo exato do campo acústico irradiado a partir de uma abertura retangular, usando o método da resposta impulsiva. Trabalha-se com as hipóteses de propagação linear em meio homogêneo, sem atenuação e abertura plana montada sobre um refletor 
infinito e rígido. Com o método é possível calcular o campo de pressão acústica em todos os pontos do espaço, em qualquer instante, para qualquer velocidade de excitação da superfície do transdutor. As simulações do campo acústico são verificadas experimentalmente em um tanque de imersão, utilizando um hidrofone pontual e um sistema automático computadorizado de varredura de campo acústico. Para isso, utilizaram-se transdutores retangulares na faixa de freqüências de $400 \mathrm{kHz}$ a 2,2 MHz e um array de 12 elementos retangulares de $1 \mathrm{MHz}$.

\subsection{Organização}

Esta dissertação está dividida em seis capítulos, sendo que o capítulo 1 contém a introdução, justificativa, objetivo do trabalho e revisão bibliográfica. No capítulo 2 é apresentada uma revisão teórica do campo acústico, bem como as equações que descrevem a propagação e transmissão de ondas acústicas em meios fluídicos. Além disso, são mostradas expressões exatas para as respostas impulsivas do potencial de velocidade e da pressão para transdutores retangulares e as condições de contorno baseadas na existência de refletores rígidos. O capítulo 3 contém alguns conceitos dos transdutores multielementos (arrays). O capítulo 4 descreve as simulações e programas implementados. O capítulo 5 apresenta os transdutores construídos e utilizados, e as medições realizadas, assim como o sistema computadorizado de medições e as comparações resultantes. O capítulo 5 mostra, também, um exemplo de aplicação do modelo em transdutores multielementos. Finalmente, no capítulo 6, são mostradas as conclusões e as as propostas de trabalhos futuros.

\subsection{Revisão Bibliográfica}

A modelagem do campo acústico gerado por transdutores de forma circular foi bastante estudada, em razão das simplificações possíveis por sua simetria. Entretanto, no início dos anos 1960, Freedman apresentou um trabalho sobre o campo acústico gerado por transdutores de forma retangular. Comparou-os com os gerados por pistões de forma circular, usando a teoria do pistão 
plano e verificando que o comportamento de um pistão retangular produz uma melhor aproximação de uma onda realmente plana no campo próximo (FREEDMAN, 1960).

Em uma trilogia de trabalhos apresentados em 1971, Stepanishen desenvolveu o método da resposta impulsiva de algumas formas geométricas de pistões, usando uma integral de superfície. Nessa abordagem do estudo do campo acústico próximo e distante, é usada uma transformação de coordenadas para simplificar o cálculo das integrais de superfície resultantes da aplicação das funções de Green. O campo distante radiado por um transdutor retangular, ou array de elementos retangulares, é discutido tanto para excitação contínua como pulsada (STEPANISHEN, 1971a, b e c). Ainda nessa época, é apresentada por Lockwood e Willette uma solução analítica para a resposta impulsiva de um transdutor retangular no campo próximo (LOCKWOOD e WILLETTE, 1973). Em 1979, foi apresentada por Hayman e Weight uma detalhada comparação entre as formas de onda do modelo teórico e de medições experimentais nos modos de transmissão e recepção de uma onda impulsiva, usando um refletor pontual. Foram apresentados resultados para transdutores de forma circular e quadrada e discutido o efeito da frente de onda (HAYMAN e WEIGHT, 1979).

Já na década de 80, foram apresentados por Harris dois trabalhos (HARRIS, 1981a e b). No primeiro foram mostradas as bases matemáticas dos métodos empregados no cálculo do campo acústico, integral de superfície de Rayleigh, integral de King, solução de Schoch e integral de convolução, revisados e discutidos especialmente em excitação transiente. No segundo trabalho foi apresentado um modelo teórico para calcular o potencial de velocidade e o campo de pressão radiado por um pistão plano, montado em um refletor rígido infinito e possuindo uma distribuição espacial arbitrária. O método foi baseado na resposta espacial impulsiva. No final da década, Maclaren e Weight apresentaram uma modelagem detalhada da resposta impulsiva de uma onda refletida (eco) nos modos transmissão e reflexão, com alvos sólidos de vários tamanhos (pontuais e de tamanho finito) imersos em meios fluidos. Foram usados alvos metálicos circulares e estudadas 
as contribuições das ondas plana e de borda. No trabalho é mostrado que a forma da onda refletida de um alvo geométrico definido é a mesma, mesmo que ele seja construído de um material altamente ou fracamente refletivo, e que as propriedades acústicas do alvo afetam unicamente a amplitude do pulso do eco (MACLAREN e WEIGHT, 1987).

No final da década de 80, analisou-se o comportamento dos arrays para obtenção de imagens, visando a otimização das características dos transdutores (LAMBERTI et al., 1987), imagens em tempo real (OSAKI et al., 1988) e aplicação em ensaios não destrutivos (LUDWIG, 1989).

Em 1992 foram apresentadas expressões exatas para as respostas impulsivas do potencial de velocidade e da pressão para transdutores retangulares, cujas condições de contorno são calculadas baseadas na existência de refletores rígidos (SAN EMETERIO e GÓMEZ-ULLATE, 1992). Nesse mesmo ano, foi apresentado um método para calcular o campo acústico de transdutores de forma arbitrária e apodizados por meio da divisão do transdutor em pequenos quadrados e da soma de suas respostas, utilizando uma aproximação válida no campo distante (JENSEN e SVENDSEN, 1992). Nesse trabalho, qualquer excitação do transdutor pode ser manipulada e a solução resposta da onda contínua é encontrada pela transformada de Fourier. Em artigo posterior, Jensen desenvolveu uma metodologia para transdutores de geometria triangular, com uma abordagem semelhante à utilizada por San Emeterio e Gómez-Ullate, com a ressalva do próprio autor de que o método tem um custo computacional muito alto comparado com a solução retangular (JENSEN, 1996).

Em um trabalho de (SHUNG e ZIPPARO, 1996) é analisada a técnica de obtenção de imagens ultra-sônicas e os diferentes modos de processá-las, aplicadas especificamente para examinar o corpo humano em diagnósticos médicos. Uma análise da emissão, recepção e processamento das ondas ultra-sônicas geradas por transdutores multielementos foi apresentada por 
Gomez-Ullate (2000).

Uma outra maneira de calcular a pressão acústica gerada por um transdutor de geometria arbitrárias é utilizar o método da representação discreta (PIWAKOWSKI e SBAI, 1999). Esse método numérico, freqüentemente utilizado no cálculo do campo acústico produzido por transdutores multielementos, demanda elevado tempo de processamento. Isso ocorre porque necessita de uma alta discretização da abertura do transdutor afim de se aproximar o máximo possível da solução exata. Também, o campo acústico produzido por transdutores ultra-sônicos pode ser modelado pelo método dos elementos finitos (MEF) que permite modelos mais precisos e genéricos que as técnicas baseadas no modelo do pistão plano (ABBOUD, 1998; HOFER e LERCH, 2002). O modelo do pistão plano geralmente considera que a face do transdutor vibra com a mesma velocidade (módulo e fase) em toda a sua extensão. Mas em muitos casos aparecem diferenças significativas entre as simulações baseadas nessa hipótese do pistão plano e os resultados experimentais do campo acústico obtidos dos próprios transdutores, uma vez que a geometria dos transdutores utilizados na prática são em geral bi ou tridimensionais.

No MEF, na definição das condições de contorno, é possível relevar a hipótese de pistão plano. A principal diferença entre os métodos analíticos e o MEF é a visão da estrutura do problema e o procedimento para resolvê-lo. Os métodos analíticos consideram a estrutura como um meio contínuo, cujo comportamento é governado por equações diferenciais ordinárias ou parciais. Já o MEF considera a estrutura discretizada em pequenos elementos de tamanho finito. $\mathrm{O}$ comportamento desse conjunto é regido por um sistema de equações algébricas, o que pode ser resolvido por um sistema computacional. Mas essa discretização implica em um pesado processamento, sendo esta a maior barreira para a utilização do MEF (DRINKWATER e WILCOX, 2006). Nesse artigo é apresentada uma revisão dos recentes desenvolvimentos na tecnologia de arrays, focalizado nas aplicações em ensaios não destrutivos; incluindo o projeto, materiais e 
fabricação, modelagem, processamento de sinais e perspectivas futuras no desenvolvimento dos mesmos.

Em 2004, Neild e Hutchins desenvolveram um modelo para um transdutor de tamanho finito (com relação ao menor comprimento de onda emitido pela fonte), baseado na abordagem da resposta impulsiva, que pode calcular a pressão acústica transmitida entre dois transdutores retangulares. Isso foi feito integrando a resposta impulsiva sobre a face do receptor. Para obter a integral foi desenvolvido um método onde o receptor é tratado como um conjunto de elementos e, assim, a integral é simplificada. A resposta global é obtida combinando os resultados a partir dos vários elementos geométricos. A validade do modelo foi confirmada comparando a amplitude prevista da pressão pico-a-pico com os dados obtidos experimentalmente no ar (NEILD e HUTCHINS, 2004).

Em um artigo de (LEE e CHOI, 2000) são apresentados os princípios básicos do projeto de transdutores multielementos é pesquisada a dependência dos parâmetros construtivos dos arrays, tais como o número de elementos piezelétricos e o espaçamento interelementos, na deflexão e focalização dos feixes ultra-sônicos por eles gerados. Na teses de (LINGVALL, 2004) é feita uma revisão dos métodos de construção de imagens ultra-sônicas, incluindo a modelagem usando a resposta impulsiva, soluções analítica e numérica, um modelo discreto linear, métodos de focalização baseados na soma e atrasos dos sinais e uma abordagem estatística da reconstrução de imagens. 


\section{CAPÍTULO 2}

\section{MODELO TEÓRICO PARA O CÁLCULO DO CAMPO ACÚSTICO}

Entre as muitas aplicações de ultra-som, existem várias onde os transdutores são excitados por pulsos elétricos de curta duração como em ensaios não-destrutivos e em imagens médicas, por exemplo. Portanto, o campo acústico em regime transitório foi analisado amplamente, como já mencionado na introdução. As principais soluções são comparadas em (HARRIS, 1981): a integral de Rayleigh, usada nos primeiros trabalhos sobre pistões planos; a integral de King, limitada ao estudo de pistões circulares; a integral de Schoch, que reduz a integral de superfície de Rayleigh a uma integral de linha por meio de uma transformação de coordenadas; e, finalmente, a integral de convolução, que de maneira análoga à resposta impulsiva temporal da teoria dos circuitos lineares, encontra-se a função chamada resposta impulsiva ou resposta espacial impulsiva. Em um sistema linear, invariante no tempo (LTI), e de tempo contínuo, verifica-se que com uma entrada da função delta de Dirac, $\delta(t)$, obtém-se na saída a resposta impulsiva; e para uma entrada genérica $x(t)$, a resposta $y(t)$ é a convolução da resposta impulsiva com o sinal de excitação.

\subsection{Campo acústico produzido por um pistão plano de geometria arbitrária. Método da resposta impulsiva (RI)}

Para determinar a distribuição de pressão gerada por um transdutor é assumido que o transdutor se comporta como um pistão plano, circundado por um refletor rígido infinito. O modelo do pistão plano assume que a face do transdutor vibra em fase e com velocidade constante ao longo de sua superfície. Para encontrar a resposta impulsiva produzida pelo campo acústico gerado por 
um pistão plano, de forma arbitrária, o ponto de partida é a integral de Rayleigh. A Fig. (2.1) mostra a geometria atribuída no cálculo do campo acústico, onde $\boldsymbol{R}$ é o vetor posição do ponto $M, \boldsymbol{R}^{\prime}$ é o vetor posição de um ponto genérico da superfície do pistão, $p(\boldsymbol{R}, t)$ é a pressão acústica calculada no ponto $M$ e $\boldsymbol{v}$ a velocidade normal ao plano $x y$ da superfície do pistão.

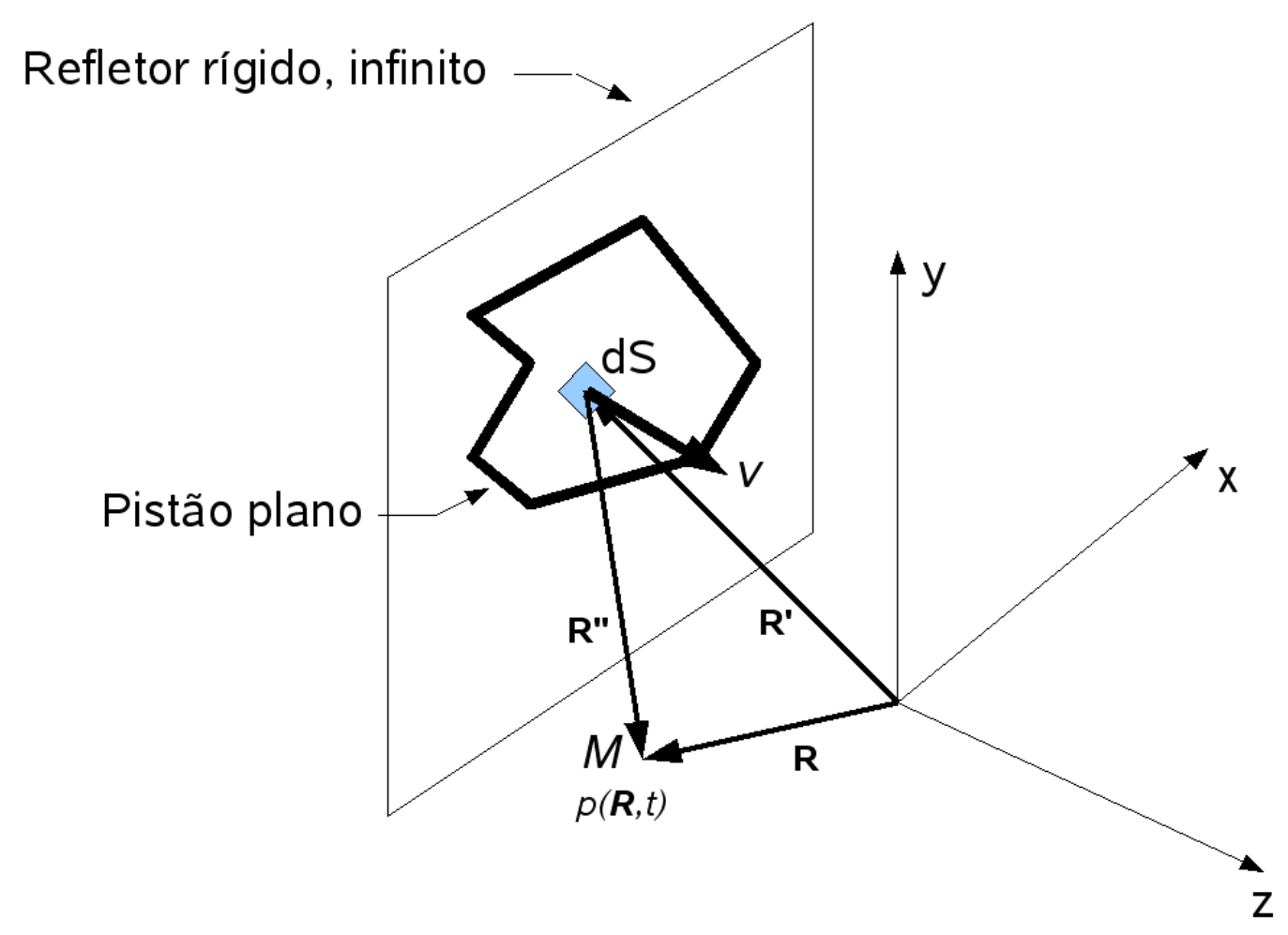

Figura 2.1. Pistão plano de geometria arbitrária.

De (KINSLER et al., 1982) pode-se escrever que a equação linear da pressão instantânea para um meio ideal (invíscido, isotrópico, homogêneo e perfeitamente elástico) é:

$$
p(\boldsymbol{R}, t)=\rho \frac{\partial \phi(\mathbf{R}, t)}{\partial t}
$$

onde $\rho$ é a densidade do fluido e $\phi$ é o potencial de velocidade, que se relaciona com a velocidade das partículas $v$, através da seguinte expressão:

$$
v(\boldsymbol{R}, t)=-\nabla \phi(\mathbf{R}, t) .
$$


A equação de Rayleigh para superfícies planas expressa o potencial de velocidade num ponto do campo, como a soma das infinitas contribuições de fontes simples de área elementar $d S$ que irradiam ondas semi-esféricas no meio, e é dada por:

$$
\phi(\boldsymbol{R}, t)=\frac{1}{2 \pi} \int_{S} \frac{v\left(\mathbf{R}^{\prime}, t-\left|\mathbf{R}-\mathbf{R}^{\prime}\right| / c\right)}{\left|\mathbf{R}-\mathbf{R}^{\prime}\right|} d S,
$$

onde $c$ é a velocidade de propagação da onda e $S$ é a área do transdutor.

Substituindo a equação acima na equação (2.1) obtém-se:

$$
p(\boldsymbol{R}, t)=\frac{\rho}{2 \pi} \int_{S} \frac{\partial v\left(\mathbf{R}^{\prime}, t-\left|\mathbf{R}-\mathbf{R}^{\prime}\right| / c\right) / \partial t}{\left|\mathbf{R}-\mathbf{R}^{\prime}\right|} d S .
$$

Usando os conceitos de convolução no tempo ( * representa a operação de convolução) e $\delta$, função delta de Dirac, pode-se escrever o potencial de velocidade como:

$$
\phi(\boldsymbol{R}, t)=v(t) * \frac{1}{2 \pi} \int_{S} \frac{\delta\left(\mathbf{R}^{\prime}, t-\left|\mathbf{R}-\mathbf{R}^{\prime}\right| / c\right)}{\left|\mathbf{R}-\mathbf{R}^{\prime}\right|} d S .
$$

Observa-se que a função de excitação $v(t)$ independe das características geométricas do transdutor. O segundo fator do segundo membro é a resposta espacial impulsiva que leva em consideração a geometria do transdutor. Esse segundo fator é chamado de resposta impulsiva do potencial de velocidade e é dado por:

$$
\phi_{i}(\mathbf{R}, t)=\frac{1}{2 \pi} \int_{S} \frac{\delta\left(\boldsymbol{R}^{\prime}, t-\left|\boldsymbol{R}-\mathbf{R}^{\prime}\right| / c\right)}{\left|\boldsymbol{R}-\mathbf{R}^{\prime}\right|} d S,
$$

e o potencial de velocidade é dado por:

$$
\phi(\boldsymbol{R}, t)=v(t) * \phi_{i}(\boldsymbol{R}, t) .
$$

A resposta impulsiva do potencial de velocidade é dada por (STEPANISHEN, 1971) e (ROBINSON et al., 1974):

$$
\phi_{i}(\boldsymbol{R}, t)=\frac{c}{2 \pi} \Omega\left(\left|\boldsymbol{R}^{\prime \prime}\right|\right)=\frac{c}{2 \pi} \Omega(c t)
$$


onde $\Omega$ é o ângulo dos arcos concêntricos ao ponto $M$ ' limitado pela borda do pistão e

$$
L=\sigma(\mid \boldsymbol{R}\urcorner) \cdot \Omega(c t)
$$

é o arco ativo. O comprimento do arco, $\sigma(|\boldsymbol{R} ”|)=\sigma(c t)$ é a projeção do vetor posição $\boldsymbol{R}$ ” no plano da abertura e são mostrados na Figura 2.2.

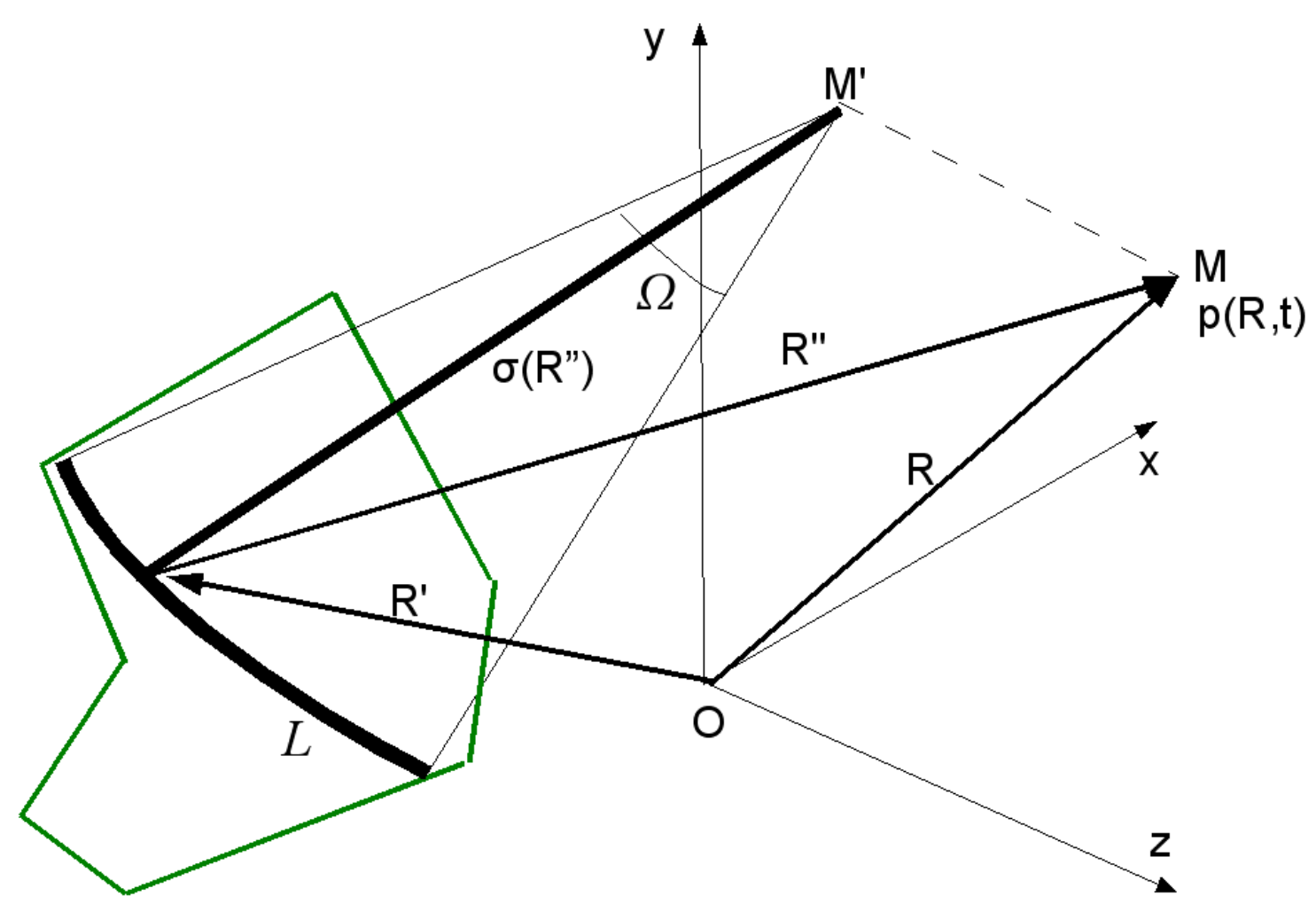

Figura 2.2. Pistão plano de geometria arbitrária e arco ativo L.

\subsection{Campo próximo e campo distante}

No eixo acústico de um transdutor ultra-sônico plano de geometria simples (por exemplo, circular ou retangular), a radiação gerada por ele acompanha dois padrões: a região do chamado campo próximo e a região do campo distante (Vide Fig. 2.3). No campo próximo a radiação acústica predominante está localizada na faixa frontal ao transdutor, com interferências construtivas e destrutivas, encontrando-se máximos e mínimos de intensidade. Já na segunda região, a radiação predominante é a de uma onda esférica com decaimento exponencial de sua intensidade, representando o fenômeno conhecido como difração acústica. 


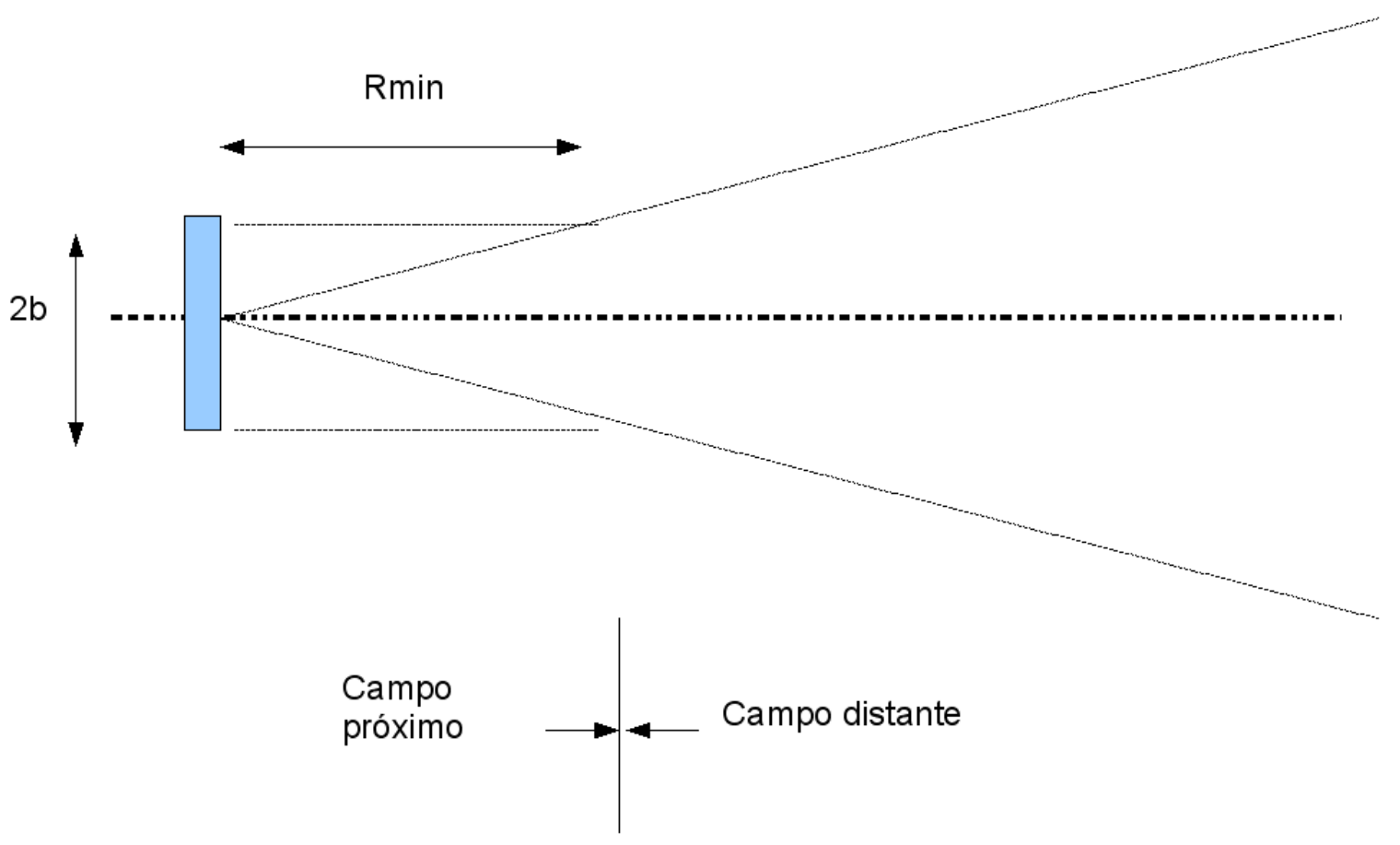

Figura 2.3. Campo próximo e campo distante de um transdutor.

Um critério para determinar o limite inferior do campo distante é que as distâncias das várias porções da fonte ao eixo acústico não devem diferir de aproximadamente meio comprimento de onda (KINSLER et al., 1982), ou seja,

$$
\mathrm{R}_{\max }-\mathrm{R}_{\min } \approx \lambda / 2
$$

onde $\mathrm{R}_{\max }$ é a máxima distância a partir da fonte até o ponto onde está medindo-se o campo e $\mathrm{R}_{\min }$ é a distância até o ponto mais próximo da fonte. Se a maior dimensão da fonte é $2 b$ e traçando a tangente geométrica à frente de onda no ponto $A$ (vide Figura 2.4), a mesma corta o segmento $b$ no ponto médio $(b / 2)$, e pode-se escrever:

$$
\begin{aligned}
& \frac{\lambda / 2}{b / 2}=\frac{b}{R \min } \text { ou } \\
& \mathrm{R}_{\min } \approx \mathrm{b}^{2} / \lambda .
\end{aligned}
$$




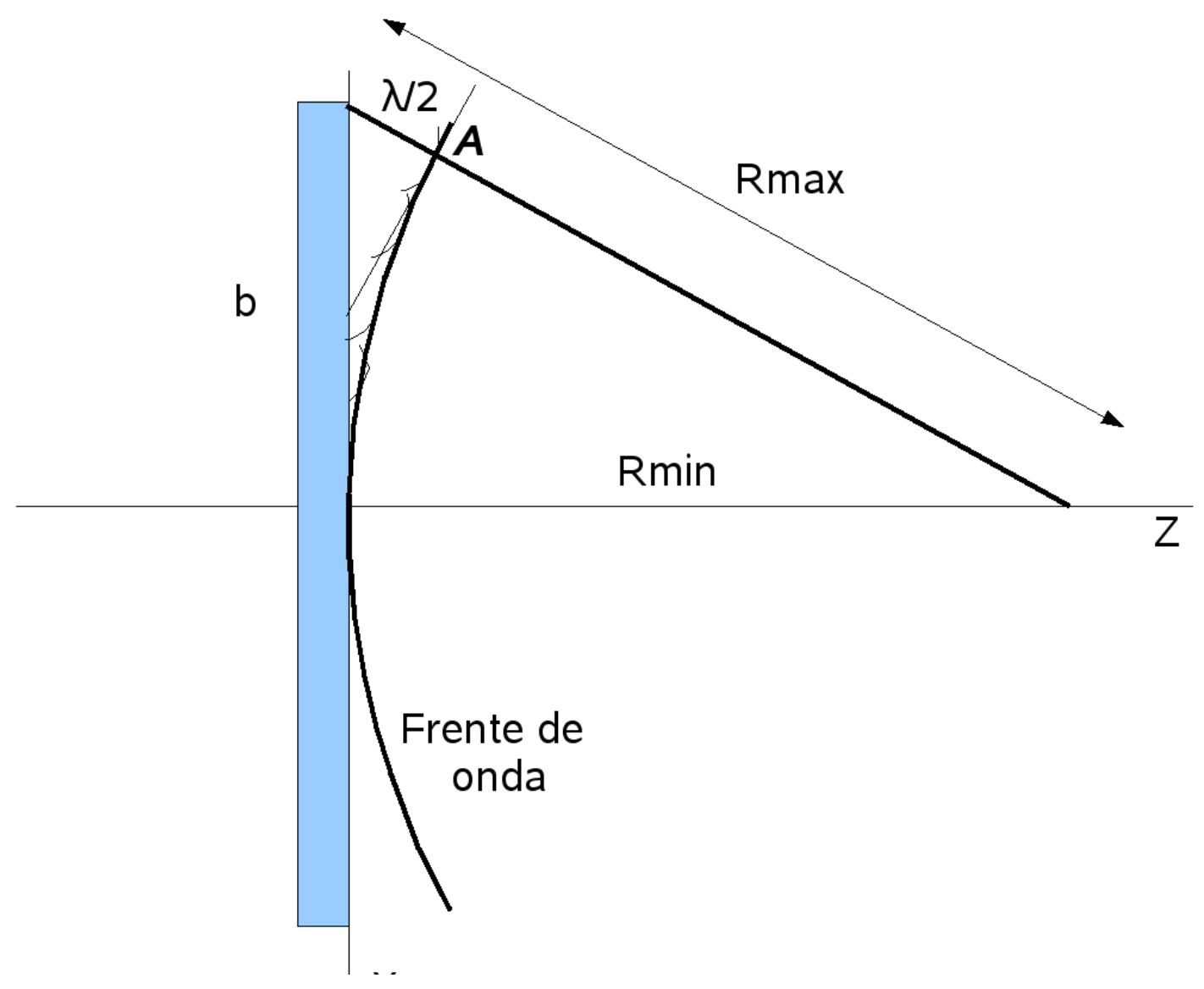

Figura 2.4. Geometria para cálculo de $\mathrm{R}_{\min }$.

\subsection{Campo acústico produzido por um transdutor retangular}

Com as mesmas hipóteses da seção 2.1, porém com um pistão retangular, é obtida nesta seção a solução exata da resposta temporal da pressão gerada com essa geometria. Os lados do pistão retangular medem $2 b$ e $2 a$, sendo $a \leq b$, como mostrado na Fig. 2.5. A pressão acústica na posição $\boldsymbol{R}$ no instante $t$ é representada por $p(\boldsymbol{R}, t)$. 


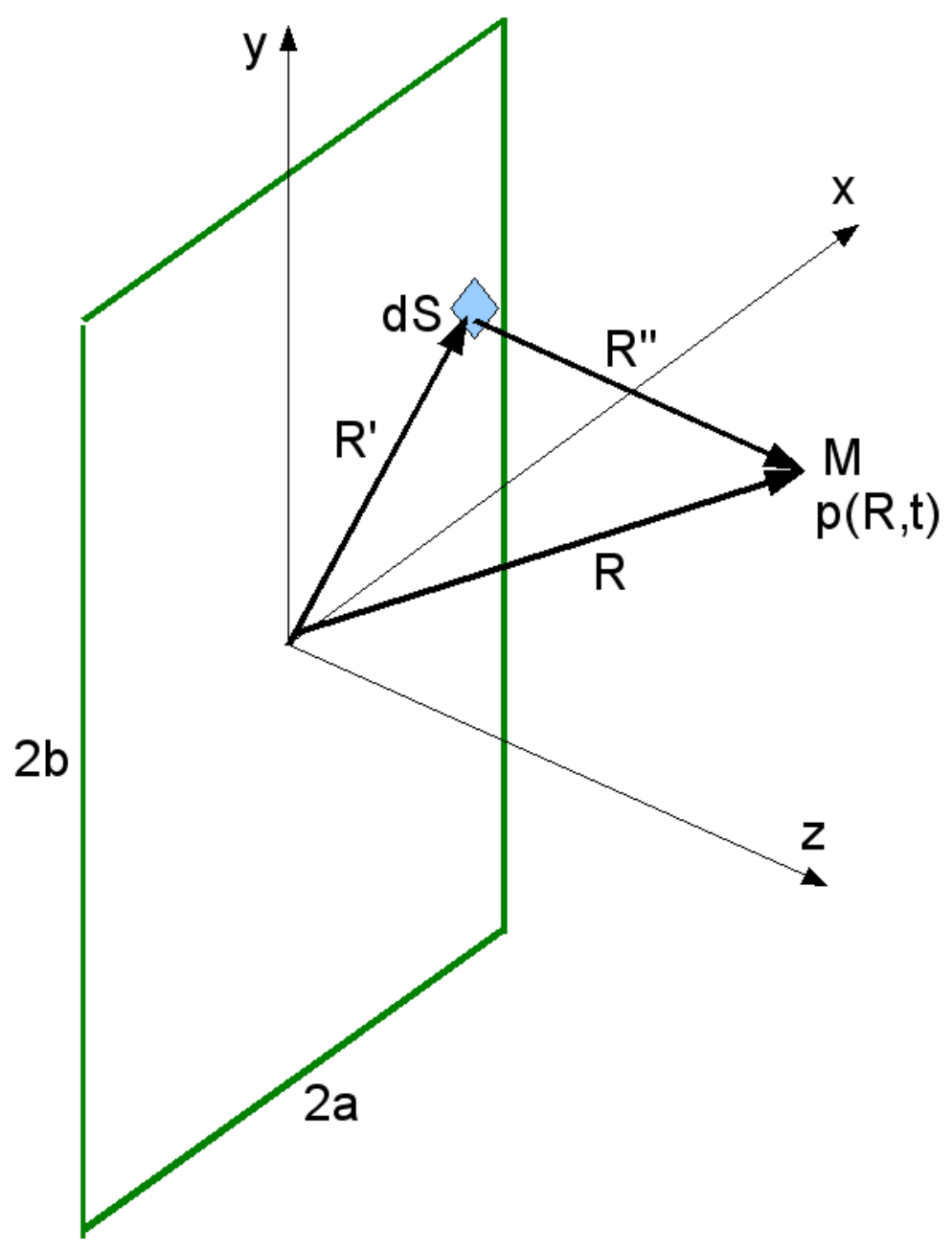

Figura 2.5. Geometria do pistão retangular.

A pressão acústica é calculada a partir do potencial de velocidade $\varnothing(\boldsymbol{R}, t)$ e o potencial de velocidade se relaciona com a velocidade das partículas $v(\boldsymbol{R}, t)$ através da Eq. (2.2) da seção 2.1:

$$
v(\boldsymbol{R}, t)=-\nabla \phi(\boldsymbol{R}, t)
$$

A pressão acústica é dada por:

$$
p(\boldsymbol{R}, t)=p_{i}(\boldsymbol{R}, t) * v(t)
$$

onde $p_{i}(\boldsymbol{R}, t)$ é a resposta impulsiva da pressão e $v(t)$ é a velocidade de vibração do pistão retangular. A resposta impulsiva da pressão pode ser entendida como a pressão gerada pelo pistão retangular quando a velocidade de vibração do pistão é um impulso unitário, ou seja, $v(t)=\delta(t)$. A resposta impulsiva da pressão relaciona-se com o potencial de velocidade impulsivo $\phi_{i}(\boldsymbol{R}, t)$ 
através da seguinte expressão, caso particular da Eq. (2.1):

$$
p_{i}(\boldsymbol{R}, t)=\rho \frac{\partial \phi_{i}(\boldsymbol{R}, t)}{\partial t} .
$$

O potencial de velocidade impulsivo $\phi_{i}(\boldsymbol{R}, t)$ é calculado somando-se as contribuições das ondas semi-esféricas geradas por cada um dos elementos de área infinitesimal $d S$ do pistão retangular (HUTCHINS e HAYWARD, 1990):

$$
\phi_{i}(\boldsymbol{R}, t)=\frac{1}{2 \pi} \iint_{S} \frac{\delta\left(t-\boldsymbol{R}^{\prime \prime} / c\right)}{\boldsymbol{R}^{\prime \prime}} d S .
$$

O potencial de velocidade impulsivo $\phi_{i}(\boldsymbol{R}, t)$ é geralmente obtido resolvendo a integral da Eq. (2.12) numericamente, o que demanda um alto custo computacional.

Uma solução analítica exata do potencial de velocidade impulsivo para um transdutor retangular foi obtida por SAN EMETERIO e GÓMEZ-ULLATE (1992) e será utilizada para calcular a distribuição de pressão gerada por um transdutor retangular. A resposta impulsiva do potencial de velocidade é mostrada e explicitada nesse trabalho:

$$
\phi_{i}(\boldsymbol{R}, t)=\frac{c}{2 \pi} \Omega\left(\left|\boldsymbol{R}^{\prime \prime}\right|\right)=\frac{c}{2 \pi} \Omega(c t)
$$

onde $\Omega(c t)$ é o ângulo dos arcos concêntricos ao ponto $M^{\prime}$ limitado pela borda do pistão retangular, como mostra a Fig. 2.6. 


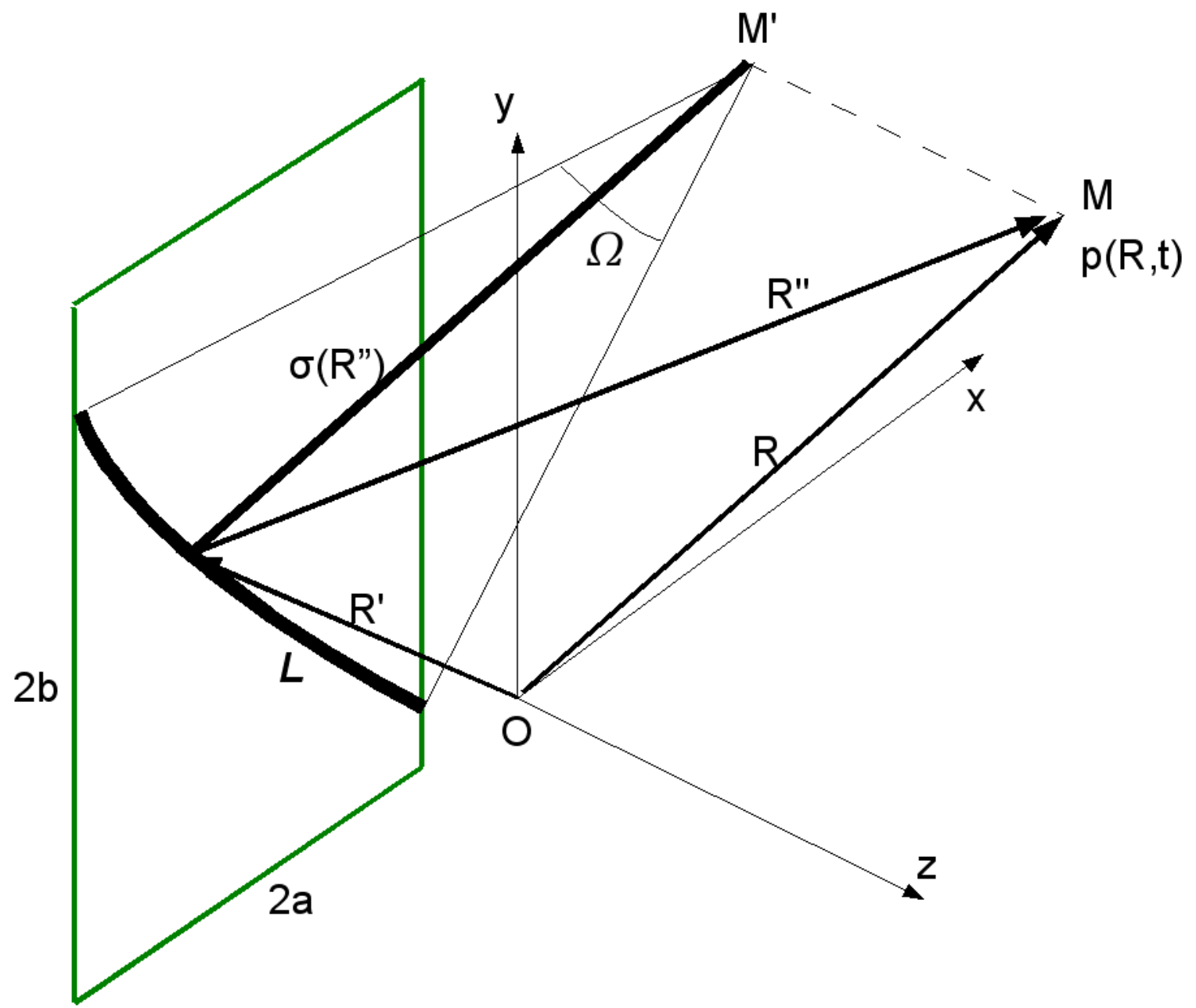

Figura 2.6. Pistão plano de geometria retangular e arco ativo L.

Devido à simetria do problema, serão calculados os ângulos $\Omega(c t)$ apenas no quadrante $x \geq 0, y \geq 0$, conforme mostra a Fig. 2.7. Não existe apenas uma equação fechada que descreve o ângulo $\Omega(c t)$ para todo $\boldsymbol{R}$. Expressões analíticas de $\Omega(c t)$ são obtidas dividindo o quadrante $x \geq 0, y \geq 0$ em quatro regiões distintas também ilustradas na Fig. 2.7. 


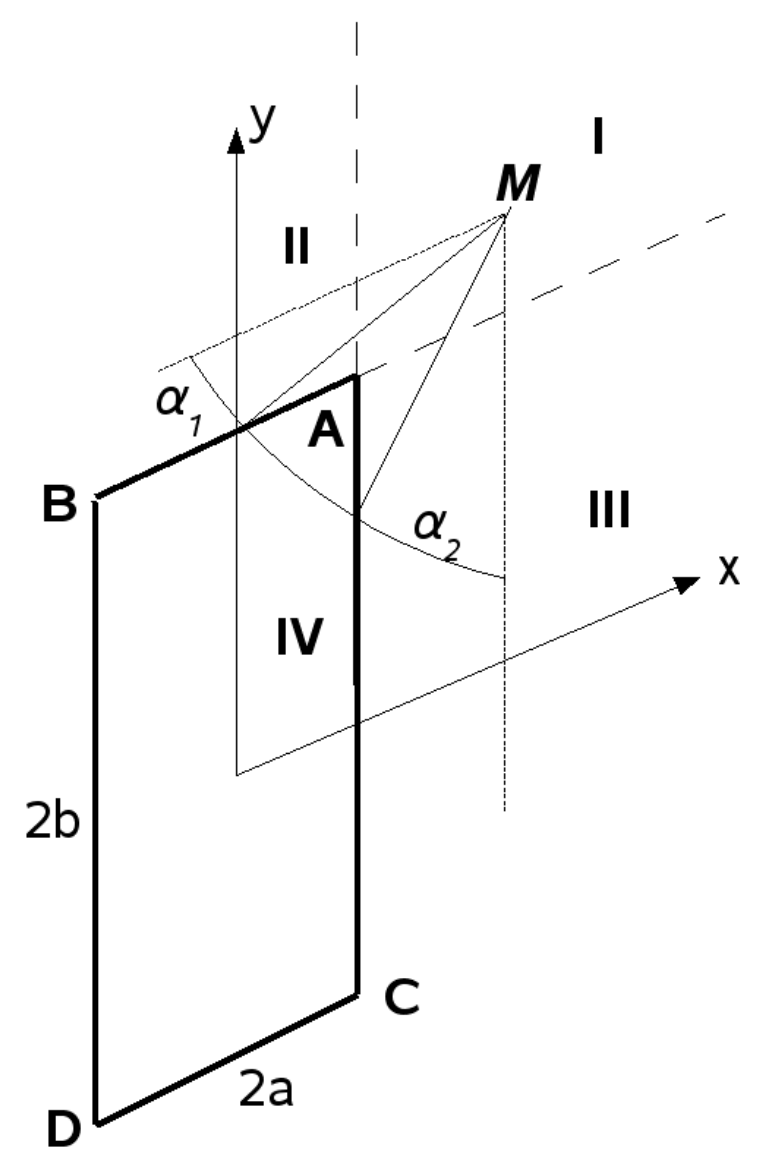

Figura 2.7. Regiões usadas para calcular o valor de $\Omega\left(\boldsymbol{R}^{\prime \prime}, t\right)$.

Os valores de $\Omega\left(\boldsymbol{R}^{\prime \prime}, t\right)$ foram calculados por (SAN EMETERIO e GÓMEZ-ULLATE, 1992) para cada uma das regiões e são mostrados na Tab. 2.1. Nessa tabela, os valores de $\alpha_{i}$ e $\bar{\alpha}_{i}$ são dados por:

$$
\begin{array}{lr}
\alpha_{i}(\boldsymbol{R}, t)=\operatorname{sen}^{-1}\left(d_{i} / \sigma(\boldsymbol{R}, t)\right) & \text { para } i=1,2,3,4 \mathrm{e} \\
\bar{\alpha}_{i}(\boldsymbol{R}, t)=\operatorname{sgn}\left(d_{i}\right) \operatorname{sen}^{-1}\left(\min \left[\left|d_{i}\right| / \sigma(\boldsymbol{R}, t), 1\right]\right) & \text { para } i=1,2,3,4,
\end{array}
$$

onde $d_{1}=x-a, d_{2}=y-b, d_{3}=x+a, d_{4}=y+b$ e $\operatorname{sgn}(x)$ vale 1 se o valor de $x$ for positivo e vale -1 se o valor de $x$ for negativo. Essas variáveis são mostradas, para maior clareza, nas figuras 2.7 e $2.8, d_{1}$ é a distância do ponto $M^{\prime}$ ao lado 1 (segmento AC), $d_{2}$ é a distância do ponto $M^{\prime}$ ao lado 2 
(segmento $\mathrm{AB}$ ), $d_{3}$ é a distância do ponto $M^{\prime}$ ao lado 3 (segmento BD) e $d_{4}$ é a distância do ponto $M^{\prime}$ ao lado 4 (segmento $\mathrm{CD}$ ). Também são mostrados os ângulos $\alpha_{i}$ e de maneira similar são definidos $\bar{\alpha}_{i}(\boldsymbol{R}, t)$.

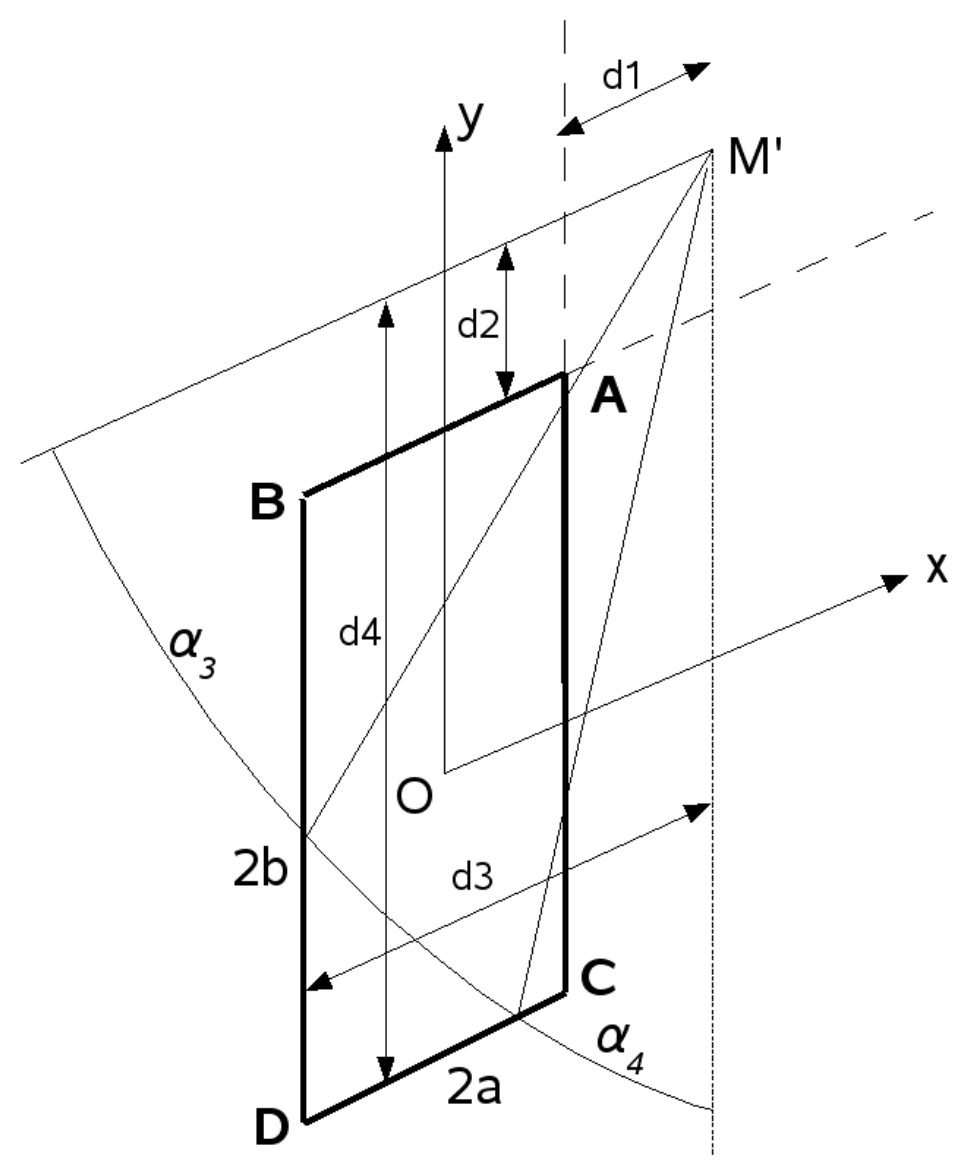

Figura 2.8. Variáveis usadas para calcular o valor de $\Omega\left(\boldsymbol{R}^{\prime \prime}, t\right)$.

A função $R^{\prime}(\boldsymbol{R}, t)=\left|\boldsymbol{R}^{\prime}(\boldsymbol{R}, t)\right|$ é dada por:

$$
R^{\prime}(\boldsymbol{R}, t)=\sqrt{c^{2} t^{2}-z^{2}}
$$

Os quatro tempos de chegada consecutivos das ondas emitidas pelos vértices A, B, C e D do retângulo ao ponto $\mathrm{M}$, usados na Tabela 2.1, são dados por: 


$$
\begin{aligned}
& t_{A}=\frac{\sqrt{d_{1}^{2}+d_{2}^{2}+z^{2}}}{c}, \\
& t_{B}=\frac{\sqrt{d_{2}^{2}+d_{3}^{2}+z^{2}}}{c}, \\
& t_{C}=\frac{\sqrt{d_{1}^{2}+d_{4}^{2}+z^{2}}}{c} \mathrm{e} \\
& t_{D}=\frac{\sqrt{d_{3}^{2}+d_{4}^{2}+z^{2}}}{c},
\end{aligned}
$$

onde os numeradores são as distâncias entre o ponto genérico $\mathrm{M}$ e os pontos A, B, C e D. O tempo para a onda plana alcançar a cota $\mathrm{z}$ do ponto $\mathrm{M}$ é

$$
t_{0}=z / c
$$

Igualmente

$$
t_{i}=\frac{\sqrt{d_{i}^{2}+z^{2}}}{c}, \quad \text { para } i=1,2,3,4
$$

Define-se ainda,

$$
\begin{aligned}
t_{m} & =\min \left[t_{B}, t_{C}\right] \\
t_{M} & =\max \left[t_{B}, t_{C}\right]
\end{aligned}
$$

A resposta impulsiva do potencial de velocidade $\phi_{i}(\boldsymbol{R}, t)$ é limitada pelo intervalo de tempo $\left(t_{\min }, t_{D}\right)$, sendo que fora desse intervalo, a resposta impulsiva é igual a zero. O valor de $t_{m i n}$ é igual a $t_{A}, t_{2}, t_{1}$ e $t_{0}$ para as regiões I, II, III e IV, respectivamente. A pressão acústica em função da posição $R$ e do tempo $t$ é calculada substituindo os ângulos $\Omega\left(\boldsymbol{R}^{\prime \prime}, t\right)$ dados pela Tabela 2.1 na Eq. (2.13), em seguida substituindo a Eq. (2.13) na Eq. (2.11), e por último calculando a convolução dada pela Eq. (2.10). 
Tabela 2.1. Expressões para os ângulos $\Omega\left(R^{\prime \prime}, t\right)$.

\begin{tabular}{ccccc}
\hline Intervalo & \multicolumn{4}{c}{ Região } \\
De tempo & I & II & III & IV \\
\hline$t_{\min }<t<t_{A}$ & $\ldots$ & $\pi-2 \alpha_{2}$ & $2 \bar{\alpha}_{3}-2 \alpha_{1}$ & $-2 \pi-2 \bar{\alpha}_{1}-2 \bar{\alpha}_{2}+2 \bar{\alpha}_{3}+2 \bar{\alpha}_{4}$ \\
$t_{A} \leq t \leq t_{m}$ & $\pi / 2-\alpha_{1}-\alpha_{2}$ & $\pi / 2-\alpha_{1}-\alpha_{2}$ & $\pi / 2-\alpha_{1}-\alpha_{2}+2 \bar{\alpha}_{3}$ & $-3 \pi / 2-\alpha_{1}-\alpha_{2}+2 \bar{\alpha}_{3}+2 \bar{\alpha}_{4}$ \\
$t_{m} \leq t \leq t_{M}{ }^{a}$ & $-\alpha_{1}+\alpha_{3}$ & $-\pi-\alpha_{1}+\alpha_{3}+2 \bar{\alpha}_{4}$ & $-\alpha_{1}+\alpha_{3}$ & $-\pi-\alpha_{1}+\alpha_{3}+2 \bar{\alpha}_{4}$ \\
$t_{m} \leq t \leq t_{M}{ }^{b}$ & $-\alpha_{2}+\alpha_{4}$ & $\ldots$ & $-\pi-\alpha_{2}+2 \bar{\alpha}_{3}+\alpha_{4}$ & $-\pi-\alpha_{2}+2 \bar{\alpha}_{3}+\alpha_{4}$ \\
$t_{M} \leq t \leq t_{D}$ & $-\pi / 2+\alpha_{3}+\alpha_{4}$ & $-\pi / 2+\alpha_{3}+\alpha_{4}$ & $-\pi / 2+\alpha_{3}+\alpha_{4}$ & $-\pi / 2+\alpha_{3}+\alpha_{4}$ \\
\hline${ }^{a}$ para $t_{B} \leq t_{C}$ & & & & \\
${ }^{b}$ para $t_{C} \leq t_{B}$ & & & &
\end{tabular}




\section{CAPÍTULO 3}

\section{TRANSDUTORES MULTIELEMENTOS (ARRAYS)}

A obtenção de imagens por meio de arrays de ultra-som tornou-se popular por ser uma técnica não invasiva e por apresentar um custo menor que outras técnicas de formação de imagens (raios-X ou ressonância magnética, por exemplo). O objetivo destas imagens acústicas é localizar e caracterizar objetos por meio do campo acústico gerado por esses arrays (LINGVALL, 2004). Os arrays lineares são um excelente meio de implementar um sistema ultra-sônico de obtenção de imagens em tempo real (LEE e CHOI, 2000).

Um array é um conjunto de elementos piezelétricos independentes, cujas excitações são controladas eletronicamente para produzir um feixe ultra-sônico direcionado e/ou focalizado. Por meio de uma varredura, pode-se obter a imagem de um plano ou de um volume sem movimentação do transdutor (FRITSCH, 2001).

Os elementos, normalmente de geometria retangular, são inseridos entre duas camadas, a frontal, chamada de acoplamento, e a posterior, de retaguarda. Esses elementos são constituídos de material piezelétrico de baixa perda acústica e são responsáveis pela longa duração do pulso acústico quando aplicado um impulso elétrico. Para reduzir a duração desse pulso é usado um material de 'backing' (camada de retaguarda) que possua uma impedância acústica próxima ao do material piezelétrico, para assegurar um bom acoplamento e alta atenuação, eliminando o retorno ou reflexões dos pulsos (BUIOCHI et al., 2005).

O material mais usado na camada de retaguarda consiste em uma mistura de resina epóxi, de alta absorção ultra-sônica, preenchida com pó de tungstênio, para aumentar a densidade e, consequentemente, a impedância acústica. Além disso, o tungstênio aumenta a atenuação devido à 
dispersão provocada pelas partículas desse material. O PZT (titanato zirconato de chumbo), que é o material piezelétrico mais usado, tem uma alta impedância acústica, da ordem de 30 Mrayl. Por essa razão, e devido à baixa velocidade de fase e densidade da resina epóxi, é necessária uma alta concentração de tungstênio para combinar com a impedância acústica do PZT.

O feixe ultra-sônico gerado por um transdutor multielemento depende principalmente da geometria do array e dos seus elementos, do pulso emitido, dos atrasos associados com os elementos na emissão e na recepção e da apodização. Neste capítulo, será feita uma explanação sobre os parâmetros básicos dos feixes acústicos e o campo acústico produzido por um array.

\subsection{Parâmetros dos feixes acústicos}

\section{Resolução lateral}

Define a mínima distância entre dois refletores localizados num plano paralelo à face do transdutor, ou seja, é a capacidade para discriminar dois pontos na mesma profundidade. A resolução lateral depende da largura do feixe no foco a uma distância focal $l_{f}$, e é determinada pelo tamanho da abertura $D(D=2 b$, lado maior do array de abertura retangular $)$ e pelo comprimento de onda $\lambda$ (FRITSCH, 2001), dada por:

$$
\Delta x=l_{f} \cdot \lambda / D
$$

\section{Profundidade do foco}

Uma forma freqüentemente usada para se obter a profundidade de foco (KINO, 2000) é medir a distância à qual o feixe mantém-se acima do nível de $-3 \mathrm{~dB}$ com relação à máxima amplitude do campo acústico, nesse caso é dada por:

$$
P F=7,1 \lambda\left(l_{f} / D\right)^{2},
$$




\section{Resolução axial}

É a mínima distância $\Delta z$ entre dois refletores pontuais na direção de propagação para que possam ser visualizados separados. Em aplicações de imagens é importante ter boa resolução axial, portanto, a largura de banda, $B$, dos pulsos oscila entre 50 e $100 \%$ da freqüência central do transdutor. A resolução axial é (FRITSCH, 2001)

$$
\Delta z \approx c / 2 B
$$

Para um transdutor de $5 \mathrm{MHz}$ e largura de banda de $60 \%(B=3 \mathrm{MHz})$, na água $(c=1500 \mathrm{~m} / \mathrm{s})$, a resolução axial é de aproximadamente $0,25 \mathrm{~mm}$.

$$
\Delta z=1500 /(2 * 3)=0,25 \mathrm{~mm} \text {. }
$$

\subsection{Campo acústico gerado por arrays lineares}

A Fig. 3.1 mostra um array linear de elementos retangulares, os mais utilizados nesse tipo de configuração. Esse array possibilita obter imagens em um plano perpendicular às faces dos elementos do transdutor, chamado de plano azimutal. 


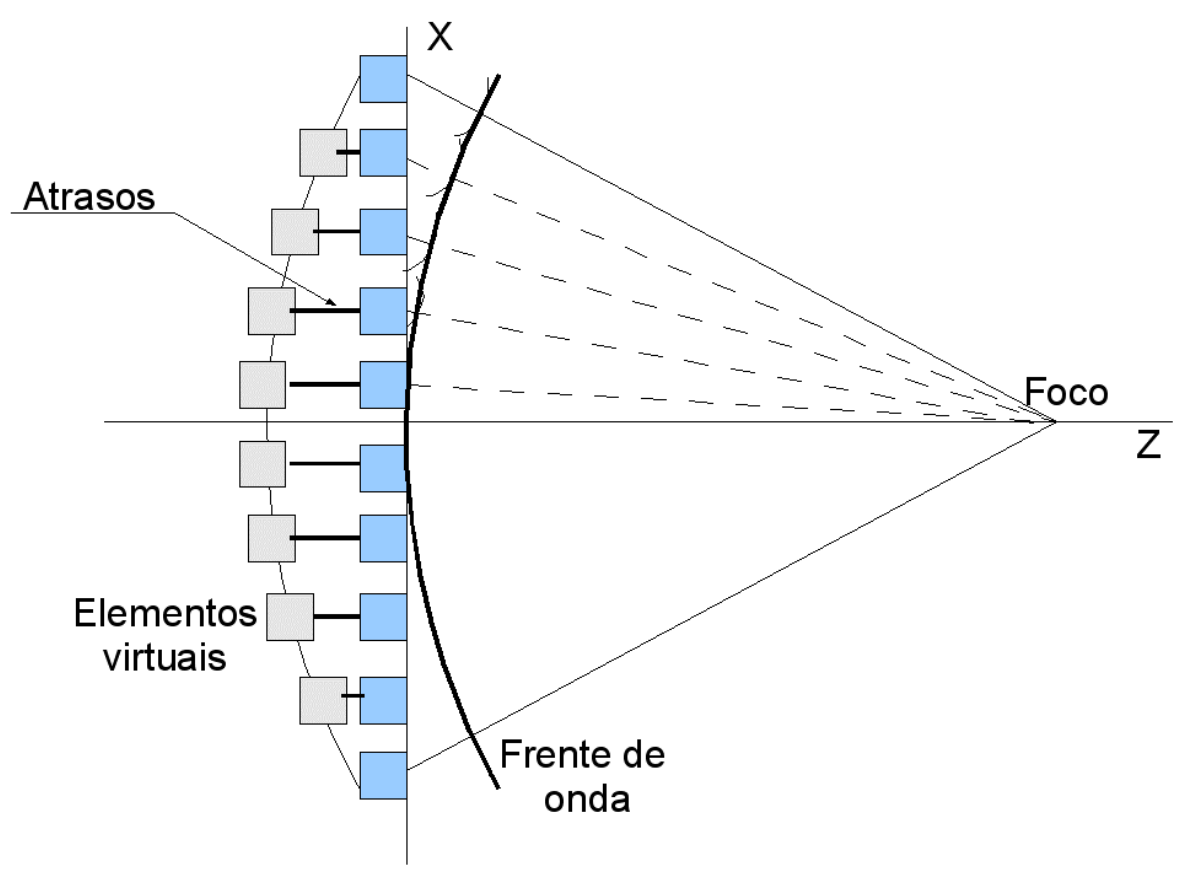

Figura 3.1. Focalização sem deflexão do feixe acústico de um array linear.

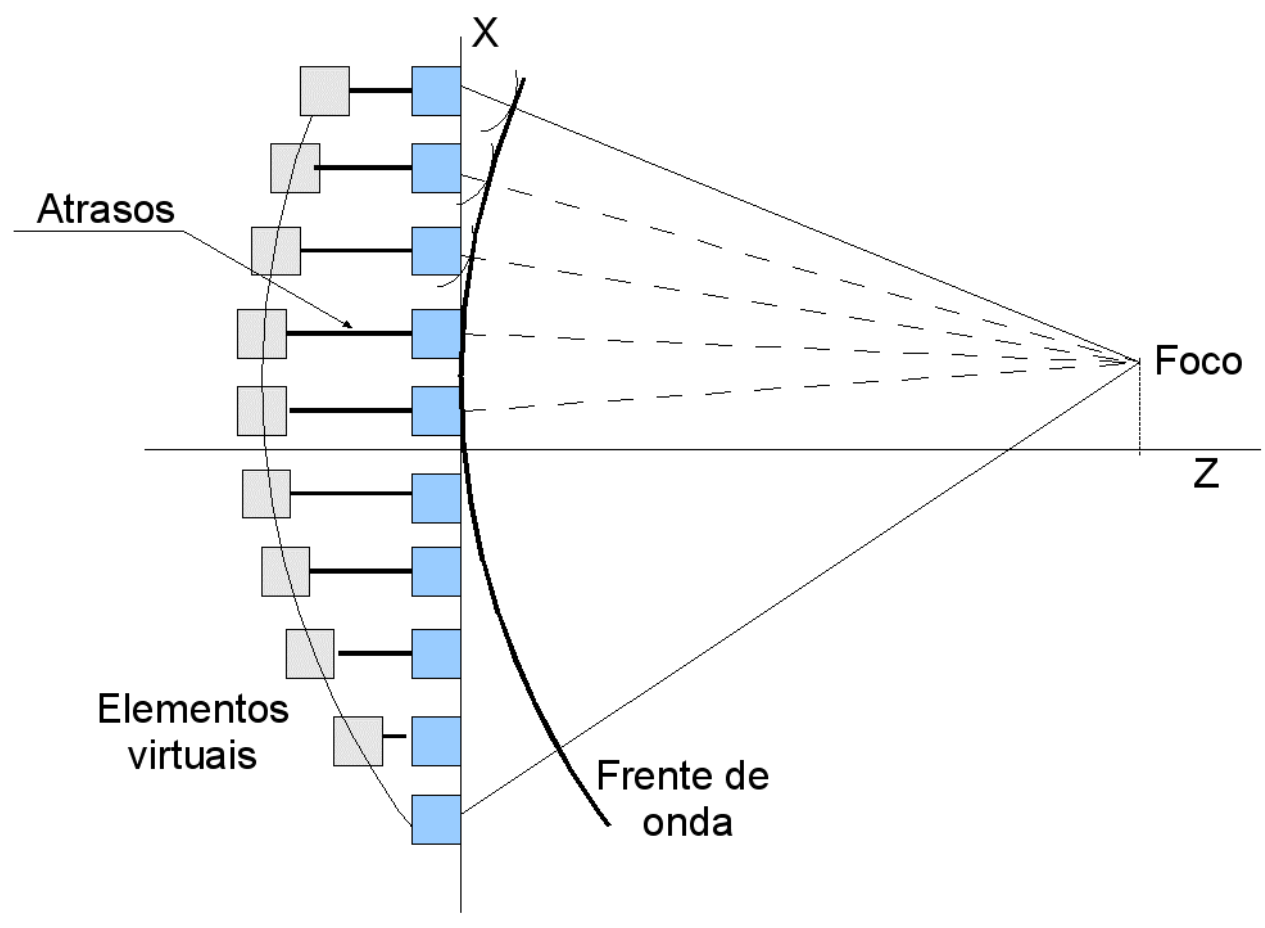

Figura 3.2. Focalização com deflexão do feixe acústico de um array linear.

É possível conseguir uma focalização (com ou sem deflexão) do feixe acústico por meio de uma adequada distribuição de atrasos no disparo dos pulsos dos diferentes elementos do array 
(focalização na emissão). Isso equivale a uma frente de onda originada pela excitação simultánea dos elementos virtuais indicados nas Fig. 3.1 e 3.2, que mostram, respectivamente, uma focalização sem e com deflexão. Assim, como é possível conseguir essas focalizações utilizando adequados atrasos na emissão, dado que o emissor e receptor são os mesmos elementos, os atrasos também podem ser inseridos na recepção dos sinais, que são posteriormente processados.

A Fig. 3.3 mostra o diagrama da amplitude da pressão em função do ângulo medido a partir do eixo principal de um array operando em excitação contínua (JINBO, 2007). Essa figura apresenta o diagrama de pressão para um array de 12 elementos com um ângulo de deflexão de $0^{\circ}$, mas em outras direções angulares aparecem os chamados lóbulos secundários, mostrando a existência de campo de menor intensidade.

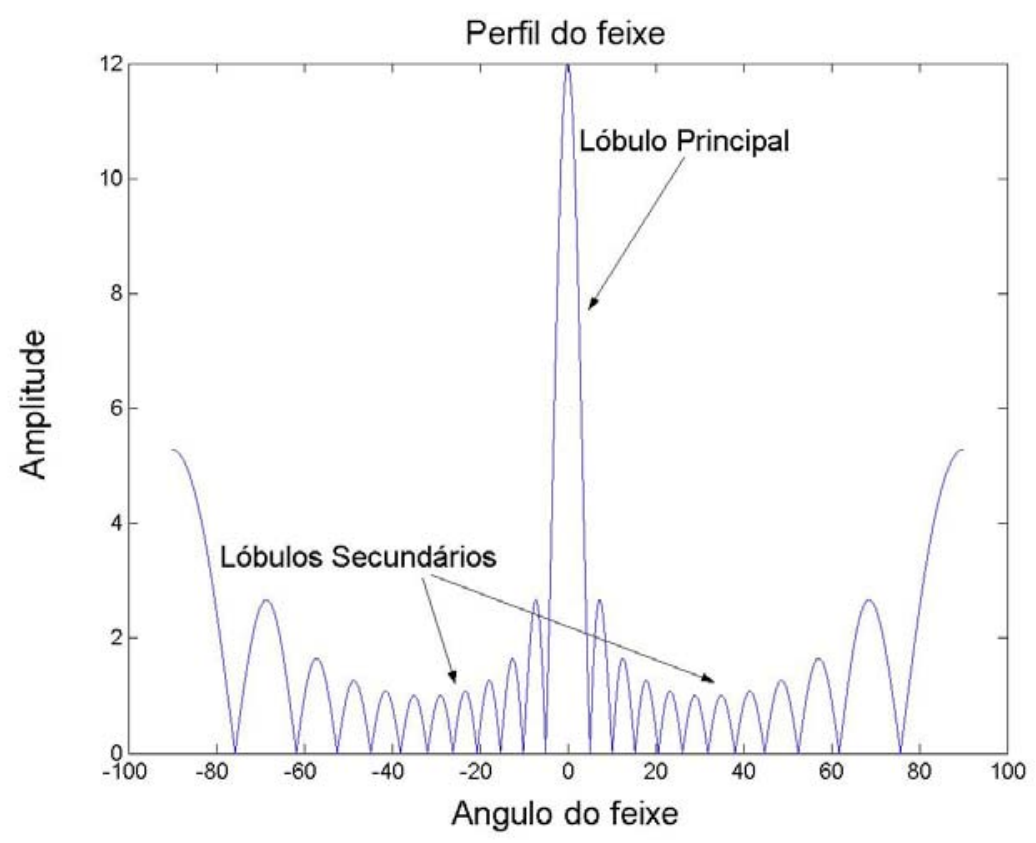

Figura 3.3. Lóbulos principal e secundários do campo acústico gerado por um array linear.

Como o array é um transdutor constituído por elementos periódicos, durante a excitação podem aparecer lóbulos indesejáveis de alta intensidade em direções diferentes à prevista pela deflexão, chamados lóbulos de espaçamento, como mostrado na Fig. 3.4. A formação dos lóbulos de espaçamento é originada pela interferência construtiva entre ciclos consecutivos de um 
sinal emitido por dois elementos separados a uma distância $d>>\lambda$. Para evitar os lóbulos de espaçamento, o espaço entre os elementos não deve ser superior a $\lambda / 2$, onde $\lambda$ é o comprimento de onda no meio de propagação (KINO, 2000).

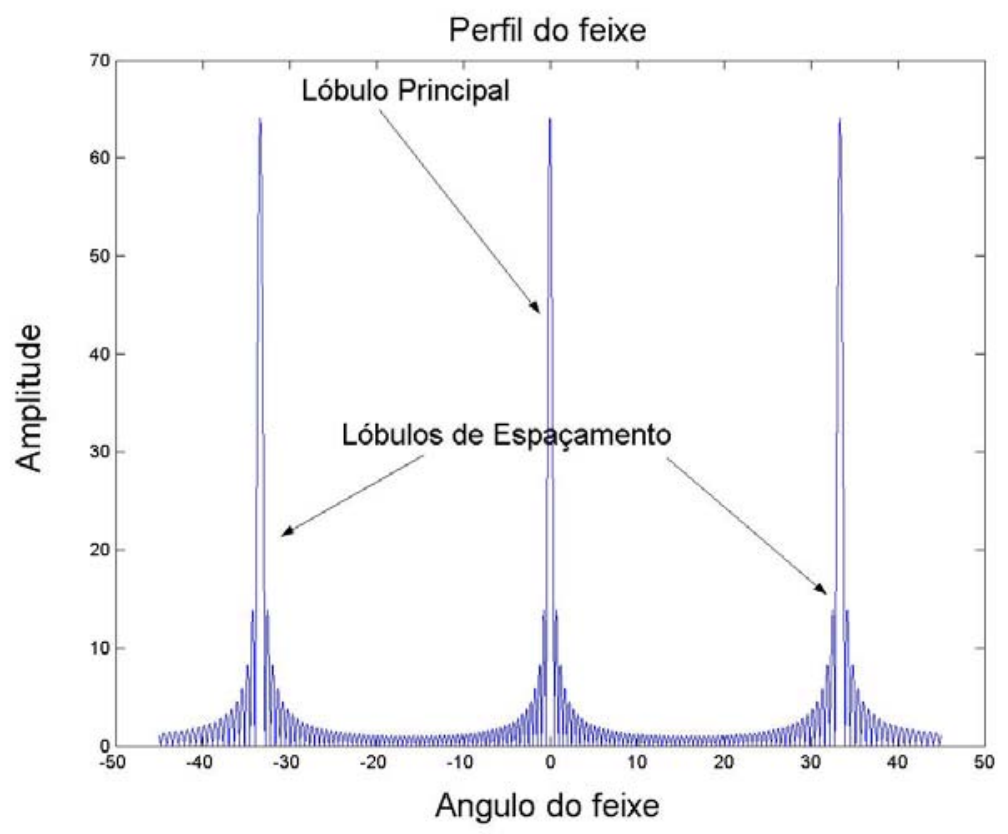

Figura 3.4. Lóbulos de espaçamento do campo acústico gerado por um array linear.

\subsection{Projeto de arrays lineares}

Os princípios que norteiam o projeto de arrays lineares são apresentados em (LEE e CHOI, 2000) e mencionados a seguir. As medidas que caracterizam o desempenho de um array são a deflexão e focalização do feixe acústico. Sejam $N$ o número de elementos do transdutor, $d$ o passo entre elementos, $l_{f}$ a distância focal e $\alpha$ o ângulo de deflexão do feixe ultra-sônico, como mostrado na Fig. 3.5, a distância $D$ do elemento $n+1$ ao eixo acústico do transdutor vale:

$$
D=\frac{2 n-N+1}{2} \cdot d .
$$

e a distância $l$ do elemento $n+1$ ao foco é: 


$$
l=\sqrt{l_{f}^{2}+D^{2}-2 \cdot l_{f}} \cdot \text { Dsen } \alpha .
$$

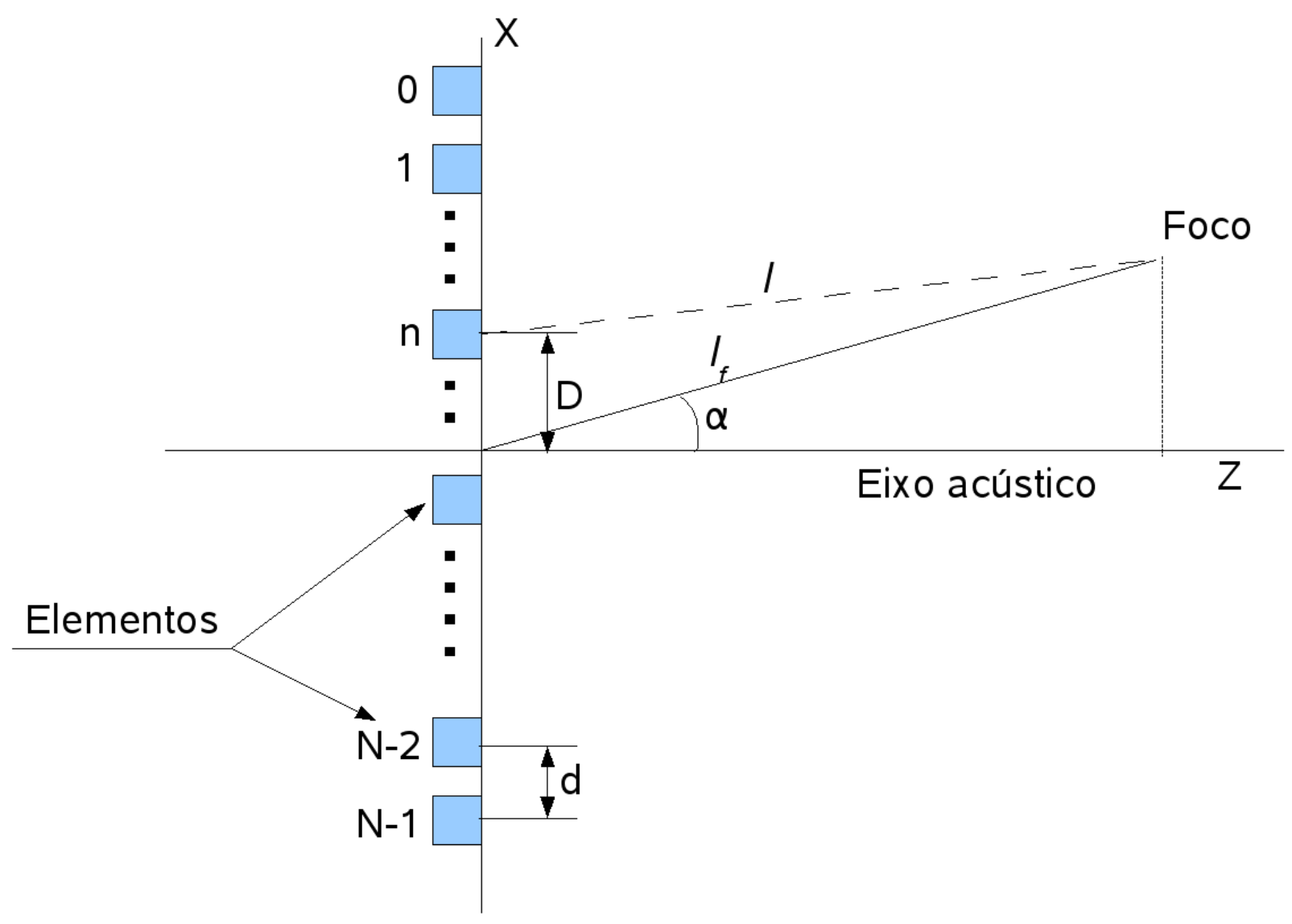

Figura 3.5. Geometria de um array linear de $\mathrm{N}$ elementos.

Como já mencionado, uma sequiência adequada de atrasos possibilita definir uma direção da frente de onda. Assim, para um determinado ângulo de deflexão $\alpha$, o atraso de cada elemento $T[n]$ pode ser obtido por:

$$
T[n]=\frac{l_{f}-l}{c}+t_{o},
$$

onde $c$ é a velocidade de propagação e $t_{o}$ é um tempo arbitrário usado para evitar valores negativos de atraso.

Os atrasos na excitação de cada elemento são calculados, segundo a Eq. 3.6, para qualquer 
ângulo de deflexão e distância focal. As ondas ultra-sônicas de radiação de cada elemento piezelétrico retangular, com seus adequados atrasos, são somadas em razão do princípio de superposição de Huygens, definindo dessa maneira o campo acústico defletido e focalizado.

Existem vários parâmetros que devem ser definidos no projeto de um array linear, tais como o número de elementos, o passo, a largura dos elementos, a freqüência e a largura de banda. $\mathrm{O}$ número de elementos é normalmente ajustado em $2^{n}$ onde $n$ é um inteiro. Esses parâmetros afetam a diretividade do feixe ultra-sônico; por exemplo, o feixe ultra-sônico abre muito quando o número de elementos diminui, resultando em uma pobre focalização; por outro lado, quando esse número aumenta a focalização melhora. Porém, deve-se chegar a uma solução de compromisso entre o custo e o desempenho, ou seja, o número de elementos deve ser otimizado. A diretividade de um feixe ultra-sônico pode ser melhorada aumentando o passo entre elementos, embora sem ultrapassar o valor limite de meio comprimento de onda, para que os lóbulos de espaçamento não cresçam demasiadamente. 


\section{CAPÍTULO 4}

\section{MATERIAIS E MÉTODOS}

Neste capítulo é apresentado o modelo implementado para a simulação do campo acústico de transdutores retangulares e de array e os respectivos protótipos usados na verificação experimental do modelo. Além disso, são apresentados os sinais gerados por cada um dos protótipos, bem como o sistema computadorizado utilizado nas medições do campo acústico.

\subsection{Modelos implementados}

O modelo desenvolvido por Stepanishen (1971) e aperfeiçoado por San Emeterio e GómezUllate (1992) permite calcular o campo acústico gerado por transdutores retangulares, descritos como pistões planos circundados por refletores rígidos infinitos, conhecendo as suas características físicas e geométricas e a função velocidade de excitação de sua face.

O fluxograma da Fig. 4.1 apresenta o algoritmo implementado para a obtenção da resposta espacial impulsiva, calculada a partir do item 2.3 do capítulo 2. Após a definição das variáveis do transdutor, do meio e dos incrementos temporal e espacial (e conseqüentemente o número de pontos a serem calculados), determina-se a região onde estes pontos estão localizados (Fig. 2.7). Utilizando-se a Tabela 2.1, obtêm-se os ângulos $\Omega\left(\boldsymbol{R}^{\prime}, t\right)$ que permitem calcular a resposta impulsiva do potencial de velocidade, segundo a expressão da Eq. 2.13. Os blocos "Reg I", "Reg II", "Reg III", "Reg IV" representam os pontos incluídos nessas regiões (no fluxograma é mostrado unicamente o fluxo completo correspondente à região I). Após uma derivação (“Diff”), obtém-se a resposta impulsiva da pressão acústica e, por meio de operação de convolução com a velocidade da 
face do transdutor, chega-se à pressão. Como a pressão calculada é um sinal variando no tempo, para obter o campo acústico, calcula-se o valor pico-a-pico do sinal (PaP). Essas operações são representadas pelo bloco "Diff + Convolução + PaP". O algoritmo completo é mostrado no Apêndice A. 


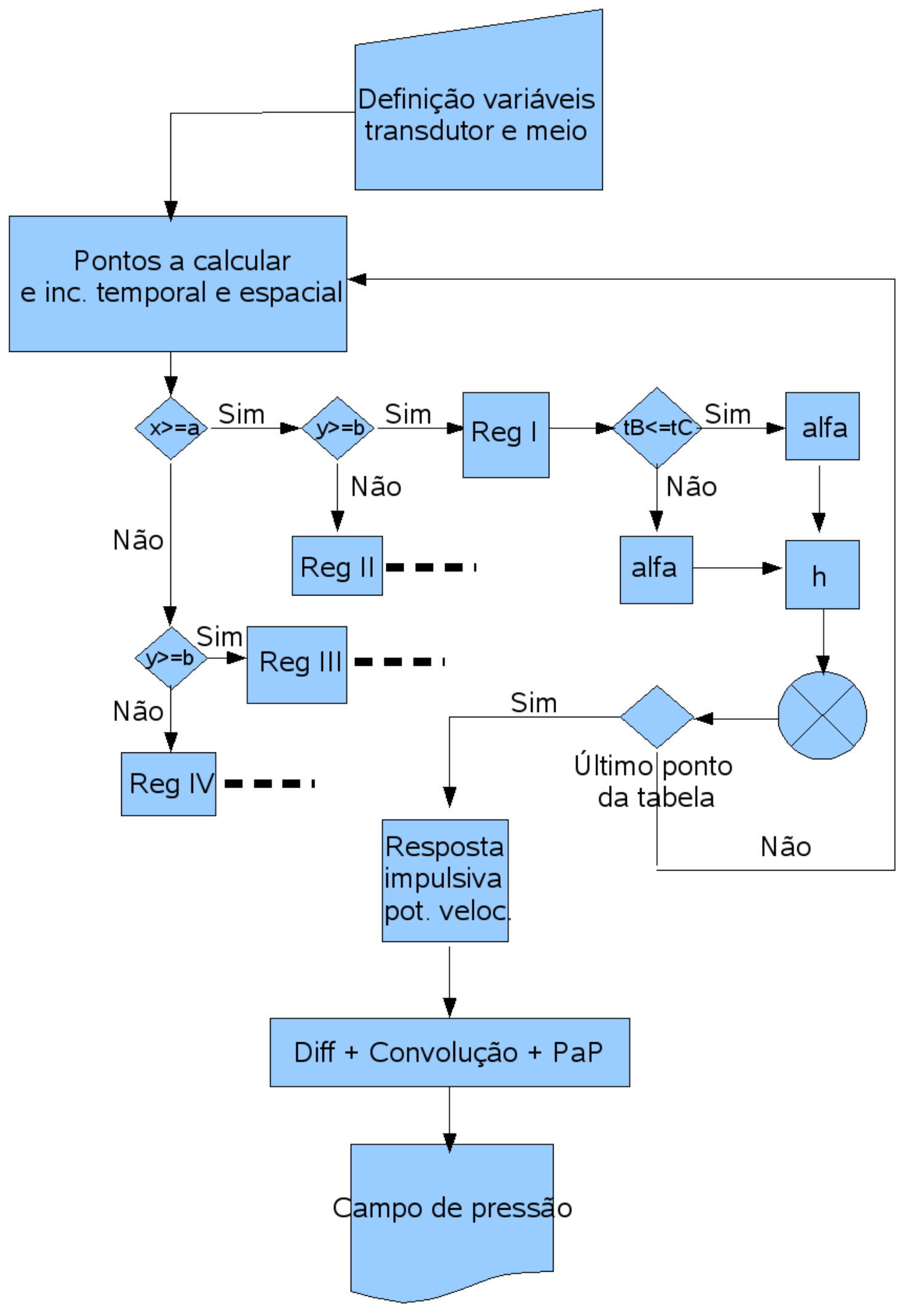

Figura 4.1. Fluxograma da simulação da resposta espacial impulsiva. 


\subsection{Transdutores monoelemento}

Para verificar o funcionamento do modelo, foram construídos quatro transdutores retangulares com as dimensões indicadas na Tabela 4.1.

Tabela 4.1. Dimensões dos transdutores construídos.

\begin{tabular}{cccc}
\hline TRANSDUTOR & Largura - 2.a (mm) & Comprimento - 2.b (mm) & Espessura (mm) \\
\hline$\# 1$ & 10,8 & 18,1 & 0,95 \\
$\# 2$ & 8,8 & 20,4 & 6,4 \\
$\# 3$ & 4,6 & 19,3 & 6,4 \\
$\# 4$ & 2,8 & 20,5 & 6,4 \\
\hline
\end{tabular}

As características acústicas dos protótipos (freqüência e limite inferior do campo distante) são mostradas na Tabela 4.2. Utilizaram-se as freqüências de $2,2 \mathrm{MHz}$ e de $400 \mathrm{kHz}$. O comprimento de onda do primeiro transdutor (\#1) é $\lambda=0,68 \mathrm{~mm}$ e dos outros (\#2, \#3 e \#4) é $\lambda=3,7$ $m m$, para propagação em água $(c=1500 \mathrm{~m} / \mathrm{s})$. O limite inferior do campo distante $R_{\min }$ é calculado pela Eq. 2.9. Verifica-se que o campo distante nos transdutores \#2, \#3 e \#4 inicia a uma distância bem menor que no $\# 1$.

Tabela 4.2. Características acústicas dos transdutores construídos.

\begin{tabular}{ccc} 
TRANSDUTOR & Freqüência (MHz) & Limite inferior do campo distante $-\boldsymbol{R}_{\min }(\mathbf{m m})$ \\
$\# \# 1$ & 2,2 & 72 \\
$\# 2$ & 0,4 & 27 \\
$\# 3$ & 0,4 & 27 \\
\hline
\end{tabular}


O transdutor \#1 (Fig. 4.2) foi construído com uma cerâmica piezelétrica retangular (obtida a partir de um disco de material titanato zirconato de chumbo, PZT-5A) com dimensões laterais $2 a=10,8 \mathrm{~mm}$ (lado menor do retângulo) e $2 b=18,1 \mathrm{~mm}$ (lado maior do retângulo) e com uma espessura de 0,95 mm, que corresponde a uma freqüência de ressonância de 2,2 MHz. Para reduzir a largura do pulso emitido pelo transdutor, a cerâmica piezelétrica foi acoplada a uma camada de retaguarda de tungstênio (22,4\% em volume) e epóxi, alcançando uma impedância acústica de 7 Mrayl. A camada de retaguarda tem uma atenuação suficiente para que a onda acústica que se propaga para trás do transdutor não seja refletida para o material piezelétrico. Entre a cerâmica piezelétrica e o meio de propagação foi feita uma camada de compatibilização acústica de $1 / 4$ de comprimento de onda $(0,68 / 4 \mathrm{~mm}=0,17 \mathrm{~mm})$. Para essa camada foi utilizada uma mistura de epóxi e alumina, na proporção em massa de 1:2.

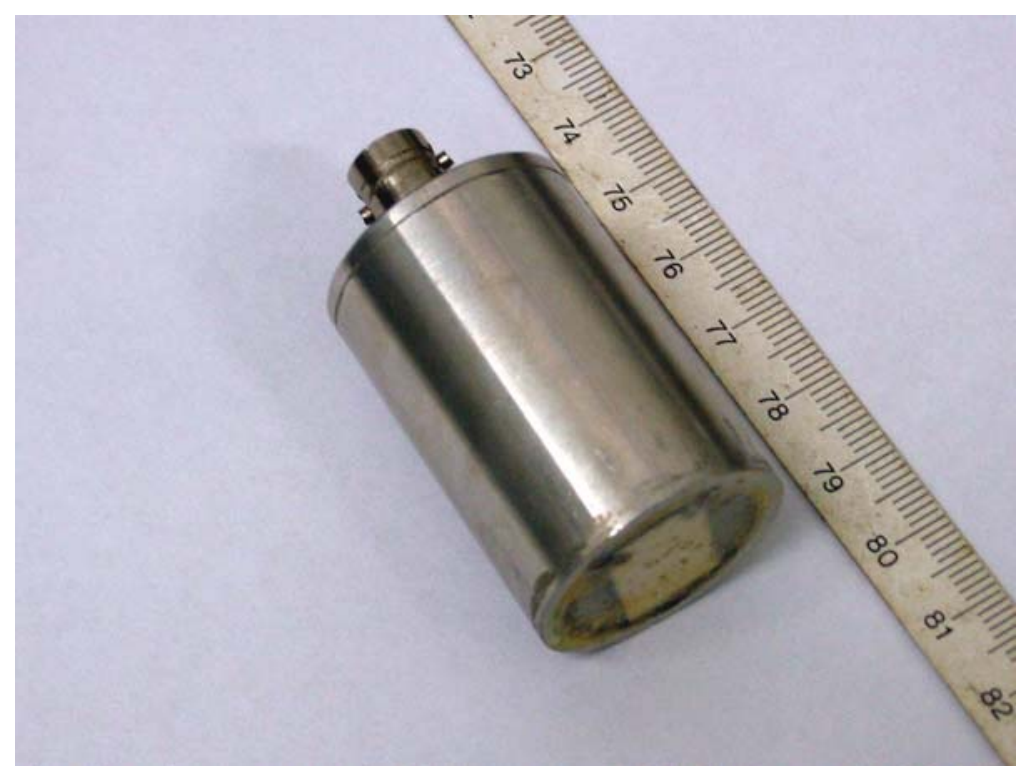

Figura 4.2. Protótipo do transdutor \#1 (monoelemento). 
Com o mesmo procedimento já relatado, foram construídos os transdutores \#2, \#3 e \#4 de $400 \mathrm{kHz}$, porém a partir de um disco de material titanato zirconato de chumbo, PZT-5A, de 6,4 mm de espessura.

\subsection{Características do protótipo do array linear}

Para a obtenção dos resultados experimentais foi utilizado um transdutor matricial linear de 12 elementos de cerâmica piezelétrica PZT-5A, com freqüência central de $1 \mathrm{MHz}$, e uma abertura acústica de $16 \mathrm{~mm}$ x $14 \mathrm{~mm}$, construído no Laboratório de Ultra-som do Departamento de Engenharia Mecatrônica e de Sistemas Mecânicos da Escola Politécnica da USP (BUIOCHI et al., 2006). A Fig. 4.3 mostra a representação esquemática dos elementos do array e a Fig. 4.4 o protótipo utilizado.

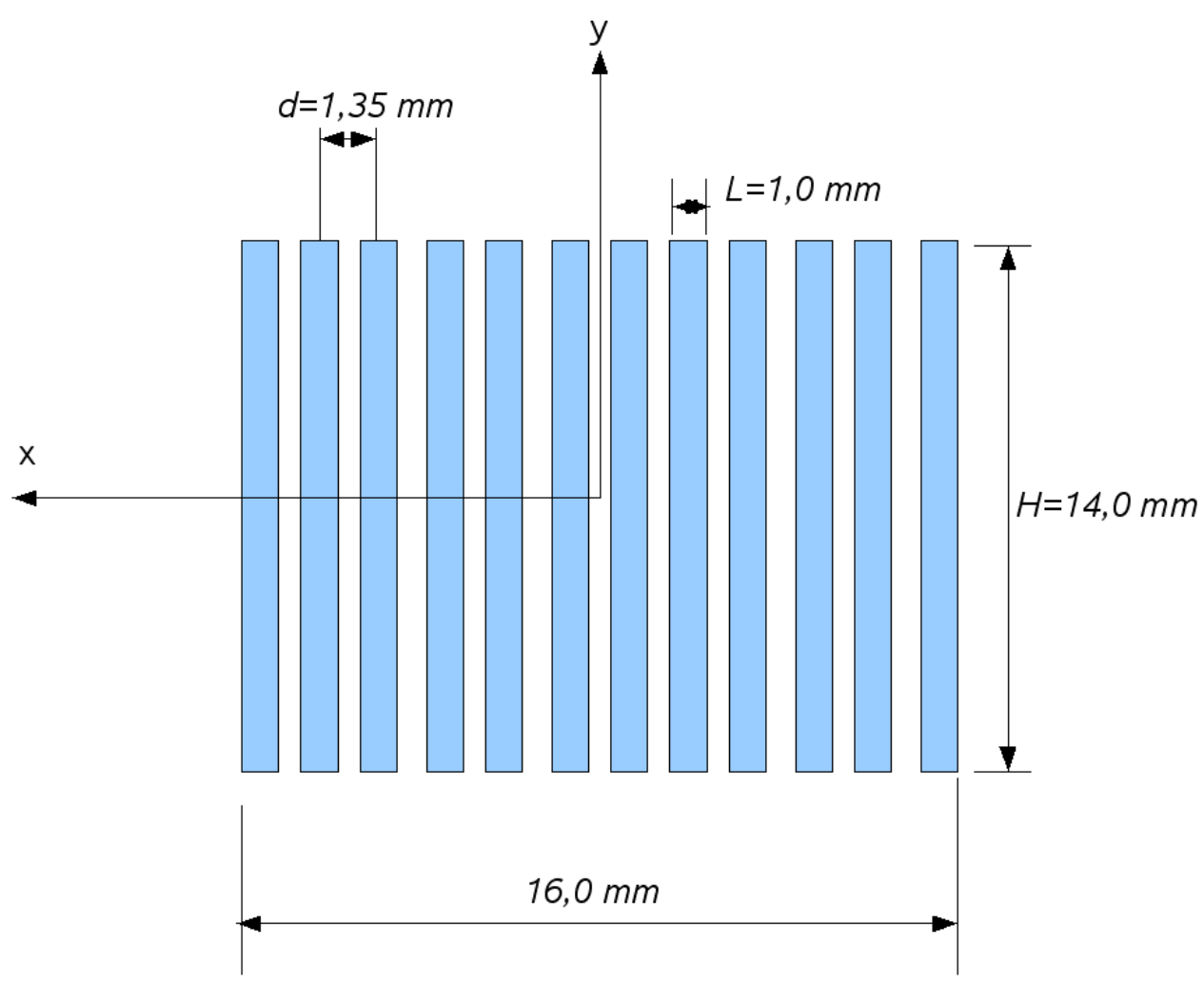

Figura 4.3. Geometria do array usado na simulação e verificação experimental. 


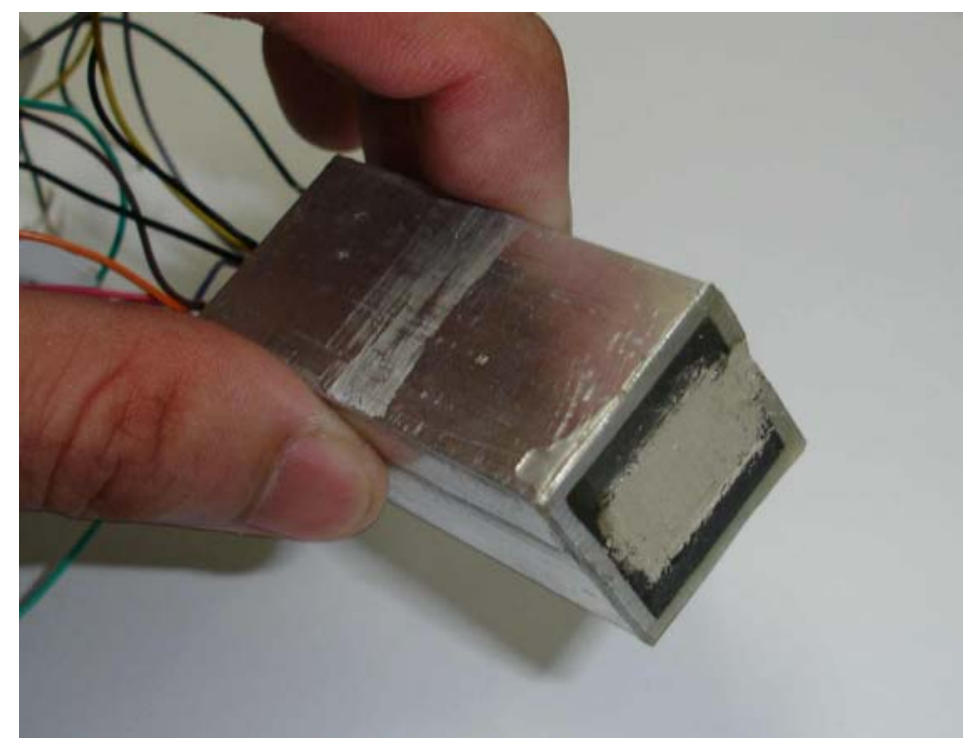

Figura 4.4. Protótipo do transdutor matricial linear.

Para o transdutor matricial linear, também foram realizadas simulações utilizando o software Matlab para avaliar o modelo implementado no capítulo 2.

Para a validação do modelo implementado, compara-se a resposta simulada com resposta experimental obtida a partir do mapeamento do campo acústico do array, em três pontos: um no eixo acústico, $M_{1}(0,0,30 \mathrm{~mm})$, e os outros dois fora dele, $M_{2}(5 \mathrm{~mm}, 0,30 \mathrm{~mm})$ e $M_{3}(10 \mathrm{~mm}, 0,30$ $m m$ ). Para o cálculo da seqüência de atrasos que comanda a direção da frente de onda, divide-se o problema de focalização e deflexão em quatro casos, como analisados a seguir.

A expressão geral das contribuições de cada um dos elementos na pressão, ao longo da reta $y=0$ e $z=z_{0}$ é dada por: 


$$
p(x, t)=\sum_{0}^{11} p_{i}\left(x_{i}, T_{i}\right),
$$

onde $p_{i}$ é a contribuição do elemento $i$ na pressão total, $x$ a ordenada do ponto $M$ referida ao eixo acústico do array, $x_{i}$ a ordenada do ponto $M$ referida ao elemento $i$ e $T_{i}$ o atraso na excitação desse elemento.

Primeiro caso: emissão sem focalização e sem deflexão.

Neste primeiro caso, os 12 elementos são excitados simultaneamente. Assim, como não existem atrasos de excitação, a expressão geral das contribuições de cada um dos elementos na pressão, ao longo da reta $y=0$ e $z_{0}=30 \mathrm{~mm}$, é reduzida para:

$$
p(x, t)=\sum_{0}^{11} p_{i}\left(x_{i}\right) .
$$

A Fig. 4.5 mostra a distância $D_{i}$ do elemento $i$ ao eixo acústico do array, a ordenada $x_{i}$ do ponto $M$ ao elemento $i$, usados na simulação. A ordenada $x_{i}$ é:

$$
x_{i}=x+D_{i} .
$$

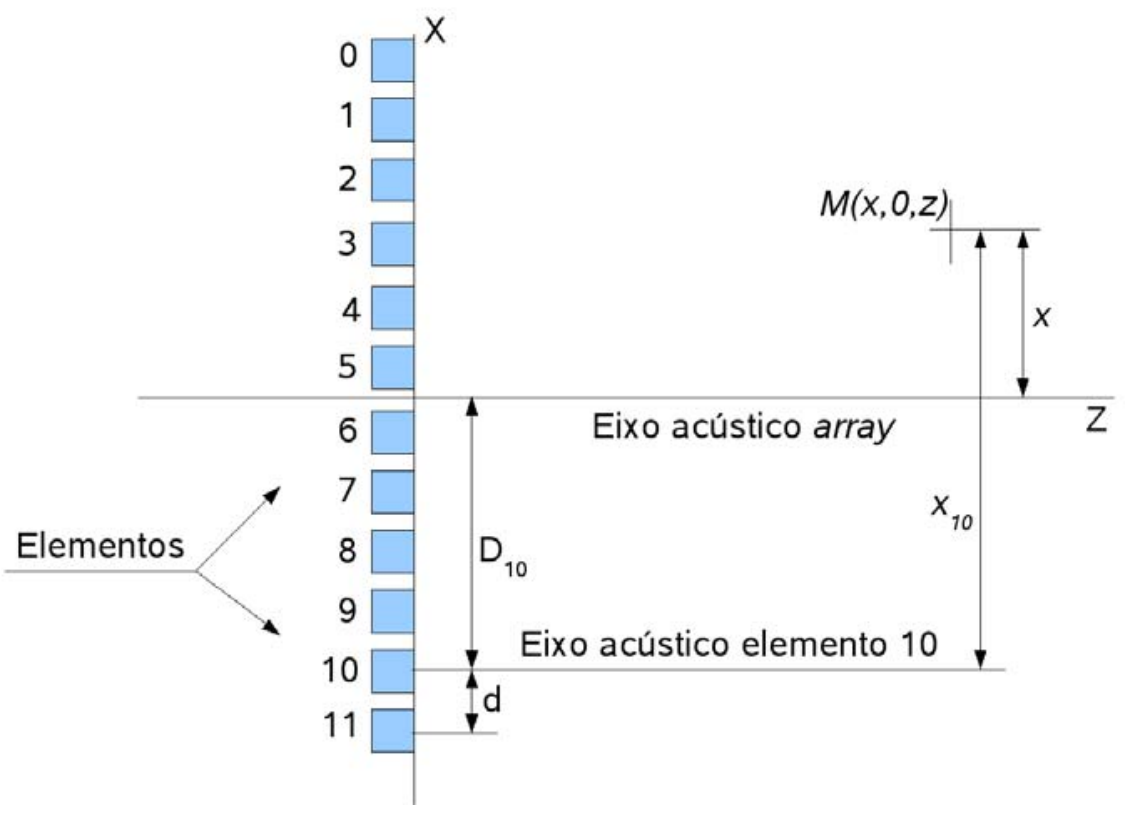

Figura 4.5. Geometria das coordenadas das simulações. 
Segundo caso: focalização sem deflexão.

A Fig. 4.6 mostra a geometria usada para simular o campo acústico, bem como os pontos $M_{1}, M_{2}$ e $M_{3}$ utilizados para o cálculo da resposta em pressão do array.

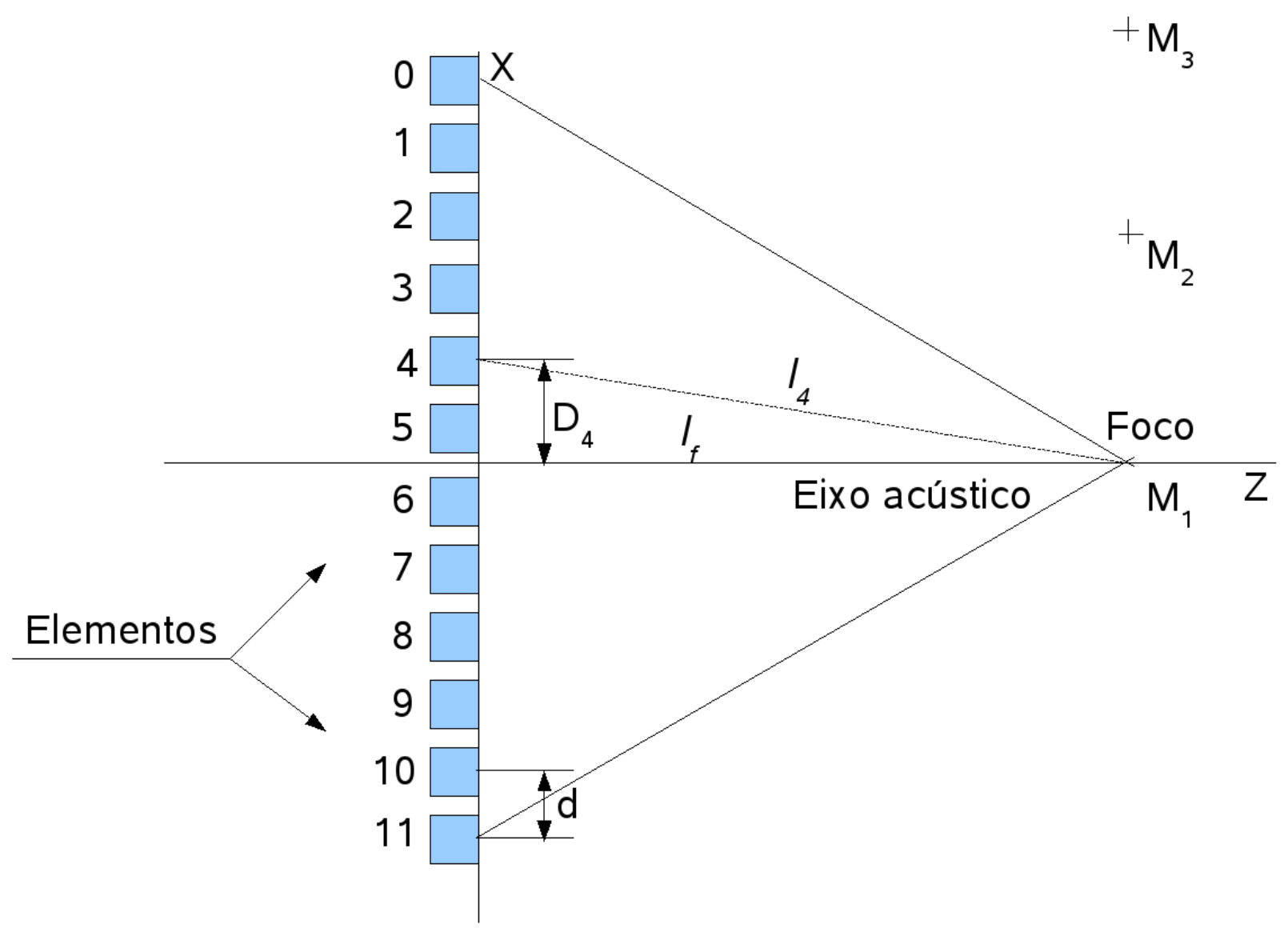

Figura 4.6. Geometria da focalização sem deflexão.

Pela distribuição simétrica dos elementos do array com relação ao eixo acústico e considerando que o foco $F(0,0,30 \mathrm{~mm})$ está localizado no eixo acústico $\left(l_{f}=30 \mathrm{~mm}\right)$, aplicando as equações 3.4 e 3.5, calcula-se os atrasos mostrados na Tabela 4.3, onde $l_{i}$ é a distância do elemento $i$ ao foco, $\Delta l_{i}$ é a diferença entre a distância $l_{i}$ e a distância focal $l_{f}$. 
Tabela 4.3. Atrasos dos elementos do array em focalização sem deflexão.

\begin{tabular}{|c|c|c|c|c|}
\hline Elementos & $\boldsymbol{D}_{\boldsymbol{i}}(\mathbf{m m})$ & $\boldsymbol{l}_{\boldsymbol{i}}(\mathbf{m m})$ & $\Delta \boldsymbol{l}_{\boldsymbol{i}}(\mathbf{m m})$ & $\boldsymbol{T}_{\boldsymbol{i}}(\mathbf{n s})$ \\
\hline$\# 5, \# 6$ & 0,675 & 30,0 & 0,007 & 5 \\
\hline$\# 4, \# 7$ & 2,025 & 30,0 & 0,068 & 45 \\
\hline$\# 3, \# 8$ & 3,375 & 30,2 & 0,189 & 126 \\
\hline$\# 2, \# 9$ & 4,725 & 30,3 & 0,369 & 246 \\
\hline$\# 1, \# 10$ & 6,075 & 30,6 & 0,608 & 405 \\
\hline$\# 0, \# 11$ & 7,425 & 30,9 & 0,905 & 603 \\
\hline
\end{tabular}

Terceiro caso: deflexão sem focalização.

A Fig. 4.7 mostra a geometria usada para simular o feixe acústico defletido sem focalização, bem como os pontos $\mathrm{M}_{1}, \mathrm{M}_{2}$ e $\mathrm{M}_{3}$. Conforme visto no segundo caso, são calculados os atrasos de cada elemento do array. As distâncias dos diferentes elementos ao elemento \#11, projetadas segundo a direção de propagação da onda, definem os atrasos correspondentes ao respectivo elemento. 


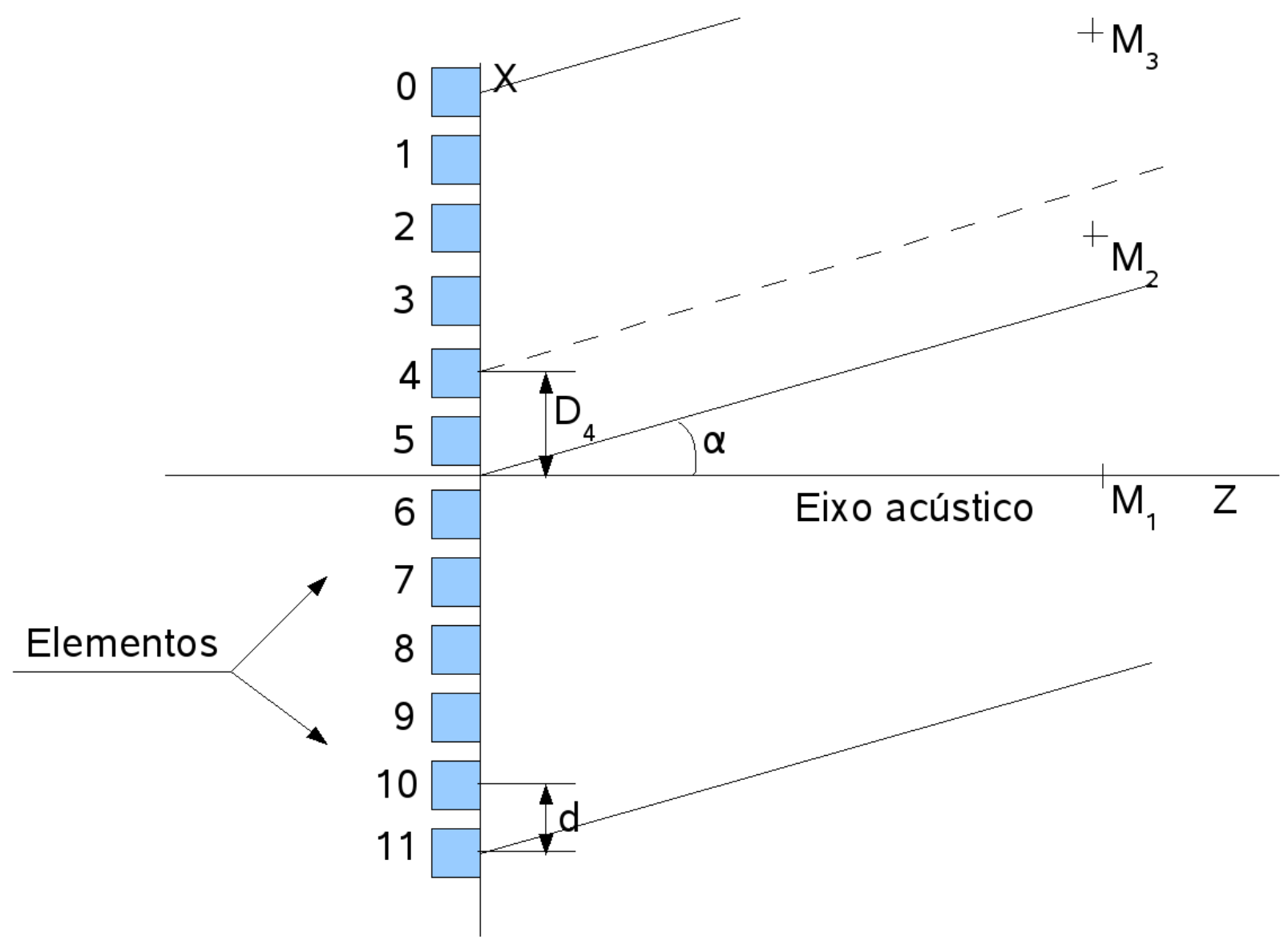

Figura 4.7. Geometria da deflexão sem focalização.

Tabela 4.4. Atrasos dos elementos do array com deflexão e sem focalização.

\begin{tabular}{|c|c|c|c|c|}
\hline Elementos & $\boldsymbol{D}_{\boldsymbol{i}}(\mathbf{m m})$ & $\boldsymbol{l}_{\boldsymbol{i}}(\mathbf{m m})$ & $\boldsymbol{\Delta} \boldsymbol{i}(\mathbf{m m})$ & $\boldsymbol{T}_{\boldsymbol{i}}(\mathbf{n s})$ \\
\hline$\# 0$ & $-7,425$ & 14,85 & 7,425 & 0 \\
\hline$\# 1$ & $-6,075$ & 13,5 & 6,75 & 450 \\
\hline$\# 2$ & $-4,725$ & 12,15 & 6,075 & 900 \\
\hline$\# 3$ & $-3,375$ & 10,8 & 5,4 & 1350 \\
\hline$\# 4$ & $-2,025$ & 9,45 & 4,725 & 1800 \\
\hline$\# 5$ & $-0,675$ & 8,1 & 4,05 & 2250 \\
\hline$\# 6$ & 0,675 & 6,75 & 3,375 & 2700 \\
\hline
\end{tabular}




\begin{tabular}{|c|c|c|c|c|}
\hline$\# 7$ & 2,025 & 5,4 & 2,7 & 3150 \\
\hline$\# 8$ & 3,375 & 4,05 & 2,025 & 3600 \\
\hline$\# 9$ & 4,725 & 2,7 & 1,35 & 4050 \\
\hline$\# 10$ & 6,075 & 1,35 & 0,675 & 4500 \\
\hline$\# 11$ & 7,425 & 0 & 0 & 4950 \\
\hline
\end{tabular}

Quarto caso: deflexão com focalização.

Como nos casos anteriores, a Fig. 4.8 mostra a geometria empregada para simular o feixe acústico defletido $\left(\alpha=30^{\circ}\right)$, e raio de focalização $\left(l_{f}=34,6 \mathrm{~mm}\right)$ e a Tab. 4.5 apresenta os atrasos de excitação empregados em cada um dos elementos do array. Também estão calculadas as respostas em pressão para os pontos $\mathrm{M}_{1}, \mathrm{M}_{2}$ e $\mathrm{M}_{3}$.

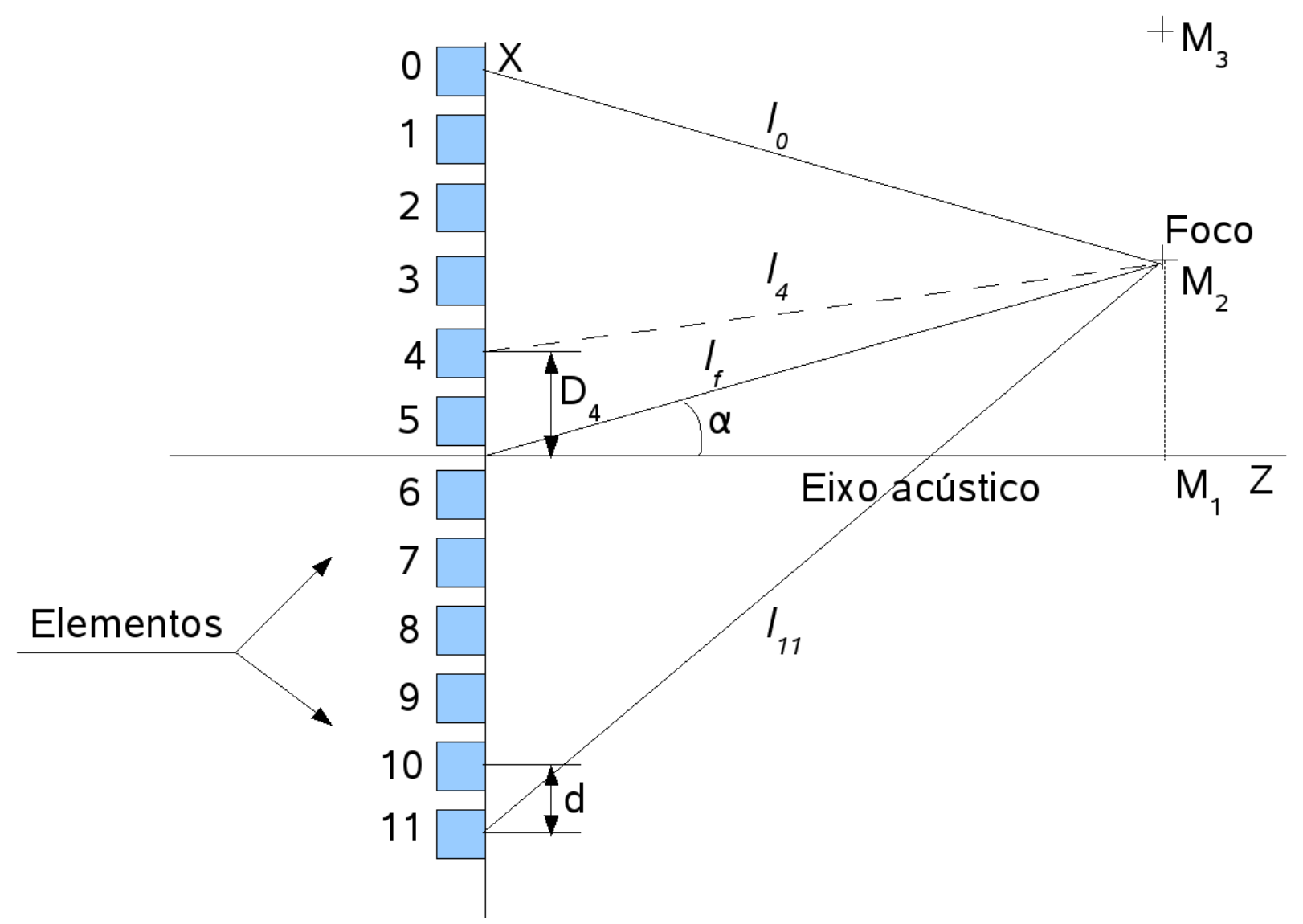

Figura 4.8. Geometria da deflexão com focalização. 
Tabela 4.5. Ordenadas e atrasos dos elementos do array com deflexão e com focalização.

\begin{tabular}{|c|r|r|r|}
\hline Elemento & $\boldsymbol{D}_{\boldsymbol{i}}(\mathbf{m m})$ & \multicolumn{1}{|c|}{$\boldsymbol{y}_{\boldsymbol{i}}(\mathbf{m m})$} & \multicolumn{1}{|c|}{$\boldsymbol{T}_{\boldsymbol{i}}(\mathbf{n s})$} \\
\hline$\# 0$ & $-7,425$ & 9,895 & 2423 \\
\hline$\# 1$ & $-6,075$ & 11,245 & 2047 \\
\hline$\# 2$ & $-4,725$ & 12,595 & 1699 \\
\hline$\# 3$ & $-3,375$ & 13,945 & 1380 \\
\hline$\# 4$ & $-2,025$ & 15,295 & 1092 \\
\hline$\# 5$ & $-0,675$ & 16,645 & 834 \\
\hline$\# 6$ & 0,675 & 17,995 & 609 \\
\hline$\# 7$ & 2,025 & 19,345 & 480 \\
\hline$\# 8$ & 3,375 & 20,695 & 260 \\
\hline$\# 9$ & 4,725 & 22,045 & 138 \\
\hline$\# 10$ & 6,075 & 23,395 & 51 \\
\hline$\# 11$ & 7,425 & 24,745 & 0 \\
\hline
\end{tabular}

\subsection{Funções de excitação}

As simulações foram realizadas com os sinais de excitação $v(t)$ mostrados nas figuras 4.9 a 4.12 para os transdutores monoelemento. Esses sinais foram adquiridos experimentalmente 
posicionando um hidrofone pontual a aproximadamente $2 \mathrm{~mm}$ distante da face desses transdutores (\#1, \#2, \#3 e \#4). Já para a simulação do array, foi utilizado somente o sinal mostrado na Fig. 4.13, obtido para o primeiro elemento, visto que os outros elementos foram excitados com o mesmo tipo de sinal. Esse sinal foi adquirido de maneira semelhante a partir da medição experimental.

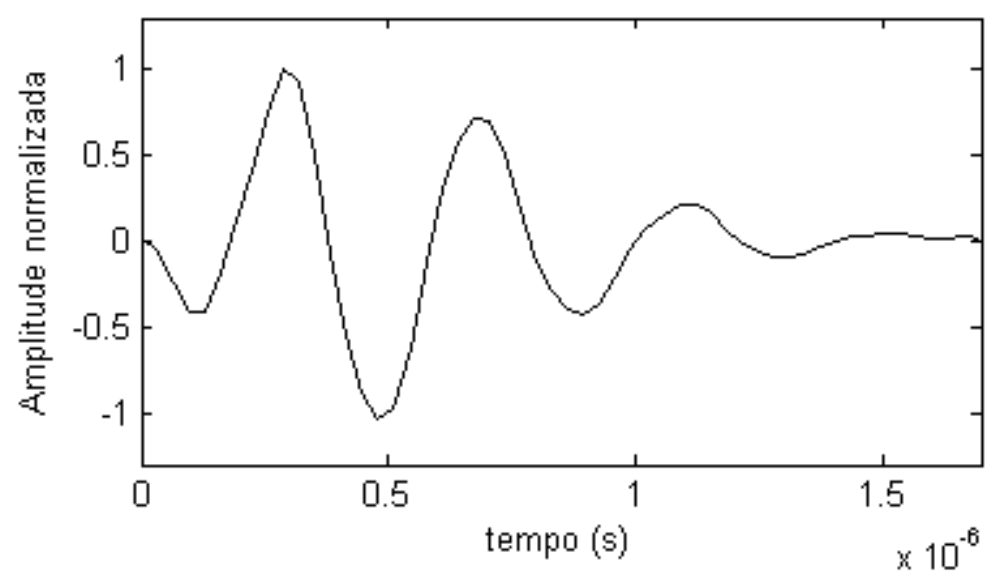

Figura 4.9. Sinal de excitação do transdutor \# 1 de 2,2 MHz.

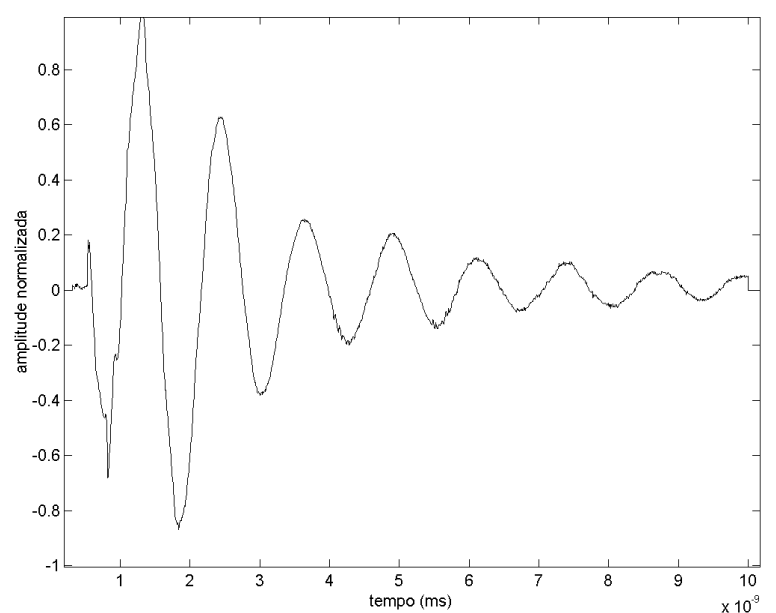

Figura 4.10. Sinal de excitação do transdutor \#2 de $400 \mathrm{kHz}$. 


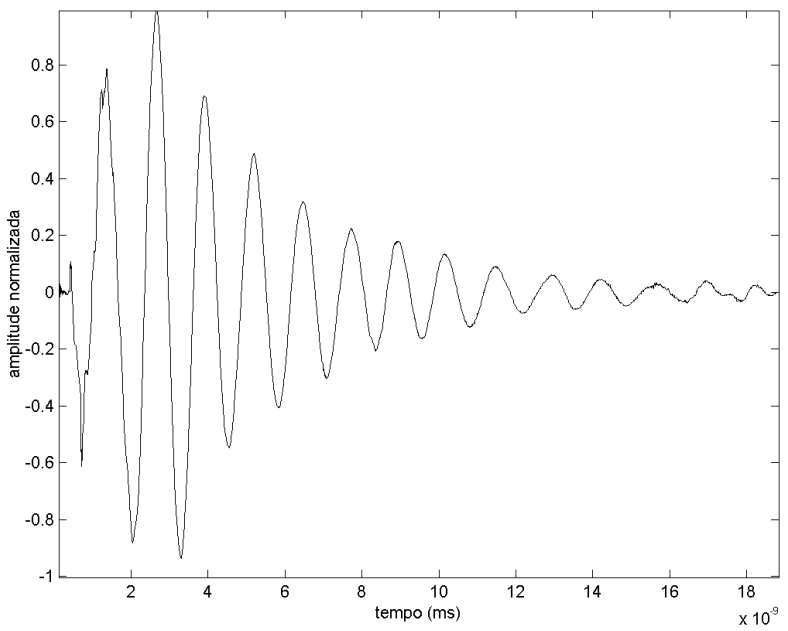

Figura 4.11. Sinal de excitação do transdutor \#3 de $400 \mathrm{kHz}$.

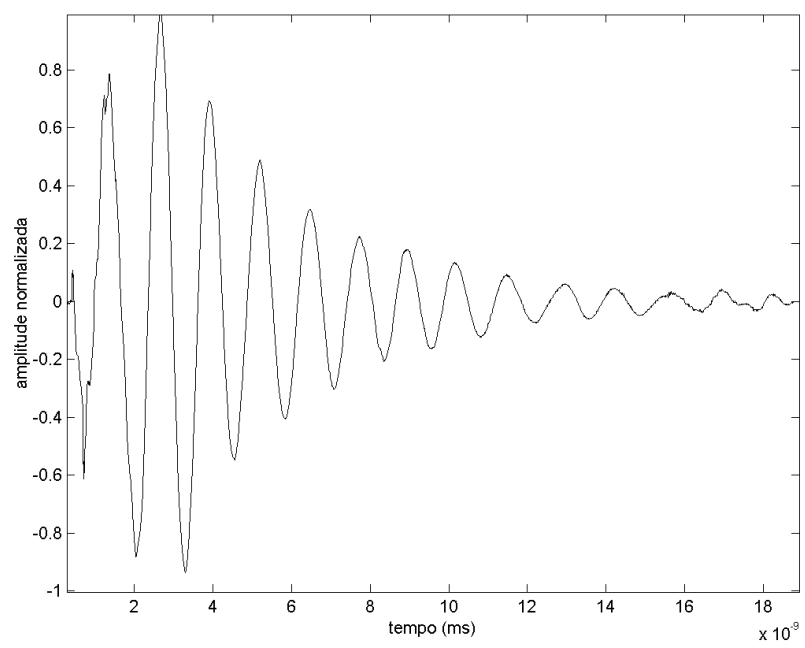

Figura 4.12. Sinal de excitação do transdutor \#4 de 400 kHz. 


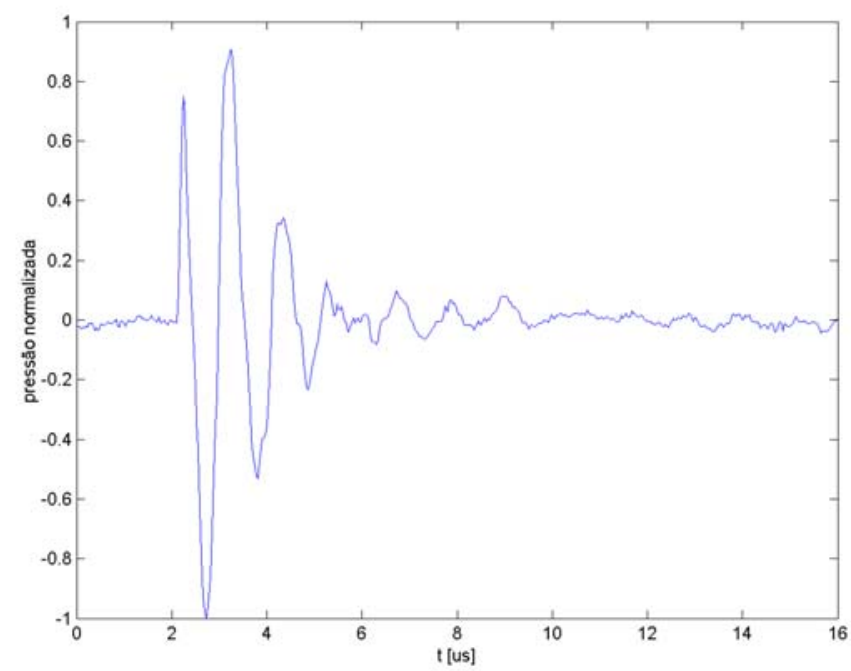

Figura 4.13. Sinal de excitação do array de $1 \mathrm{MHz}$.

\subsection{Sistema computadorizado de medição}

O campo acústico teórico obtido através do modelo é comparado com o obtido experimentalmente através de um sistema computadorizado de medição de campo acústico. O sistema de medição de campo acústico é composto de um tanque de imersão, um pulsador/receptor,

um manipulador cartesiano controlado por motores de passo e dois computadores (principal e secundário), como mostra a figura 4.14. 


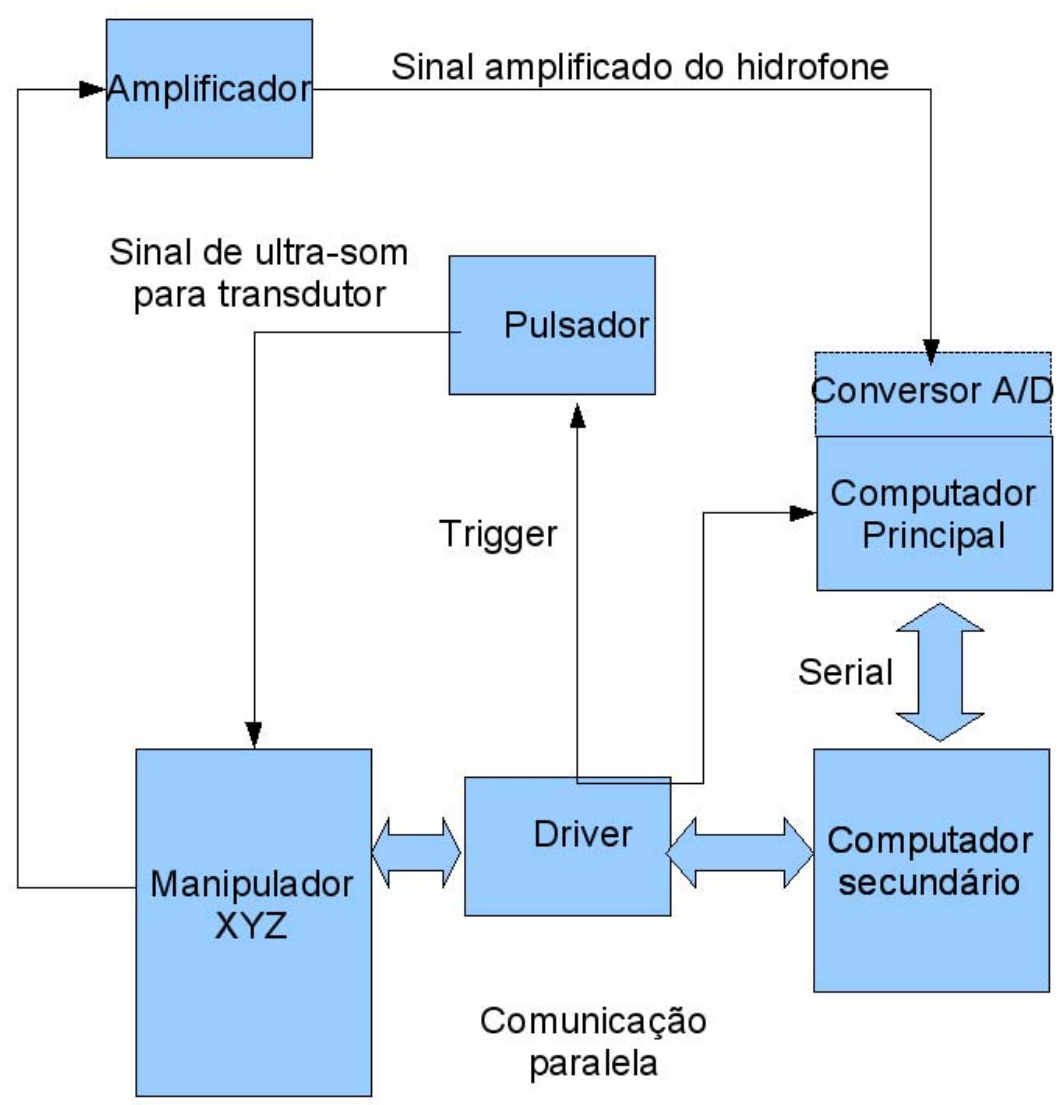

Figura 4.14. Diagrama de blocos do sistema computadorizado de medição do campo acústico.

O computador principal é responsável pela aquisição e processamento dos sinais e o computador secundário é responsável pelo controle do manipulador. Para fazer o mapeamento de campo acústico de um transdutor de ultra-som, o usuário entra com os parâmetros de varredura no computador principal. Em seguida o computador principal envia esses parâmetros para o computador secundário, que inicia o movimento do transdutor de ultra-som e que emite sinais de trigger para o pulsador/receptor e para o computador principal. Quando o pulsador/receptor recebe o sinal de trigger, ele excita o transdutor, que emite uma onda acústica que é recebida pelo hidrofone (Fig. 4.16). O sinal do hidrofone é amplificado e enviado para a placa de conversão analógico/digital (PDA12 da Signatec ${ }^{\mathrm{TM}}$ de 12 bits e $125 \mathrm{MHz}$ ) do computador principal. Então, o sinal é gravado em disco para posterior processamento em Matlab ${ }^{\mathrm{TM}}$. Na varredura de campo acústico (vide Fig. 4.15) foi utilizada uma freqüência de amostragem de $30 \mathrm{MHz}$. 


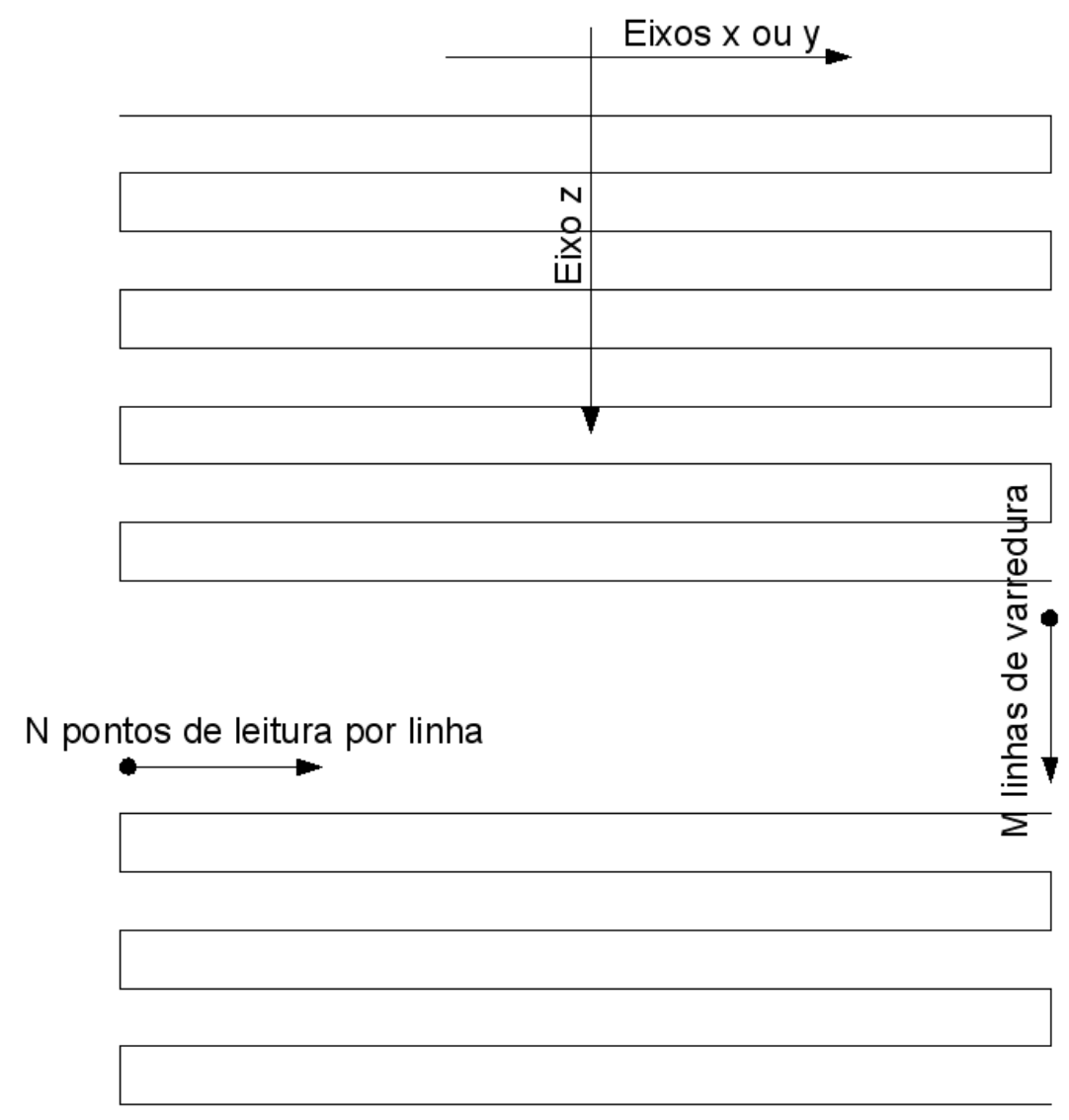

Figura 4.15. Varredura do mapeamento do campo acústico.

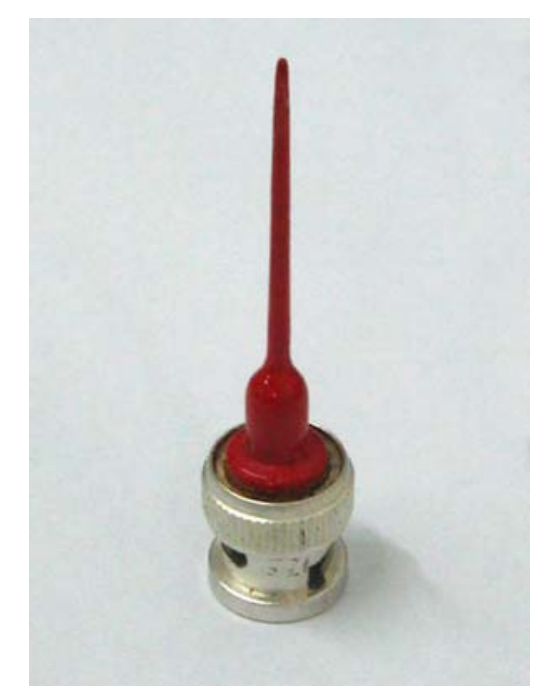

Figura 4.16. Fotografia do hidrofone pontual de $\varnothing=0,6 \mathrm{~mm}$.

A Fig. 4.17 mostra o hidrofone do sistema computadorizado de medição recebendo o sinal emitido pelo transdutor. 


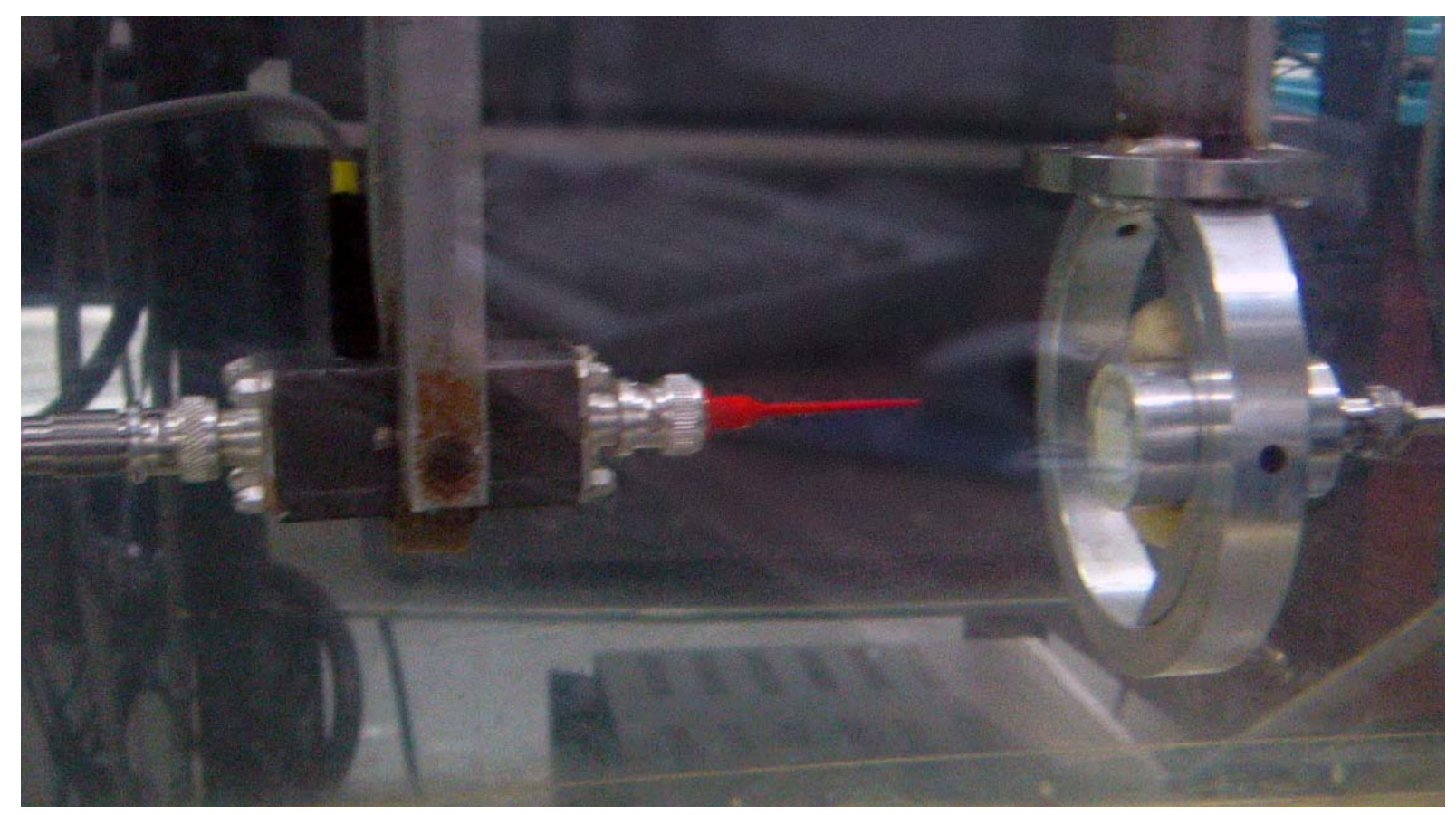

Figura 4.17. Sistema computadorizado de medição do campo acústico. 


\section{CAPÍTULO 5}

\section{RESULTADOS TEÓRICOS E EXPERIMENTAIS}

\subsection{Transdutores monoelementos}

\subsubsection{Transdutor de 2,2 MHz (\#1)}

$\mathrm{O}$ modelo implementado em Matlab ${ }^{\mathrm{TM}}$ tem como parâmetro de entrada a posição $R$ em

coordenadas cartesianas $(x, y, z)$, fornecendo a pressão acústica no ponto $R$ em função do tempo. Para melhorar a resolução do campo acústico obtido teoricamente, o vetor que representa a velocidade da face do transdutor $v(t)$ foi interpolado em 10 vezes, fornecendo uma discretização no tempo de 3,2 ns. A Fig. 5.1 mostra a comparação entre a pressão acústica obtida através do modelo e medida experimentalmente no tanque de imersão. A pressão foi medida na posição $(\mathrm{x}=0 \mathrm{~mm}, \mathrm{y}=$ $10 \mathrm{~mm}, \mathrm{z}=10 \mathrm{~mm}$ ) utilizando um hidrofone pontual de 0,6 mm de diâmetro. Pode-se observar na Fig. 5.1, que existe boa concordância entre a pressão acústica teórica e a experimental. A pequena diferença entre a pressão acústica teórica e a experimental pode estar associada ao alinhamento da face do transdutor com o plano $x y$.

A Fig. 5.1 mostra a pressão acústica em função do tempo em apenas um ponto do espaço. Neste trabalho, a distribuição de pressão espacial ou o campo acústico gerado pelo transdutor é calculado através da diferença entre a amplitude máxima e a amplitude mínima da pressão acústica em função do tempo. As comparações entre as distribuições de pressão teórica e experimental nos planos xz e yz, são mostradas nas Figs. 5.2 e 5.3, respectivamente. 
(a)

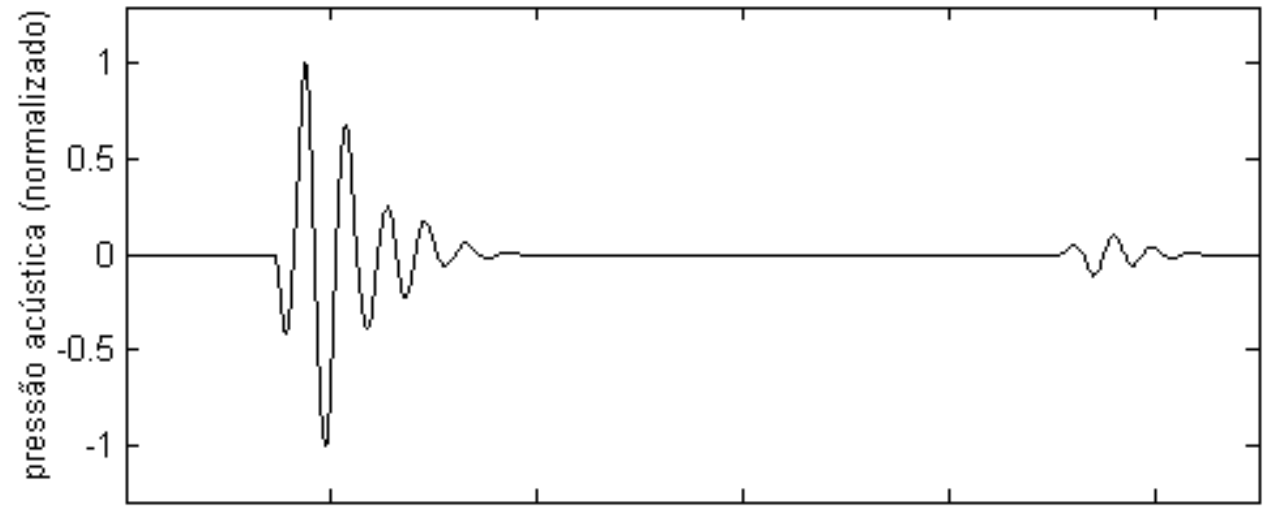

(b)

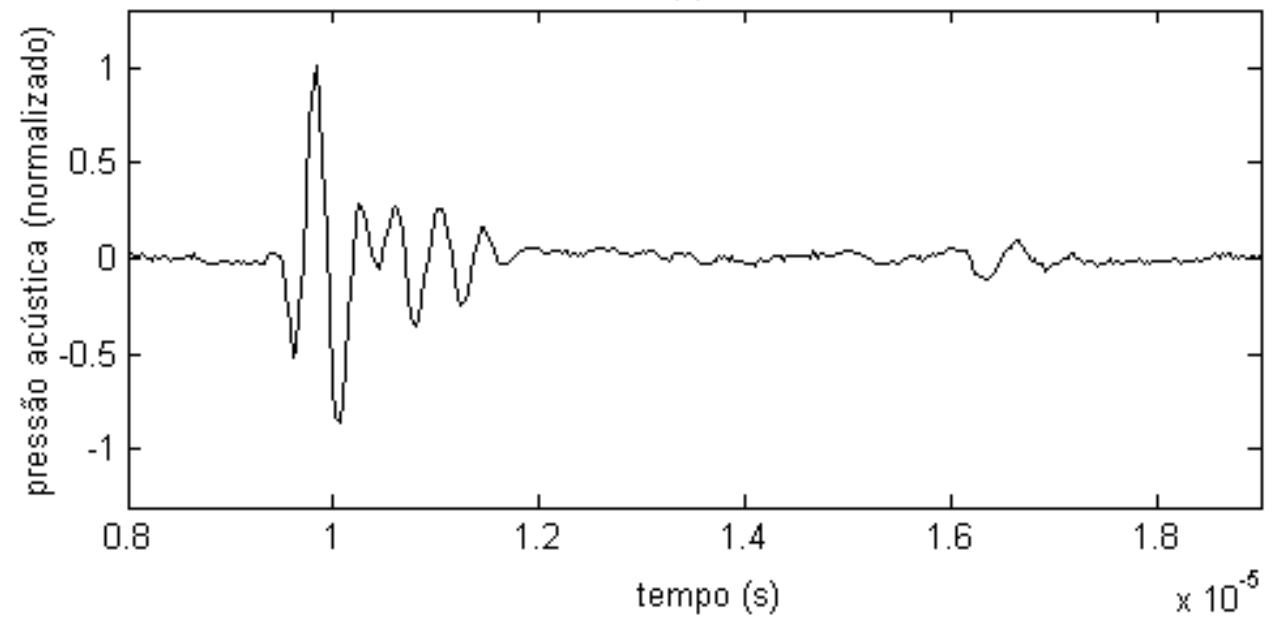

Figura 5.1. Pressão acústica em função do tempo obtida na posição $(\mathrm{x}=0 \mathrm{~mm}, \mathrm{y}=10 \mathrm{~mm}$ e $\mathrm{z}=$ 10 mm): (a) pressão teórica; (b) pressão experimental.

Como se observa nas Figuras. 5.2 e 5.3, existe excelente concordância entre os resultados obtidos teoricamente e experimentalmente. 
(a)

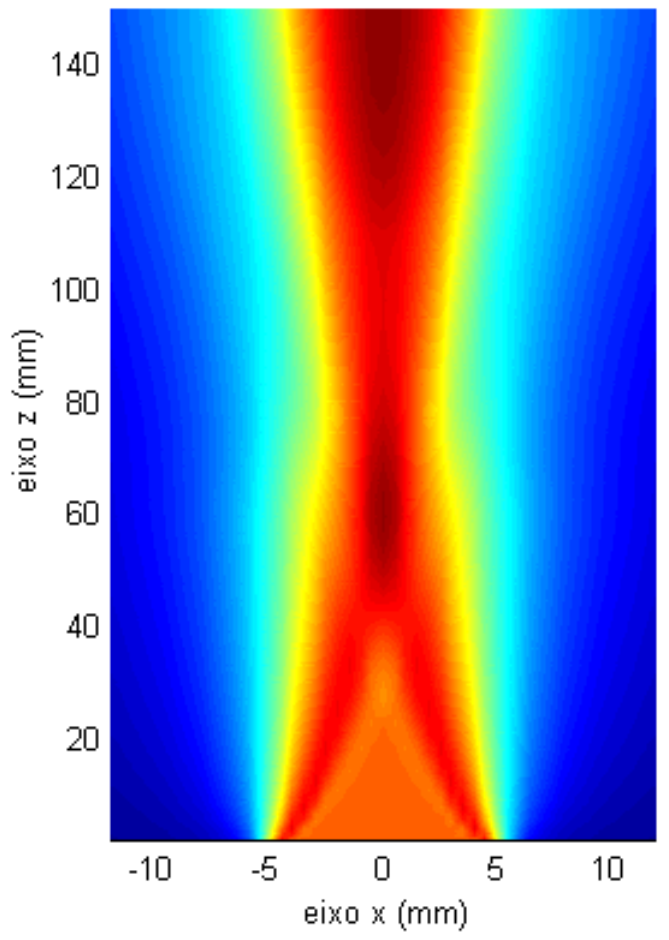

(b)

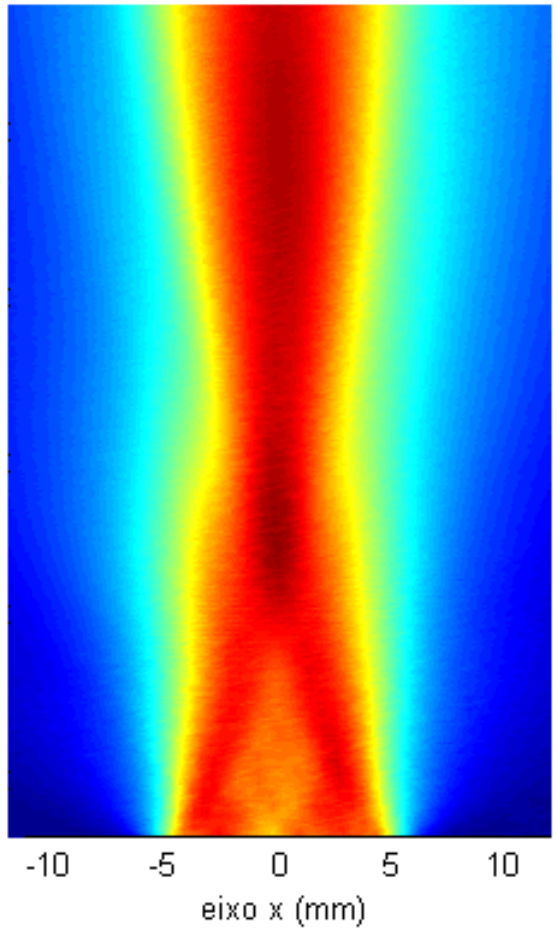

Figura 5.2. Comparação entre o campo acústico teórico e experimental no plano $x z$ sendo $y=0$ : (a) teórico; (b) experimental.

(a)

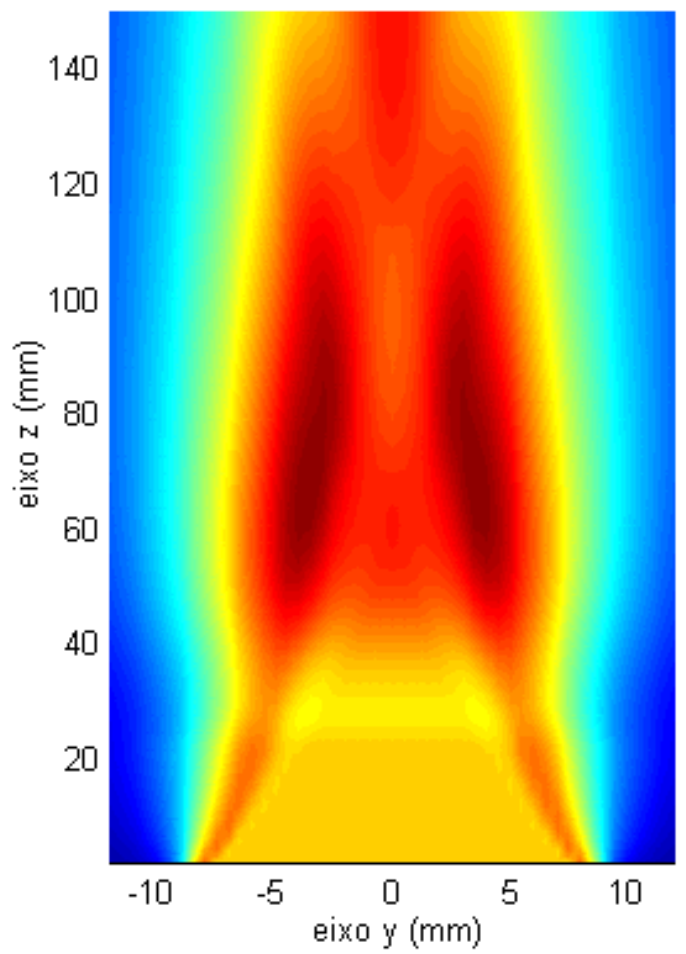

(b)

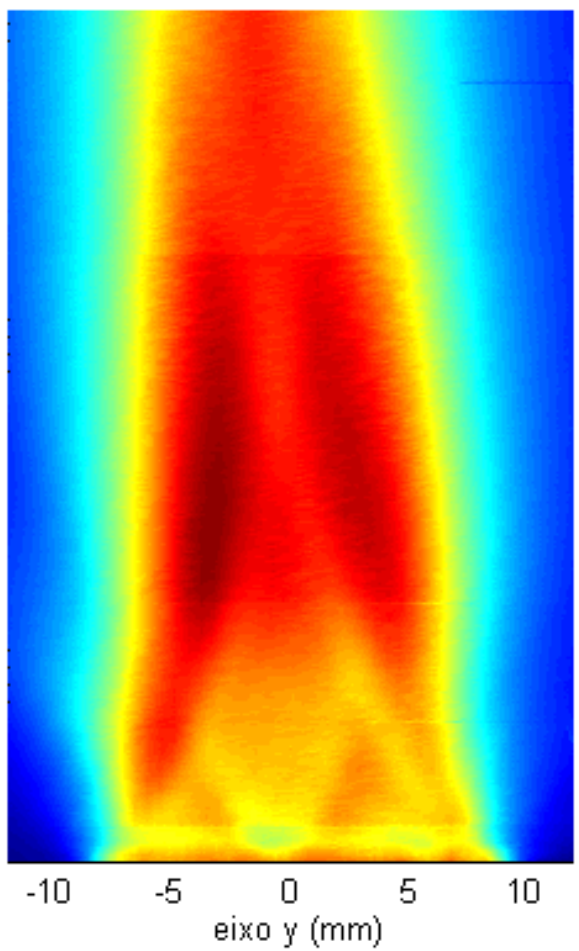

Figura 5.3. Comparação entre o campo acústico teórico e experimental no plano $y z$ sendo $x=0$ : (a) teórico; (b) experimental. 


\subsubsection{Transdutores de $400 \mathrm{kHz}(\# 2, \# 3$ e \#4)}

As figuras comparativas, entre as simulações e as medições experimentais dos sensores \#2, \#3 e \#4 (Figs. 5.4 a 5.9), mostram não haver boa concordância entre o campo teórico e o medido. Isso ocorre porque o comprimento de onda é da ordem das dimensões geométricas dos sensores. Por exemplo, no caso do sensor \#4, verifica-se pelas Tab. 4.1 e Tab. 4.2 que a largura do mesmo (2,8 $\mathrm{mm})$ é inferior ao comprimento de onda do sinal $(3,7 \mathrm{~mm})$. Embora a teoria do pistão plano baseie-se na distribuição uniforme das tensões na superficie do pistão, quando as dimensões deste são finitas, aparecem nós de tensão na superficie do pistão, assim como aparecem num guia de onda ou um resonador eletromagnético (KINO, 2000).

Quando as dimensões do transdutor são semelhantes ao comprimento de onda e o fator de mérito Q não é muito alto, esses efeitos tendem a desaparecer e o campo de tensões pode ser assumido como essencialmente uniforme, entre os elementos de excitação do transdutor. Ainda que a excitação seja perfeitamente uniforme, o campo de tensões a certa distância do transdutor, pode não ser. Por causa da difração, o feixe acústico emitido pelo transdutor aumenta sua seção com a distância e o componente do campo do feixe mostra pequenas variações na sua estrutura (KINO, 2000). 
(a)

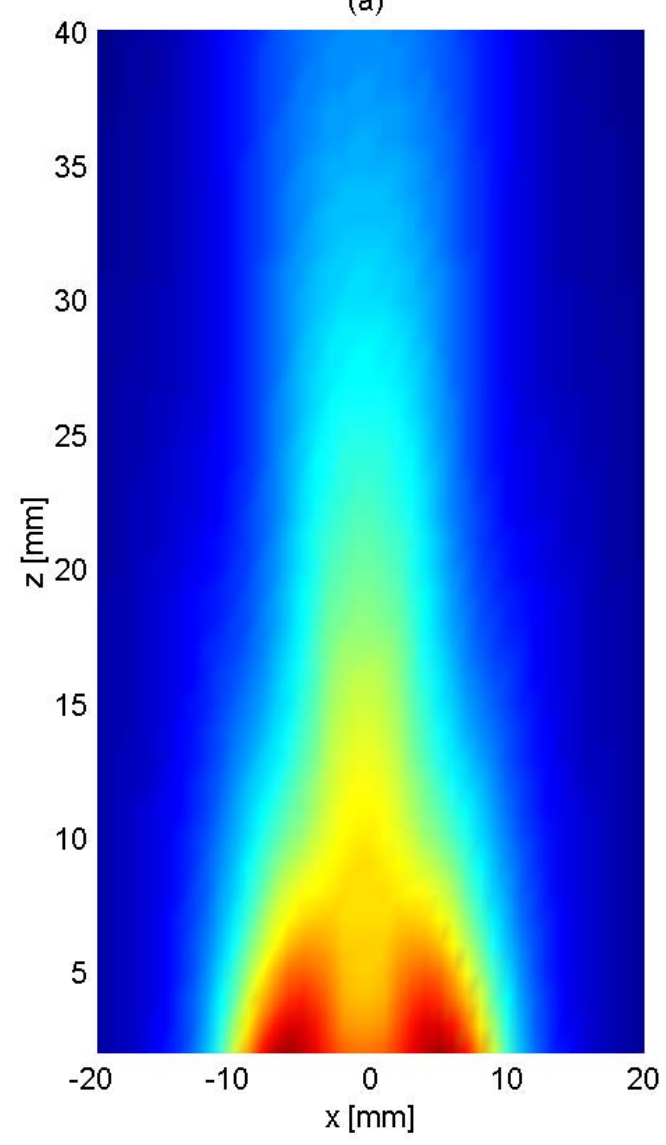

(b)

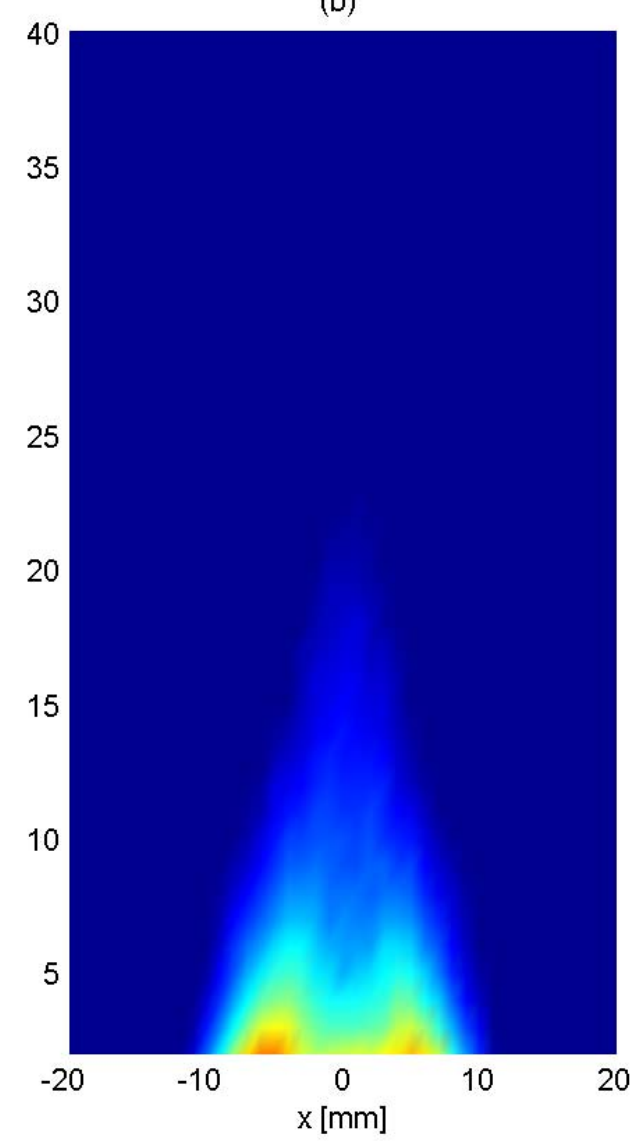

Figura 5.4. Comparação entre o campo acústico teórico e experimental no plano $x z$ sendo $y=0$ : (a) teórico; (b) experimental. (Transdutor \#2 de $400 \mathrm{kHz}$ ). 
(a)

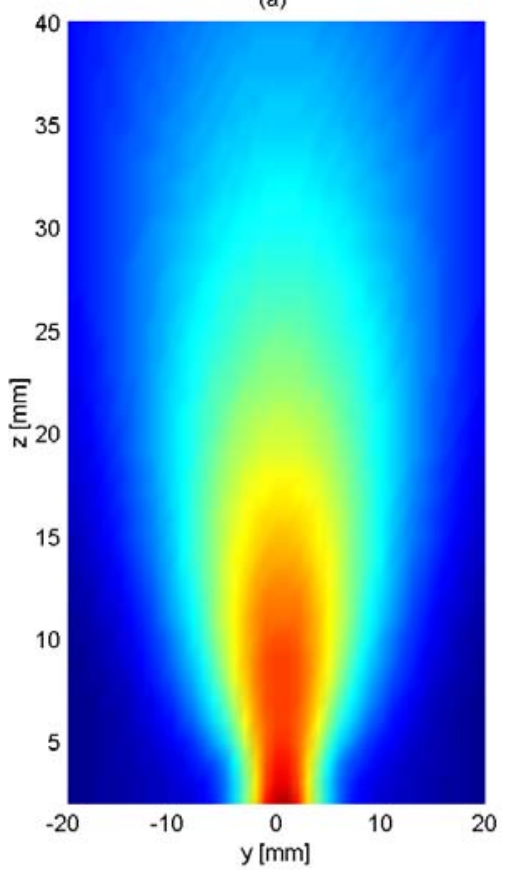

(b)

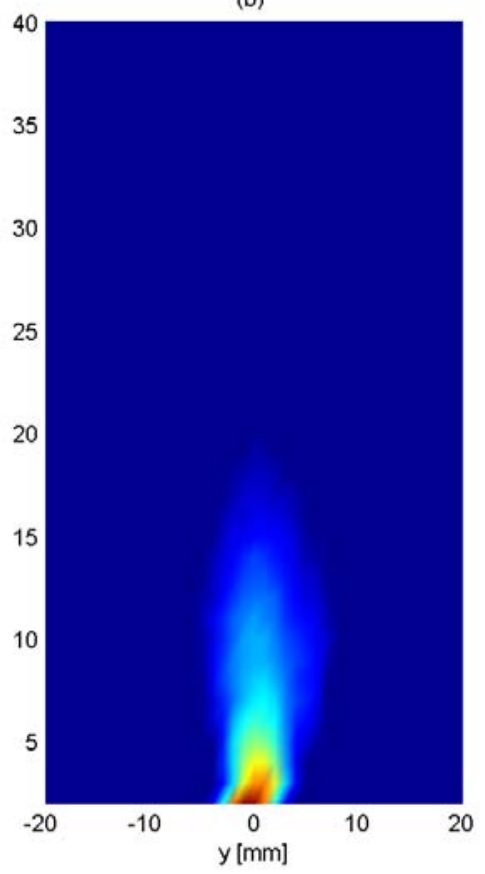

Figura 5.5. Comparação entre o campo acústico teórico e experimental no plano $y z$ sendo $x=0$ : (a) teórico; (b) experimental. (Transdutor \#2 de $400 \mathrm{kHz}$ ).
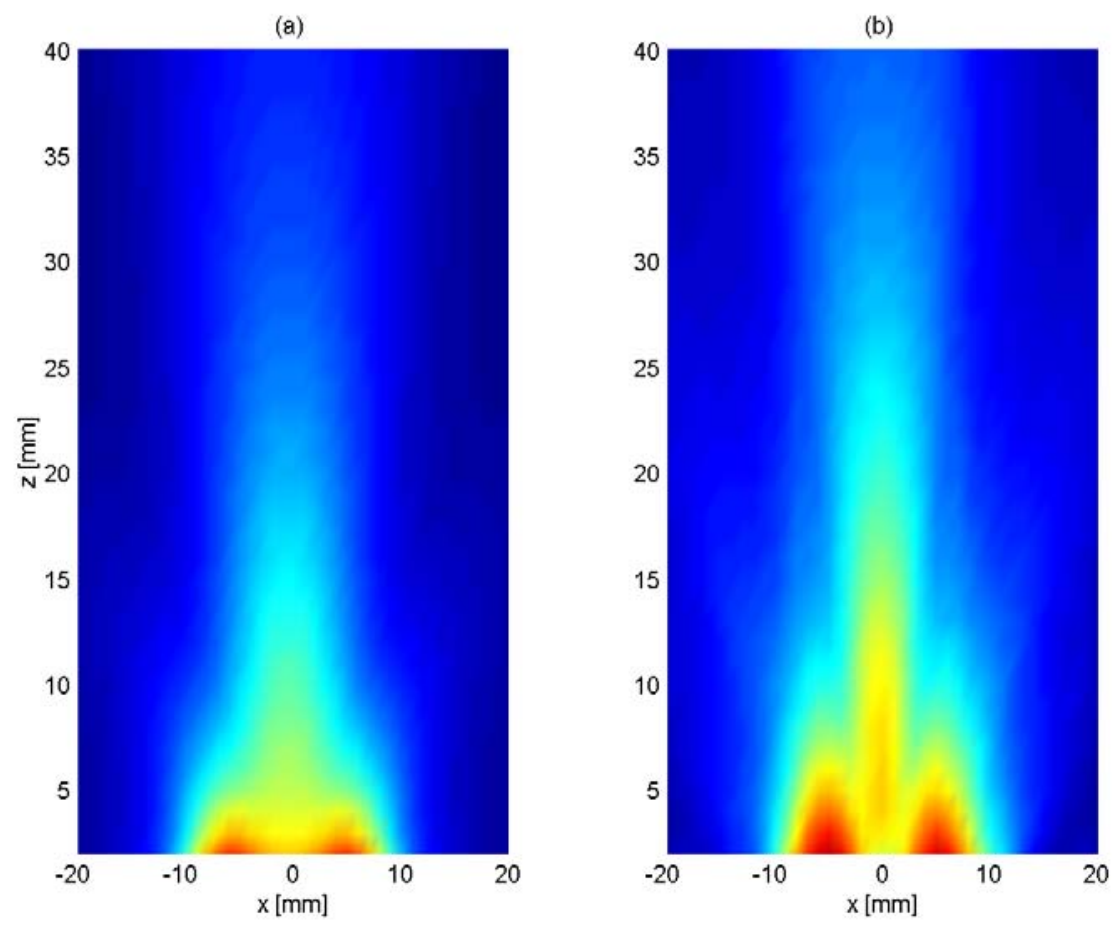

Figura 5.6. Comparação entre o campo acústico teórico e experimental no plano $x z$ sendo $y=0$ : (a) teórico; (b) experimental. (Transdutor \#3 de $400 \mathrm{kHz}$ ). 
(a)

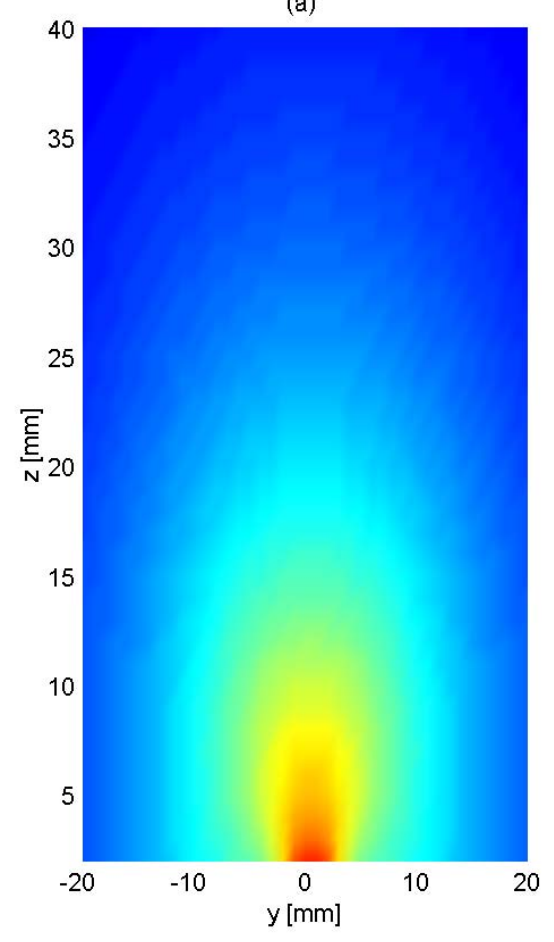

(b)

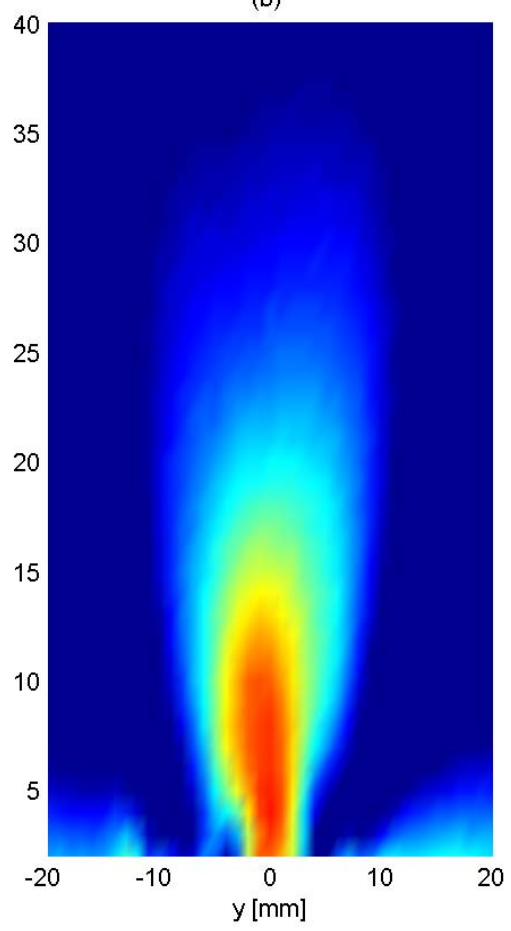

Figura 5.7. Comparação entre o campo acústico teórico e experimental no plano $y z$ sendo $x=0$ : (a) teórico; (b) experimental. (Transdutor \#3 de $400 \mathrm{kHz}$ ).
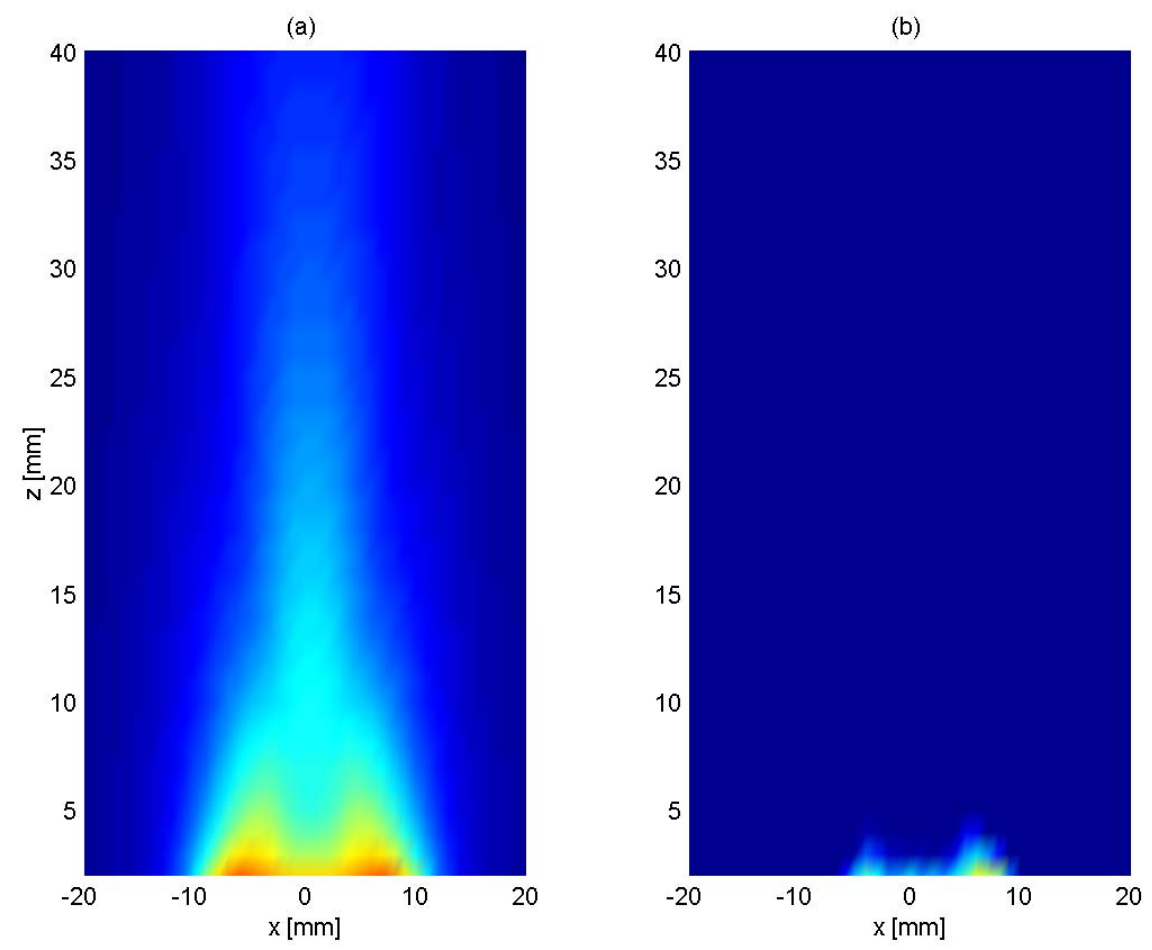

Figura 5.8. Comparação entre o campo acústico teórico e experimental no plano $x z$ sendo $y=0$ : (a) teórico; (b) experimental. (Transdutor \#4 de $400 \mathrm{kHz}$ ). 
(a)

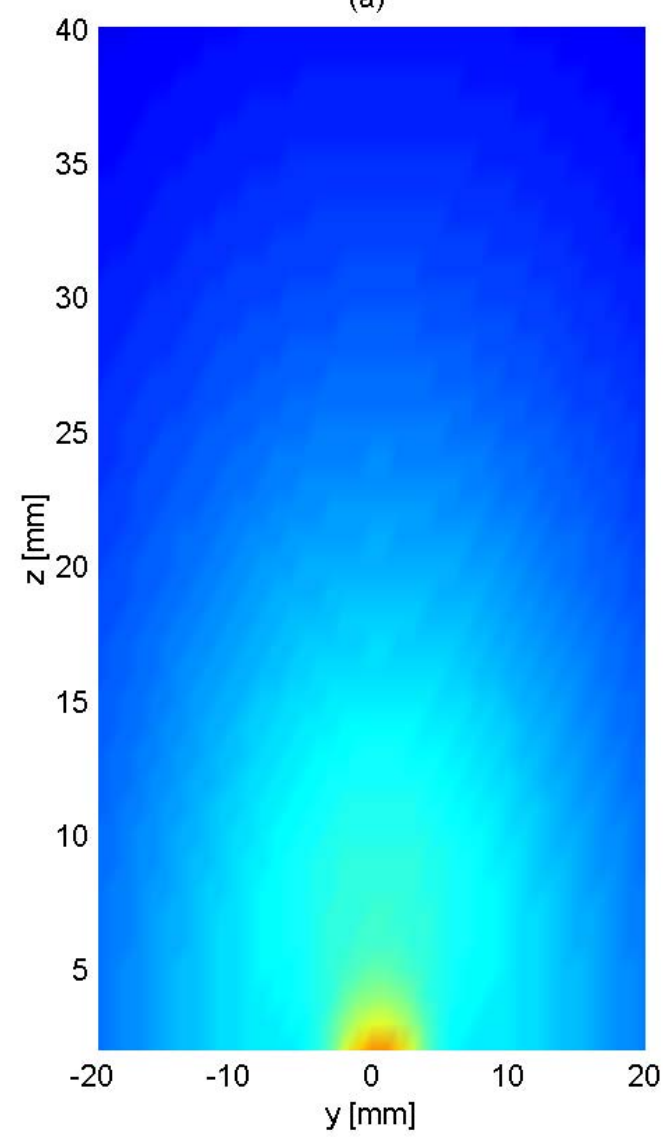

(b)

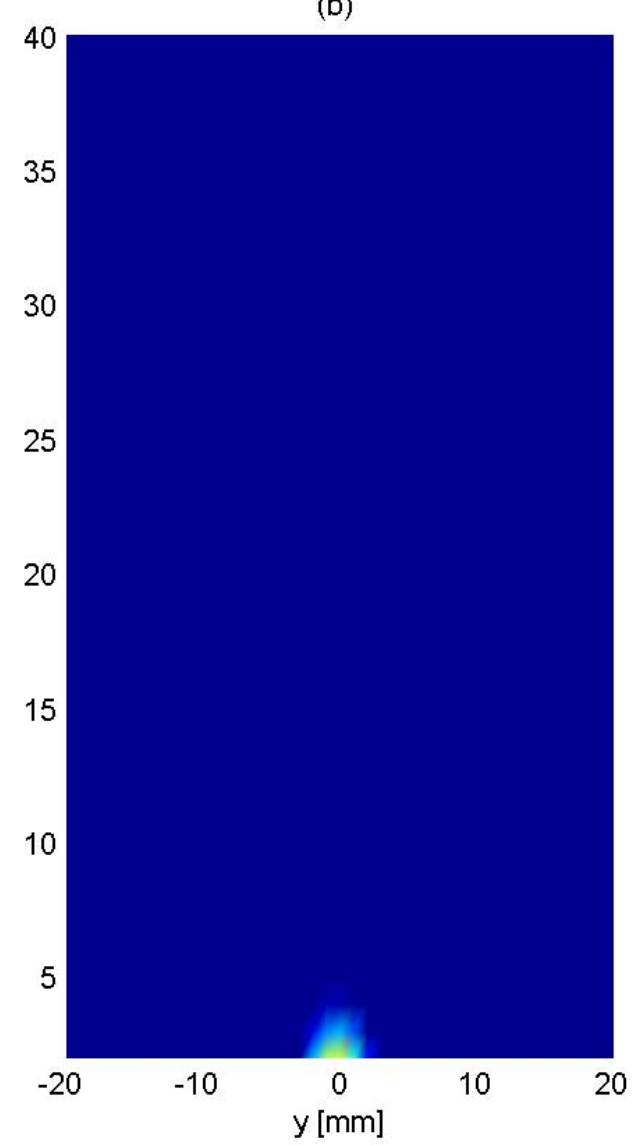

Figura 5.9. Comparação entre o campo acústico teórico e experimental no plano $y z$ sendo $x=0$ : (a) teórico; (b) experimental. (Transdutor \#4 de $400 \mathrm{kHz}$ ). 


\subsection{Transdutores multielementos (array lineares)}

Primeiro caso: validação do modelo (sem focalização e sem deflexão).

(a) M1

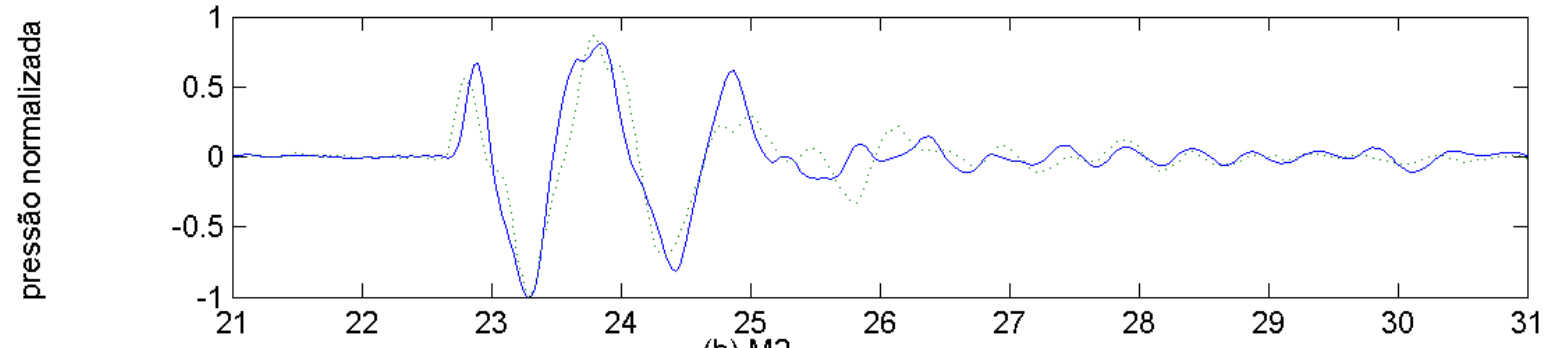

(b) M2

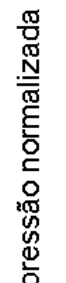

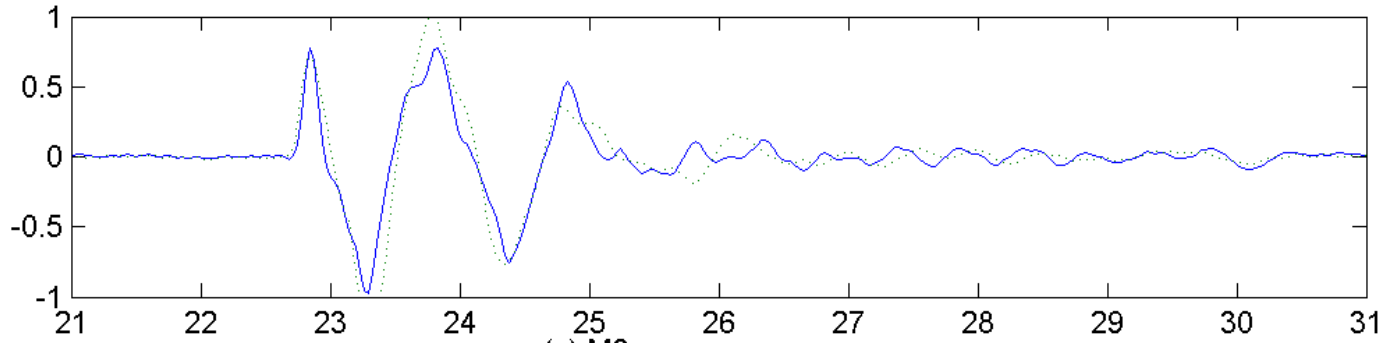

(c) M3

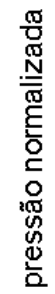

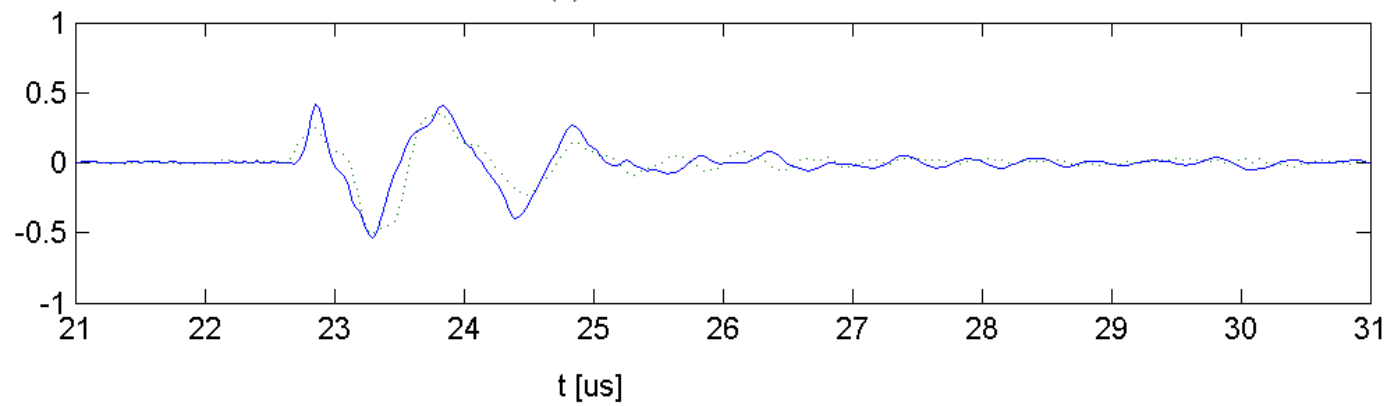

Figura 5.11. Pressão acústica em função do tempo obtida na posição dos pontos $M_{1}(0,0,30$ $m m,(a)), M_{2}(0,5 \mathrm{~mm}, 30 \mathrm{~mm},(b))$ e $M_{3}(0,10 \mathrm{~mm}, 30 \mathrm{~mm}$, (c)), sem deflexão e sem focalização: pressão teórica, linha contínua; pressão experimental, linha tracejada. 
Segundo caso: focalização sem deflexão.

(a) M1

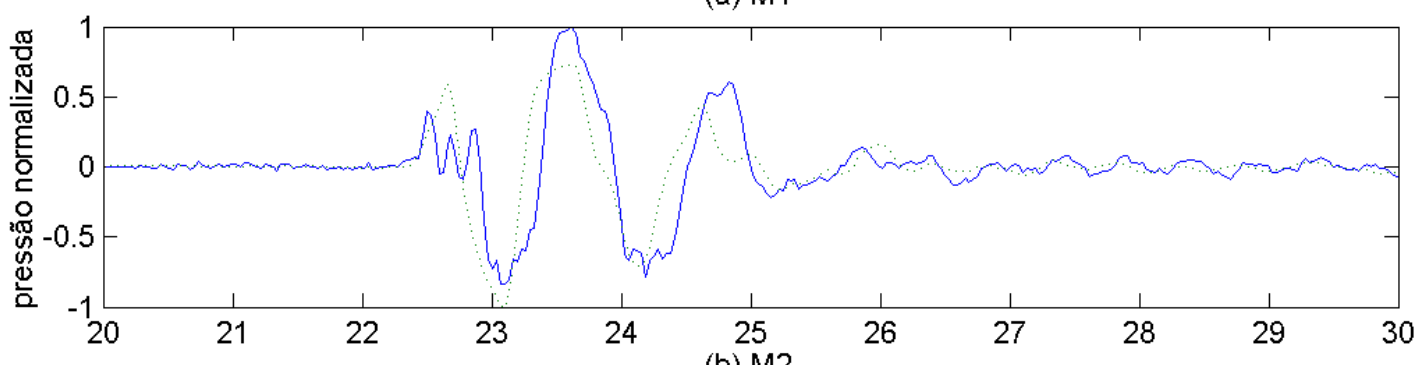

(b) M2

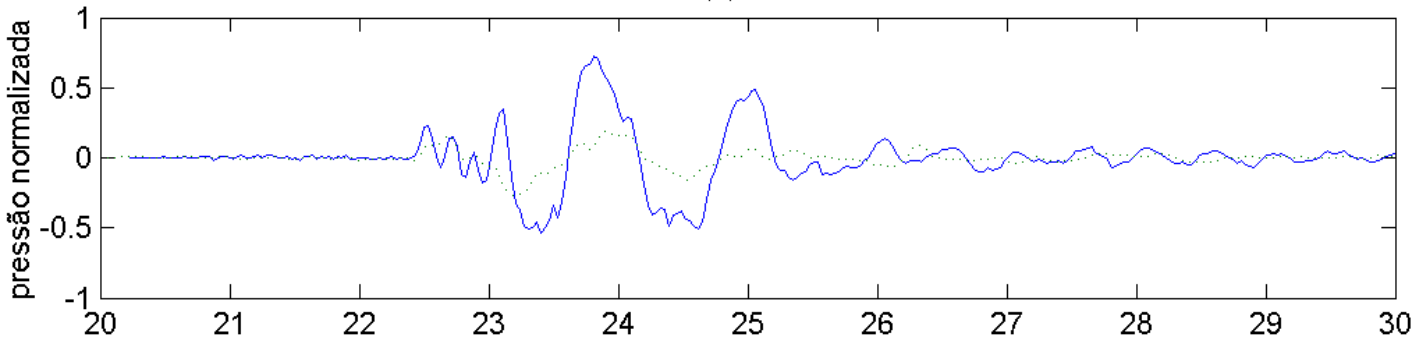

(c) M3

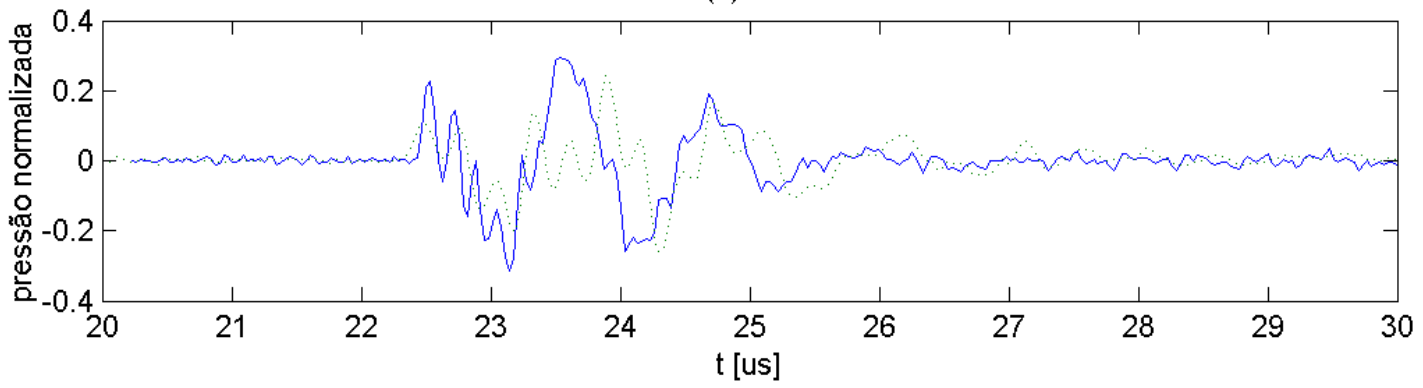

Figura 5.12. Pressão acústica em função do tempo obtida na posição dos pontos $M_{1}(0,0,30$ $\mathrm{mm},(a)), M_{2}(0,5 \mathrm{~mm}, 30 \mathrm{~mm},(b))$ e $M_{3}(0,10 \mathrm{~mm}, 30 \mathrm{~mm},(c))$, sem deflexão e com focalização no eixo acústico, em $z=30 \mathrm{~mm}$ : pressão teórica, linha contínua; pressão experimental, linha tracejada. 
Terceiro caso: deflexão sem focalização.

(a) M1

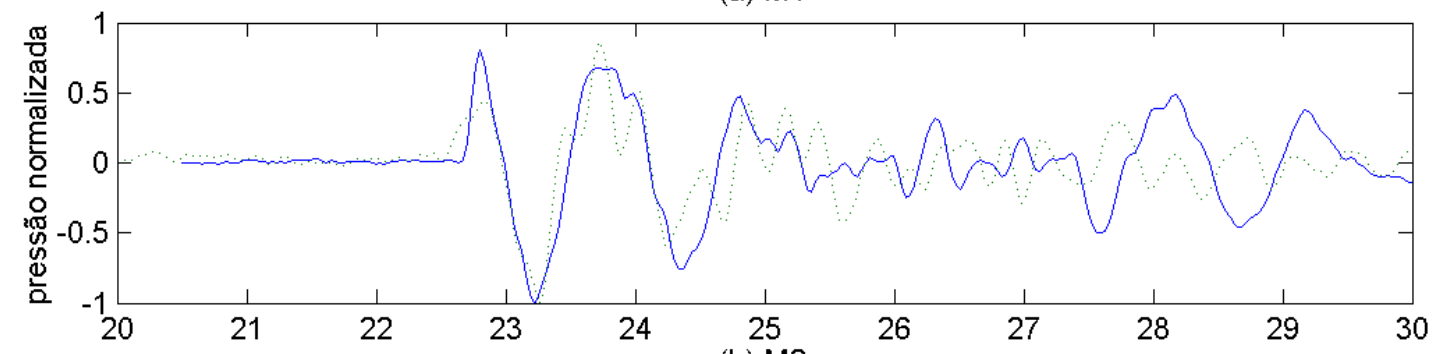

(b) M2

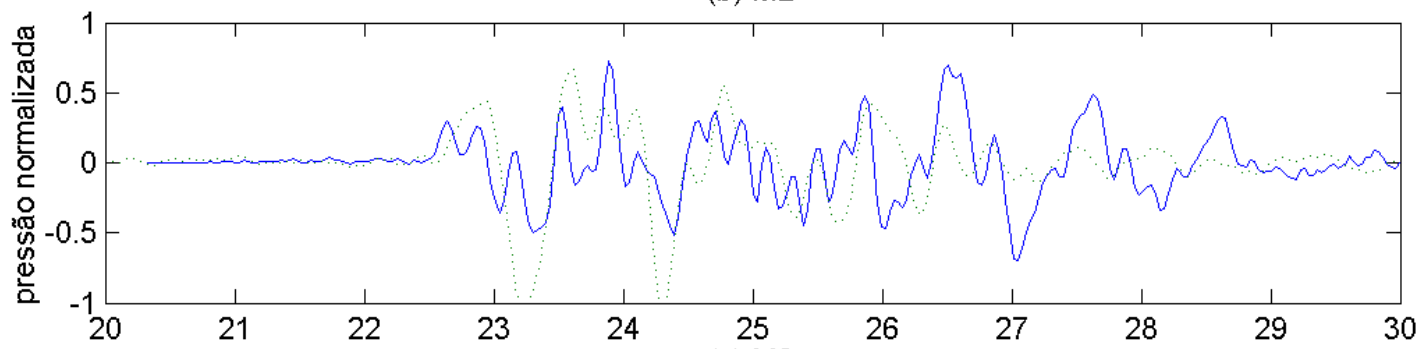

(c) M3

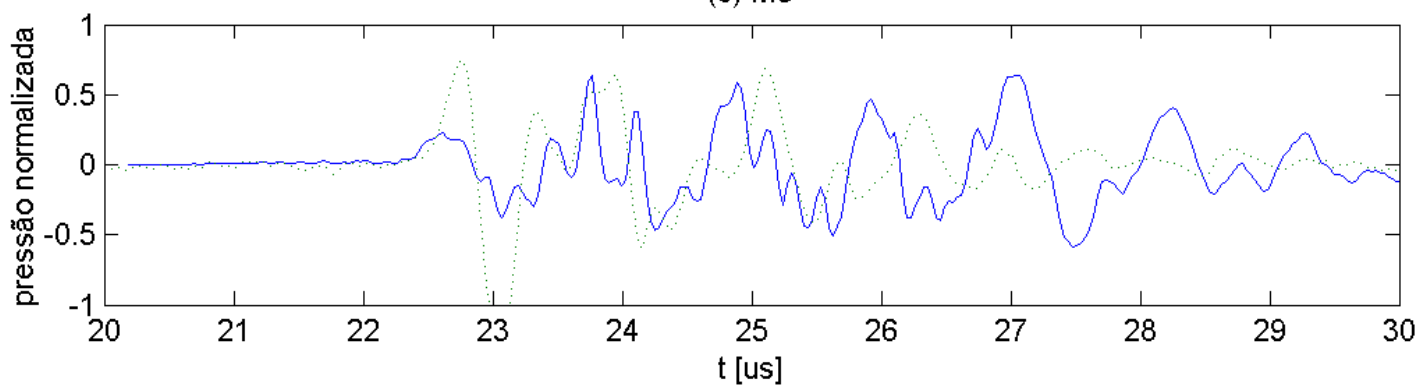

Figura 5.13. Pressão acústica em função do tempo obtida na posição dos pontos $M_{1}(0,0,30$ $m m,(a)), M_{2}(0,5 \mathrm{~mm}, 30 \mathrm{~mm},(b))$ e $M_{3}(0,10 \mathrm{~mm}, 30 \mathrm{~mm}$, (c)), com deflexão e sem focalização: pressão teórica, linha contínua; pressão experimental, linha tracejada. 
Quarto caso: deflexão com focalização.

(a) M1

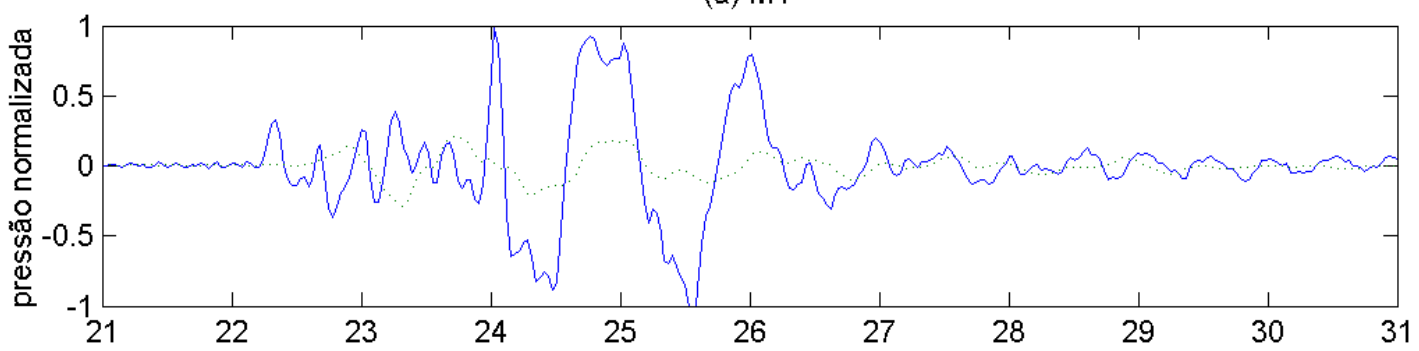

(b) $\mathrm{M} 2$

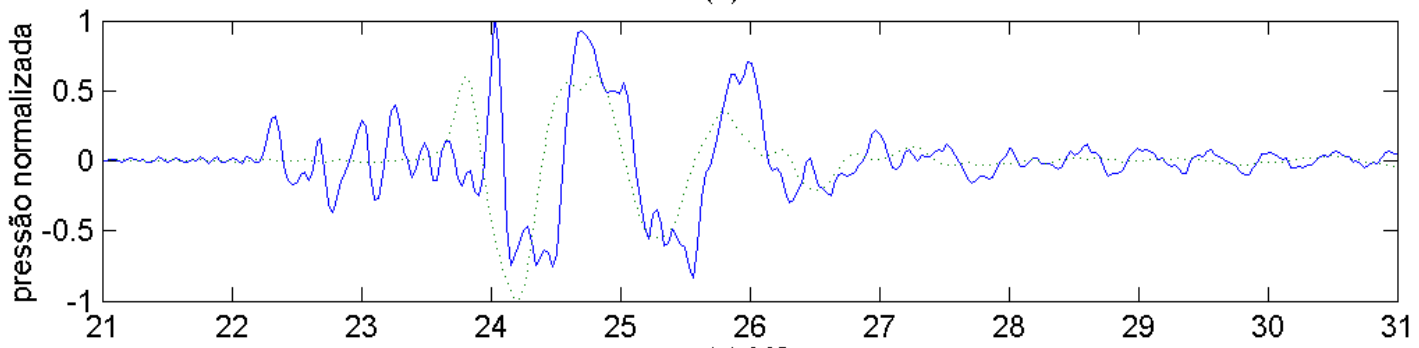

(c) $\mathrm{M} 3$

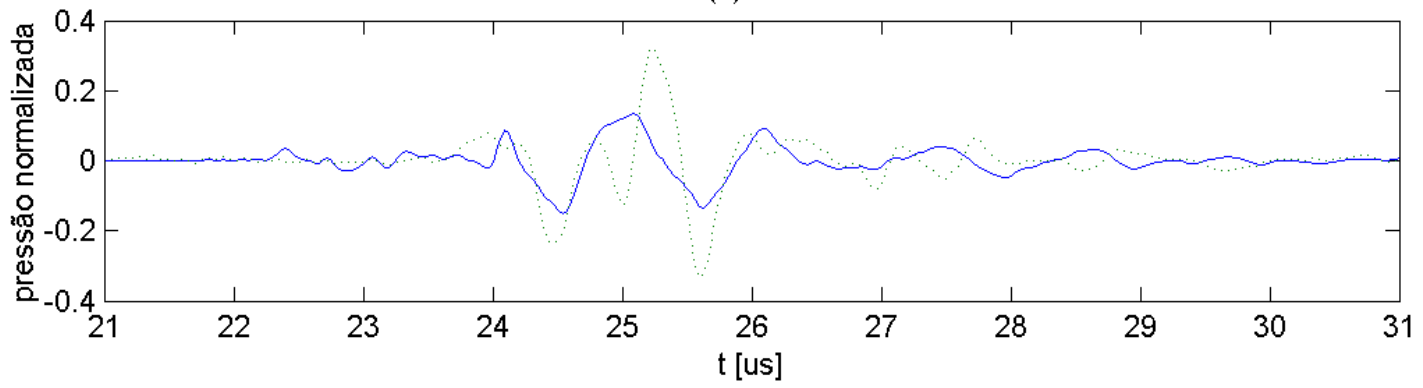

Figura 5.14. Pressão acústica em função do tempo obtida na posição dos pontos $M_{1}(0,0,30$ $\mathrm{mm},(a)), M_{2}\left(0,5 \mathrm{~mm}, 30 \mathrm{~mm}\right.$, (b)) e $M_{3}(0,10 \mathrm{~mm}, 30 \mathrm{~mm}$, (c)), com deflexão e com focalização em $z=30 \mathrm{~mm}$ : pressão teórica, linha contínua; pressão experimental, linha tracejada. 
Campo acústico do array, primeiro caso: elemento isolado.

A Fig. 5.15 mostra a comparação entre a pressão acústica obtida através do modelo e a medida experimentalmente no tanque de imersão, com um único elemento excitado. Pode-se observar na Fig. 5.15, e as seguintes, que existe boa concordância entre a pressão acústica teórica e a experimental.
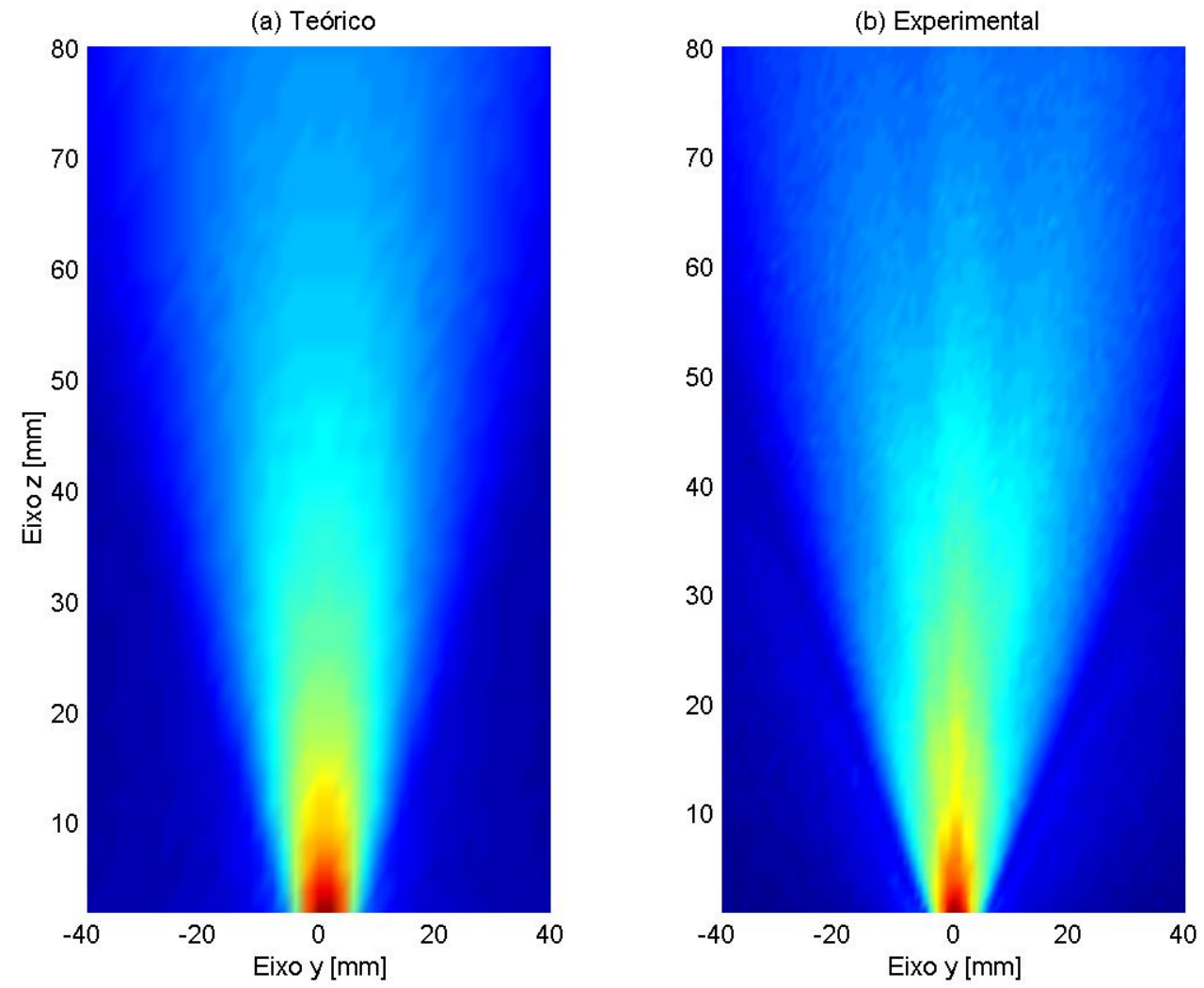

Figura 5.15. Comparação entre o campo acústico teórico e experimental gerado pela excitação isolada de um único elemento: (a) teórico; (b) experimental. (Array de $1 \mathrm{MHz}$ ). 
Campo acústico do array, segundo caso: todos os elemento simultáneos.

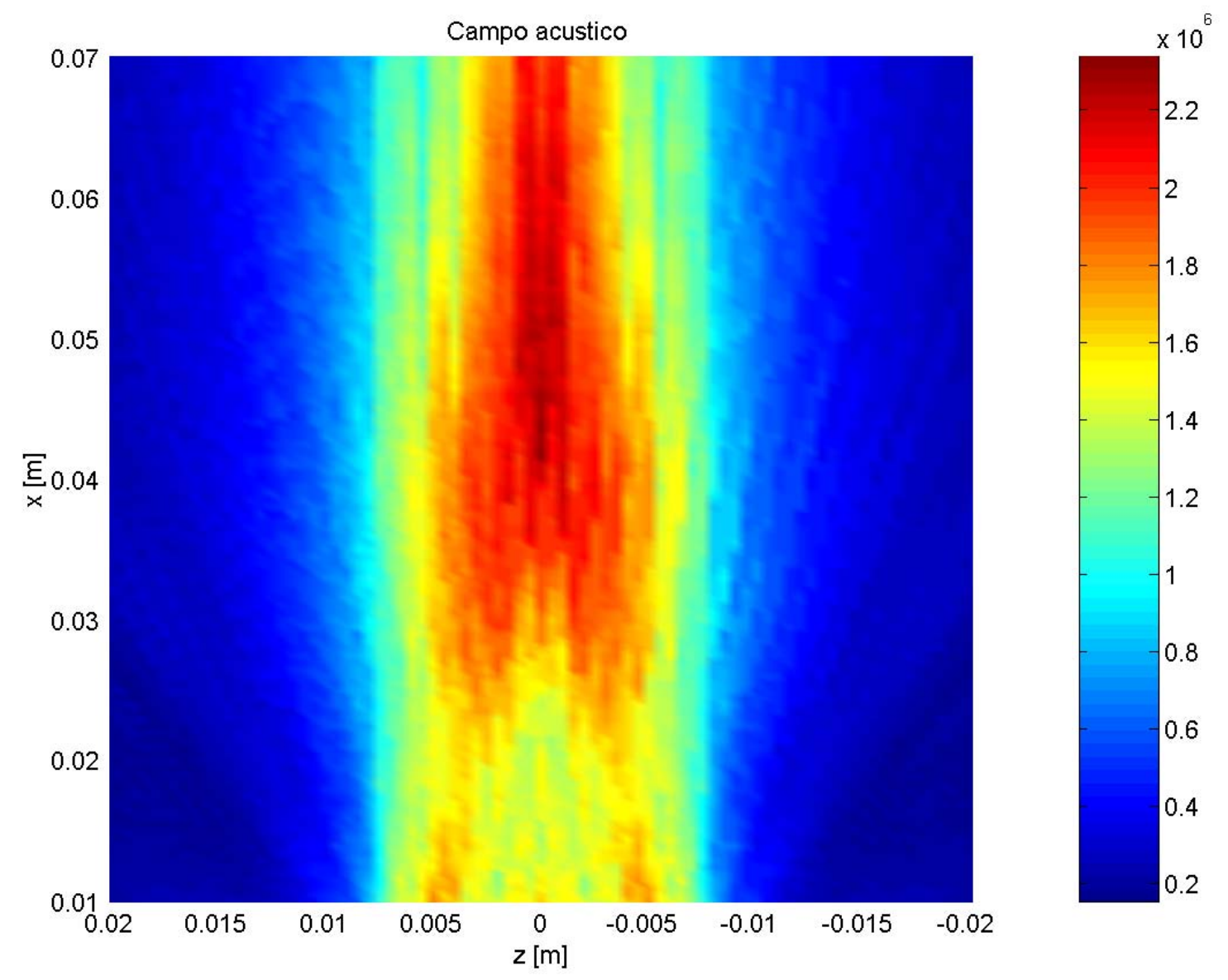

Figura 5.16. Campo acústico teórico gerado pela excitação simultánea dos elemento do array (Array de $1 \mathrm{MHz}$ ). 


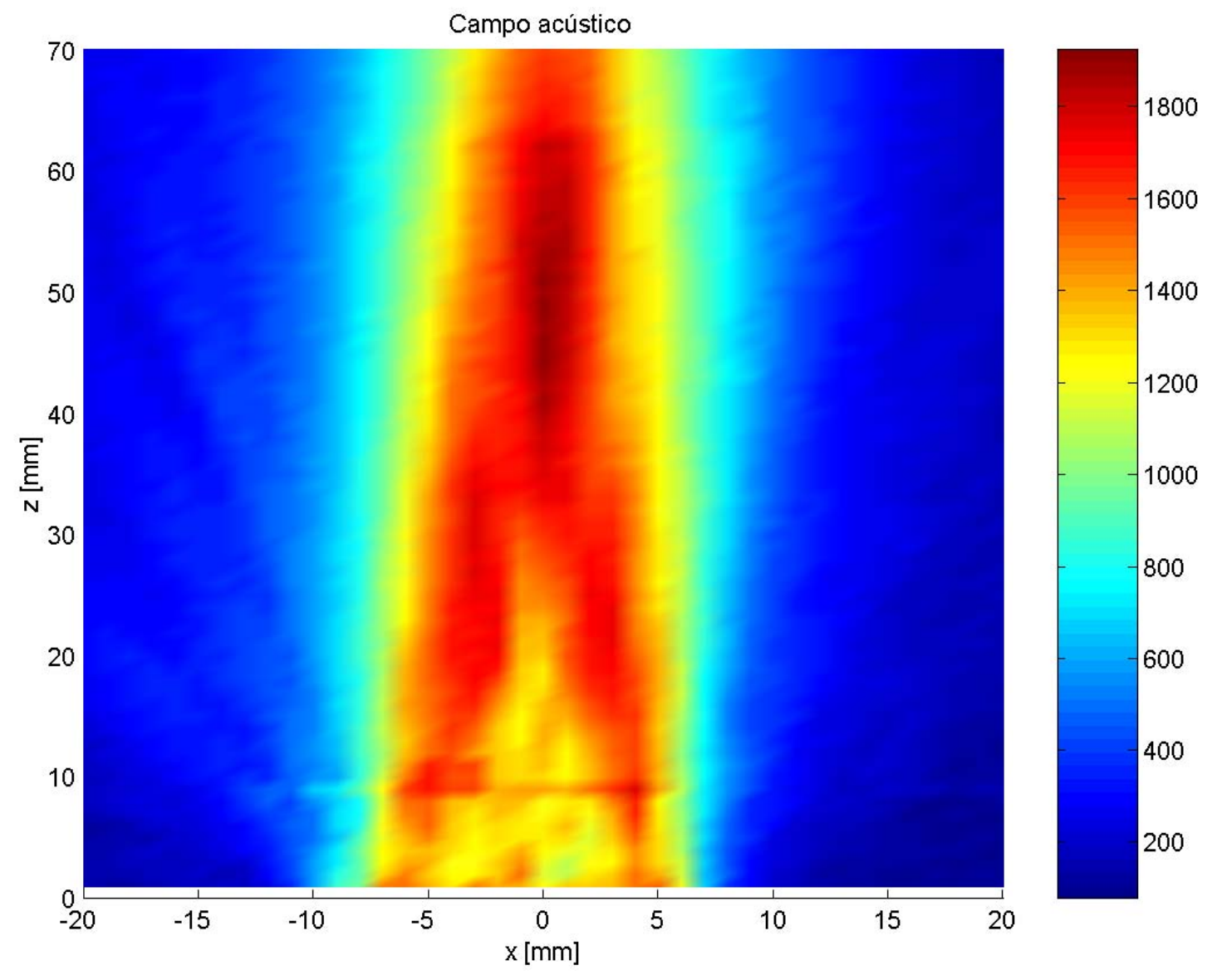

Figura 5.17. Campo acústico experimental gerado pela excitação simultánea dos elemento do array (Array de $1 \mathrm{MHz}$ ). 
Campo acústico do array, terceiro caso: focalização, sem deflexão.

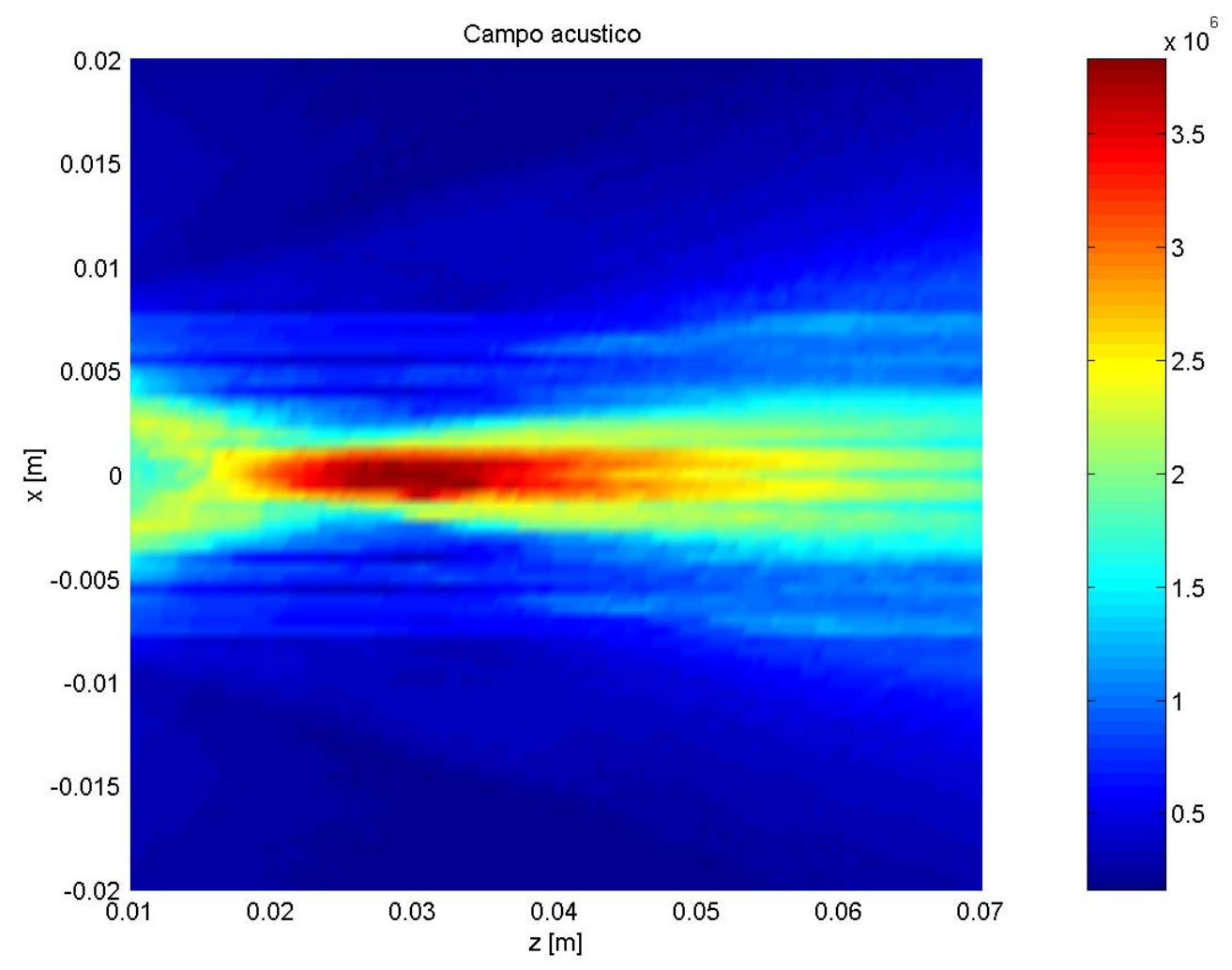

Figura 5.18. Campo acústico teórico, sem deflexão e com focalização no eixo acústico, em $z=30 \mathrm{~mm}$. 


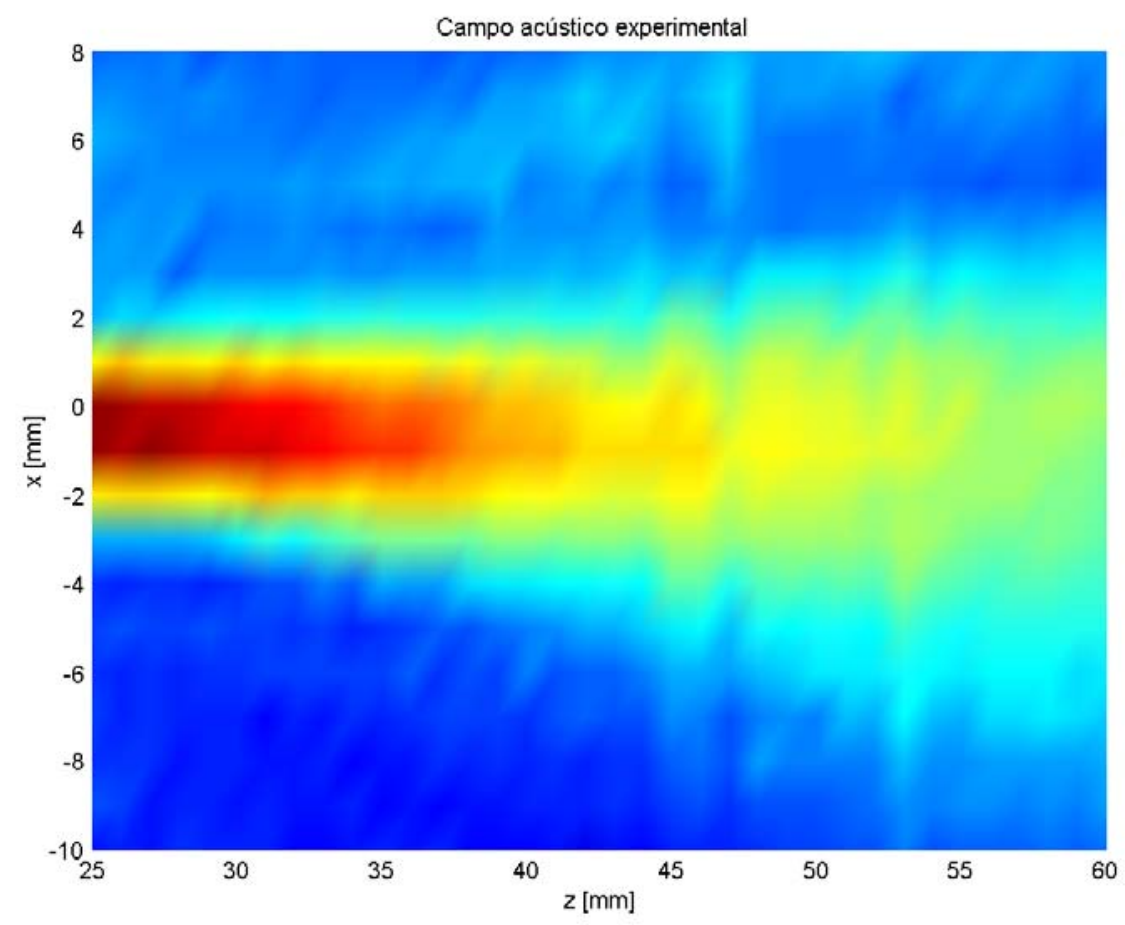

Figura 5.19. Campo acústico experimental, sem deflexão e com focalização no eixo acústico, em $z=30 \mathrm{~mm}$.

Campo acústico do array, quarto caso: focalização, com deflexão.

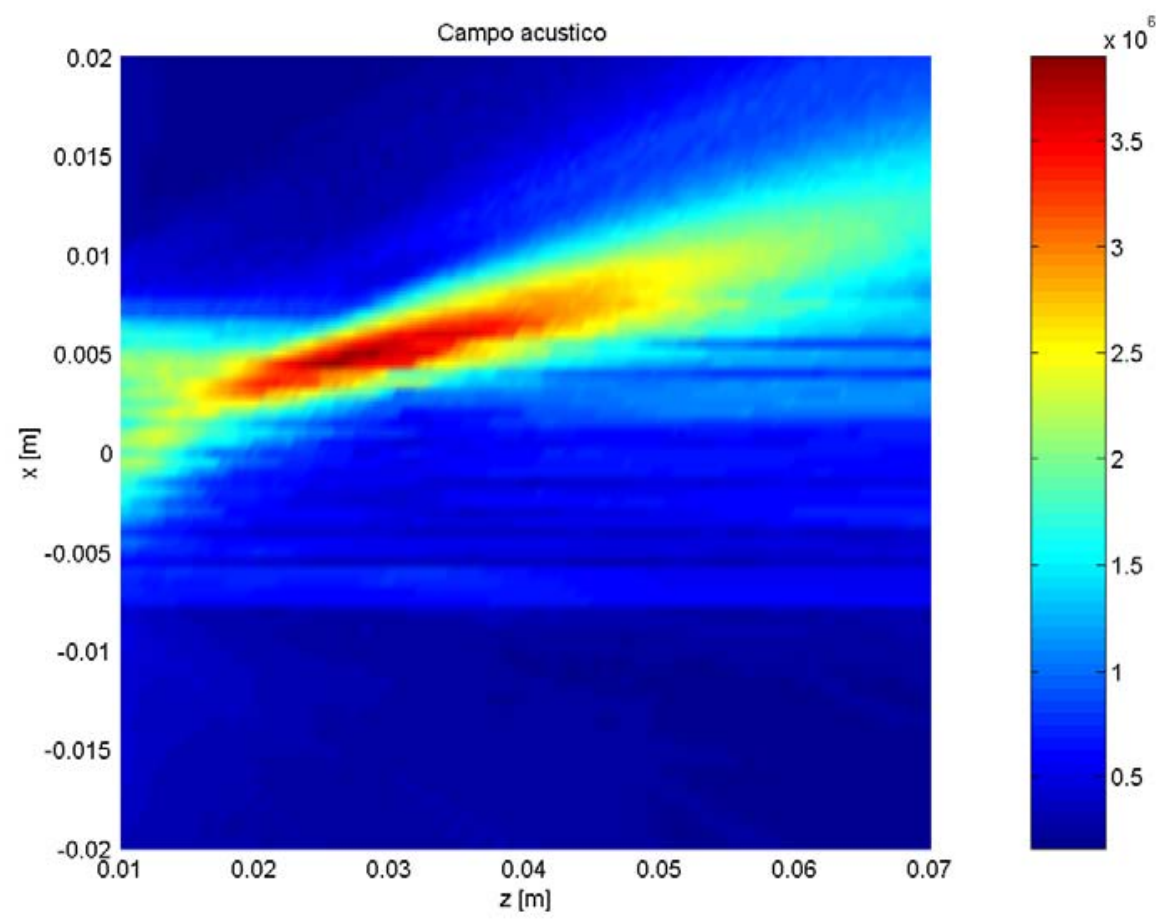

Figura 5.20. Campo acústico teórico, com deflexão de $10^{\circ}$ e com focalização em $z=30 \mathrm{~mm}$. 


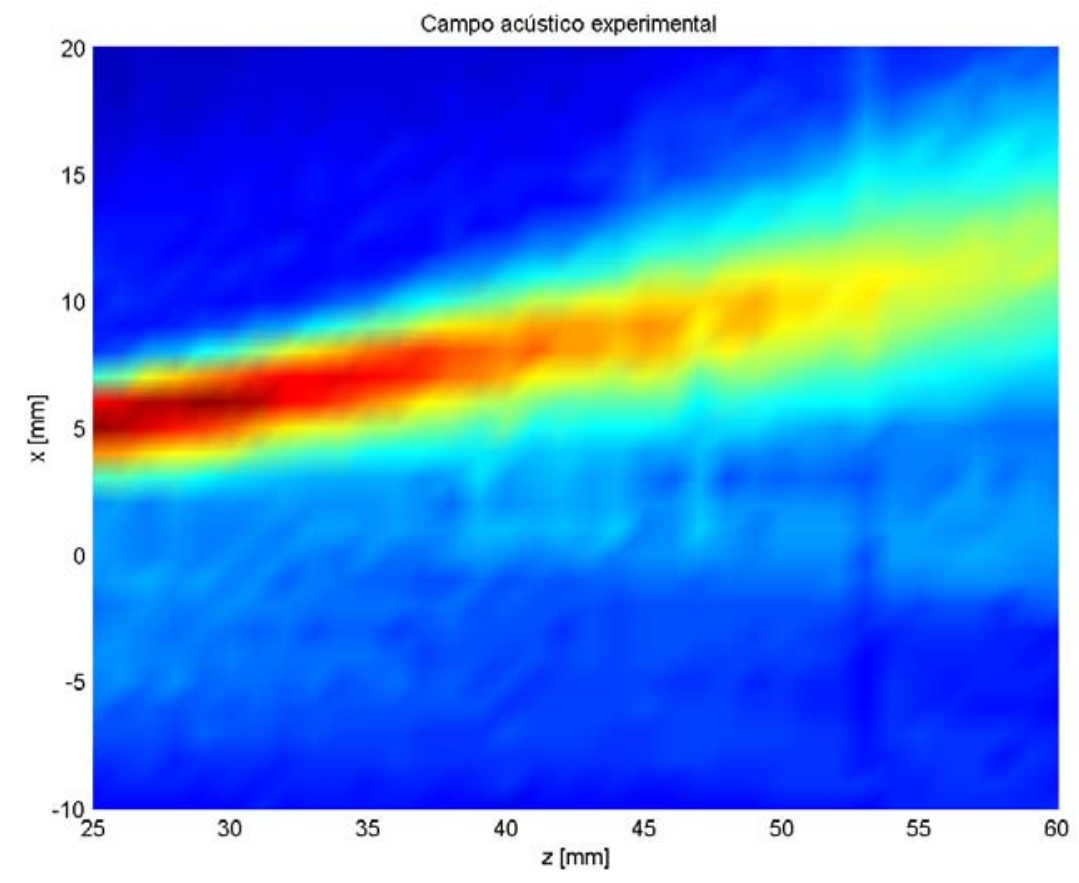

Figura 5.21. Campo acústico experimental, com deflexão de $10^{\circ}$ e com focalização em $z=30 \mathrm{~mm}$. 


\section{CAPÍTULO 6 CONCLUSÃO}

Neste trabalho foi utilizado um modelo analítico para calcular o campo acústico gerado por transdutores com geometria retangular monoelemento e multielemento (array). O campo acústico obtido com o modelo foi comparado com o obtido experimentalmente num tanque de imersão utilizando um hidrofone pontual, com quatro transdutores monoelementos retangulares e um array linear de 12 elementos.

Os resultados teóricos apresentaram boa concordância com os experimentais, exceto para baixas freqüências, condições em que as dimensões dos transdutores são próximas ao comprimento de onda. A utilização de um modelo analítico permite prever o campo acústico com menor tempo de processamento que o emprego de métodos numéricos. Entretanto, essa solução não é válida para todos os casos, como observado nos resultados obtidos para baixas freqüências, pois os transdutores não operam em modo de espessura.

Utilizando o algoritmo implementado, poderão ser verificados e comparados modelos de simulação do campo acústico para diferentes razões freqüência-abertura de transdutores, a fim de estabelecer uma relação entre o campo real e o campo simulado. Dessa forma, pode-se utilizar em trabalhos futuros comparando-o com modelos numéricos, como o Método de Elementos Finitos. 


\section{REFERÊNCIAS BIBLIOGRÁFICAS}

- Abboud, N. et al., 1998. "Finite element modeling for Ultrasonic Transducers". International Symposium Medical Imaging 1998, San Diego, USA, pp. 1-24.

- Adamowski, J. C., 1993. “Medição de Densidade de Líquidos por Ultra-som”. Tese de Doutorado. Universidade de São Paulo, São Paulo.

- Andrade, M. A. B., 2006. “Análise de materiais piezelétricos compósitos para aplicações em transdutores de ultra-som”. Dissertação de Mestrado, Universidade de São Paulo, São Paulo.

- Buiochi, F., 1994. "Análise dos métodos de medição de densidade de líquidos por ultrasom”. Dissertação de Mestrado, Universidade de São Paulo, São Paulo.

- Buiochi, F.; Jimbo, M.; Andrade, M. A. B.; Adamowski, J. C., 2006. "Transdutor matricial linear de ultra-som: modelagem, fabricação e formação de imagem”. IV Congresso Nacional de Engenharia Mecânica. Recife, Pernambuco.

- Chapman, S. J., 2003. "Programação em MATLAB para Engenheiros”. Pioneira Thomson, São Paulo.

- Elmore, W. C.; Heald, M. A., 1985. "Physics of waves”. Dover Publications, Inc., New York.

- Franco E.; Andrade, M. A. B.; San Miguel, J.; Buiochi, F.; Adamowski, J. C., 2005. "Determination of the acoustic properties of Tungsten/Epoxy and Tungsten/Polyurethane composites using Ultrasonics transmission technique”. Proceeding of COBEM 2005, Ouro Preto, MG.

- Freedman, A., 1960. "Sound field of a Rectangular Piston". Journal of the Acoustical Society of America, vol. 32, pp. 197-209.

- Fritsch, C., 2001. “Técnica electrónicas de Focalización de Haces Ultrasónicos”. Red Iberoamericana de Tecnologia Ultrasónica, Madrid. 
- Gómez-Ullate, L., 1992. “Análisis del campo ultrasónico transitorio emitido por arrays lineales sometidos a excitaciones temporales arbitrarias”. Tesis doctoral, Universidad Pontificia de Comillas, Madrid.

- Hayman, A J.; Weight, J. P., 1979. “Transmission and reception of short ultrasonic pulses by circular and square transducers". Journal of the Acoustical Society of America, vol. 66, pp. 945-951.

- Harris, G. R., 1981a. "Review of transient field theory for a baffled planar piston". Journal of the Acoustical Society of America, vol. 70, pp. 10-20.

- Harris, G. R., 1981b. “Transient field of a baffled planar piston having an arbitrary vibration amplitude distribution". Journal of the Acoustical Society of America, vol. 70, pp. 186-204.

- Hofer, M.; Lerch, R., 2002. "Finite element calculation of Wave Propagation and Excitation in Periodic Piezoelectric System", Fifth World Congress on Computational Mechanics, Vienna, Austria, pp. 1-12.

- Hutchins, D. A.; Hayward, G., 1990. "Radiated fields of ultrasonic transducers", Ultrasonic Measurement Methods, Physical Acoustics, vol XIX, pp. 1-80, Academic Press, Inc., London.

- Jensen, J. A.; Svendsen, N. B., 1992. "Calculation of pressure fields from arbitrarily shaped, apodized, and excited ultrasound transducers", IEEE Transactions on UF\&FC 39, 262-267.

- Jensen, J. A, 1996. "Ultrasound fields from triangular apertures", Journal of the Acoustical Society of America, vol. 100, pp. 2049-2056.

- Jensen, J. A., 1999. "A new Calculation procedure for spatial impulse response in ultrasound", Journal of the Acoustical Society of America, vol. 105, pp. 3266-3274.

- Jinbo, M., 2007. “Imagens ultra-sônicas em modo-B com técnicas de abertura focal sintética - SAFT”. Dissertação de Mestrado, Universidade de São Paulo, São Paulo.

- Kinsler, L. E.; Frey, A. R.; Coppens, A. B.; Sanders, J. V., 1982. "Fundamentals of Acoustics”. John Wiley \& Sons, New York. 
- Kino, G. S., 2000. “Acoustic Waves: Devices, Imaging and Analog Signal Processing”, Prentice-Hall Inc., New Jersey.

- Lamberti, N., Giua, P. E.; Pappalardo, M., 1987. "Modello matriciale e suo impiego nell'ottimizzazione della risposta impulsiva del trasduttore multielemento", Università de Salerno, Rapporti scientifici.

- Lee, J. H.; Choi, S. W., 2000. “A Parametric Study of Ultrasonic Beam Profiles for a Linear Phased Array Transducer", IEEE Transactions on Ultrasonics, Ferroelectrics, and Frequency Control, Vol. 47, No. 3, pp. 644-650.

- Ludwig, R., 1989. “A Nondestructive Ultrasonic Imaging System for Detection of Flaws in Metal Blocks", IEEE Transactions on Instrumentation and Measurement, Vol. 38, No. 1, pp. 113-118.

- Lingvall, F., 2004. “Time-Domain reconstruction methods for Ultrasonics array imaging: a statistical approach”. Thesis for the degree of Doctor of Philosophy, Uppsala University.

- Lockwood, J. C.; Willette, J. G., 1973. "High-speed method for computing the exact solution for the pressure variations in the near field of a baffled piston". Journal of the Acoustical Society of America, vol. 53, pp. 735-741.

- Maclaren, S.; Weight, J. P., 1987. “Transmit-receive mode responses from finite-sized targets in fluid media", Journal of the Acoustical Society of America, vol. 82, pp. 21022112.

- Neild, A.; Hutchins, D. A, 2004. “A theoretical model for a finite-size acoustic receiver", Journal of the Acoustical Society of America vol. 115, pp. 1546-1556.

- Piwakowski, B.; Sbai, K., 1999, “A New Approach to Calculate the Field Radiated from Arbitrarily Structured Transducer Arrays", IEEE Transactions on Ultrasonics, Ferroelectrics, and Frequency Control, Vol. 46, No. 2, pp. 422-440.

- Robinson, D. E.; Lees, S.; Bess, L., 1974. "Near field transient Radiation Patterns for Circular Pistons", IEEE Transactions on AS\&SP, Vol. 22, No. 6, pp. 395-403. 
- San Emeterio, J. L.; Gomez Ullate, L., 1992. "Diffraction impulse response of rectangular transducers", Journal of the Acoustical Society of America, vol. 92, pp. 651-662.

- $\quad$ Shung, K. K.; Zipparo, M., 1996. "Ultrasonic Transducers and Arrays”, IEEE Engineering in Medicine and Biology, November/December, pp. 20-30.

- Stepanishen, P. R., 1971a. “An Approach to Compute Time-Dependent Interaction Forces and Mutual Radiation Impedances between Pistons in a Rigid Infinite Radial Baffles". Journal of the Acoustical Society of America, vol. 49, pp. 283-292.

- Stepanishen, P. R., 1971b. "The Time-Dependent Forces and Radiation Impedances on a Pistons in a Rigid Infinite Planar Baffles ". Journal of the Acoustical Society of America, vol. 49, pp. 841-849.

- Stepanishen, P. R., 1971c. "Transient Radiation from Pistons in an Infinite Planar Baffle". Journal of the Acoustical Society of America, vol. 49, pp. 1629-1638. 


\section{APÊNDICE A - Arquivo “m” da resposta espacial impulsiva.}

function $\mathrm{h}=$ resposta_impulsiva_r(x,y,z)

$\%$ calcula a resposta impulsiva de um transdutor retangular de lado maior $2 \mathrm{~b}$ e lado menor $2 \mathrm{a}$

$\mathrm{x}=$ input ('distancia $\mathrm{x}:$ ');

$\mathrm{y}=$ input ('distancia $\mathrm{y:}$ ');

$\mathrm{z}=$ input ('distancia $\mathrm{z}$ : ');

c=1500; \%velocidade de propagacao na água $(\mathrm{m} / \mathrm{s})$

$\mathrm{a}=10.83 \mathrm{e}-3 / 2 ; \%$ lado menor do retangulo dividido por $2(\mathrm{~m})$

$\mathrm{b}=18.08 \mathrm{e}-3 / 2$; \%lado maior do retangulo dividido por $2(\mathrm{~m})$

deltat $=32 \mathrm{e}-9 ; \%$ discretizacao do tempo (s)

$\%$ variaveis usadas conforme figura 2.7

$\mathrm{d} 1=\mathrm{x}-\mathrm{a}$;

$\mathrm{d} 2=\mathrm{y}-\mathrm{b}$;

$\mathrm{d} 3=\mathrm{x}+\mathrm{a}$;

$\mathrm{d} 4=\mathrm{y}+\mathrm{b}$;

$\%$ tempo para atingir os pontos A, B, C, D

$\mathrm{tA}=\operatorname{sqrt}\left(\mathrm{d} 1^{\wedge} 2+\mathrm{d} 2^{\wedge} 2+\mathrm{z}^{\wedge} 2\right) / \mathrm{c}$

$\mathrm{tB}=\operatorname{sqrt}\left(\mathrm{d} 2^{\wedge} 2+\mathrm{d} 3^{\wedge} 2+\mathrm{z}^{\wedge} 2\right) / \mathrm{c}$;

$\mathrm{tC}=\operatorname{sqrt}\left(\mathrm{d} 1^{\wedge} 2+\mathrm{d} 4^{\wedge} 2+\mathrm{z}^{\wedge} 2\right) / \mathrm{c}$

$\mathrm{tD}=\operatorname{sqrt}\left(\mathrm{d} 3^{\wedge} 2+\mathrm{d} 4^{\wedge} 2+\mathrm{z}^{\wedge} 2\right) / \mathrm{c}$;

$\%$ tempo para atingir o plano xy, lado 1 e lado 2 do transdutor

$\mathrm{t} 0=\mathrm{z} / \mathrm{c}$;

$\mathrm{t} 1=\operatorname{sqrt}\left(\mathrm{d} 1 \wedge 2+\mathrm{z}^{\wedge} 2\right) / \mathrm{c}$;

$\mathrm{t} 2=\operatorname{sqrt}\left(\mathrm{d} 2^{\wedge} 2+\mathrm{z}^{\wedge} 2\right) / \mathrm{c}$;

$\% \% \% \% \% \%$ determina a qual regiao $(\mathrm{x}, \mathrm{y}, \mathrm{z})$ pertence e determina tmin

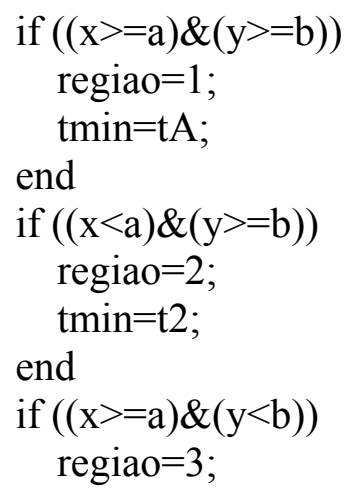




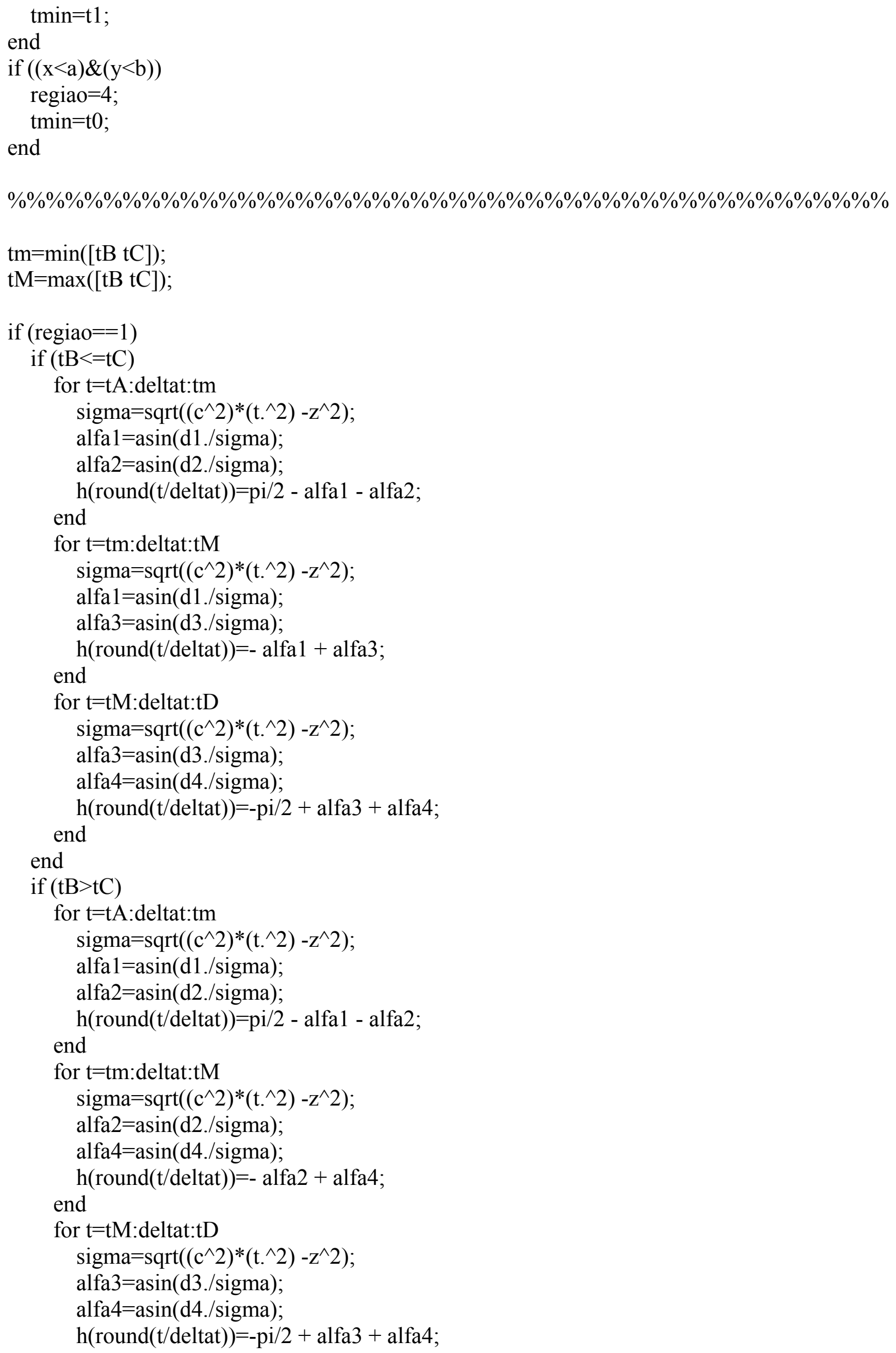




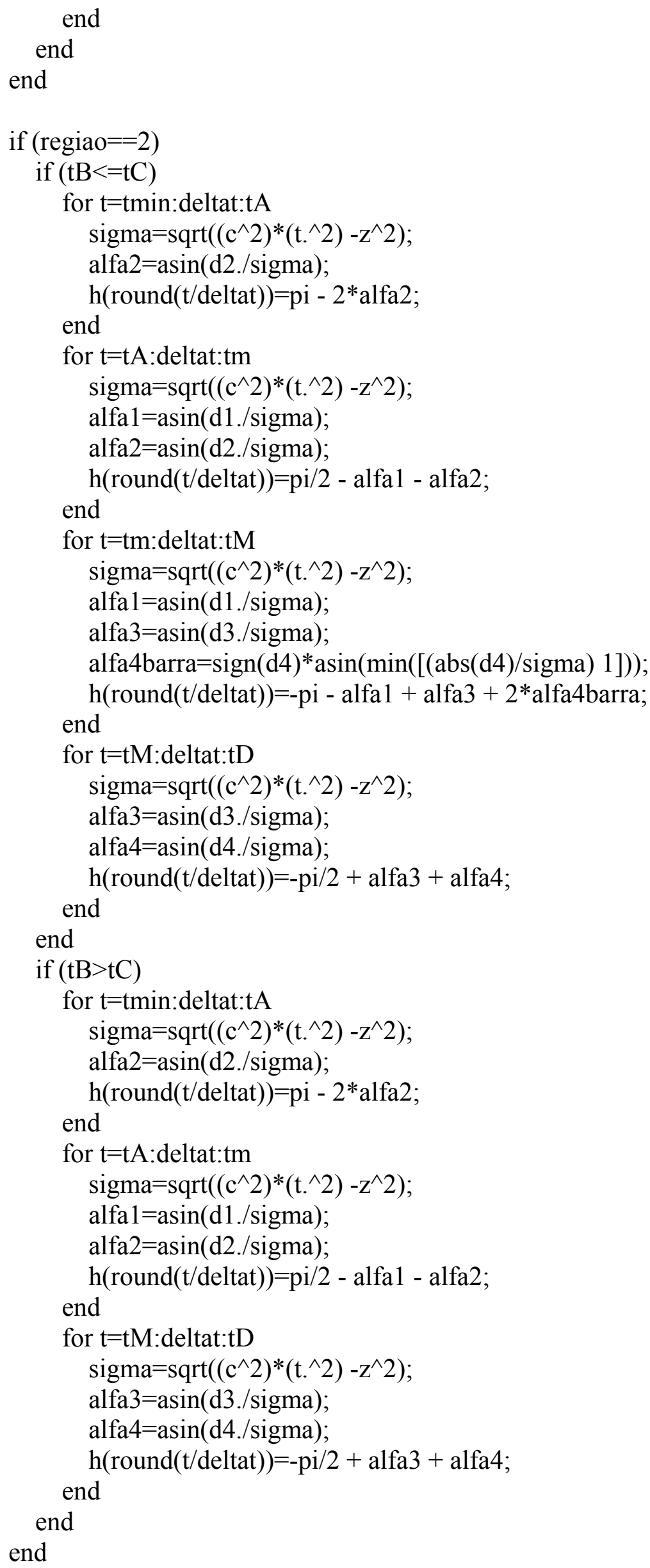




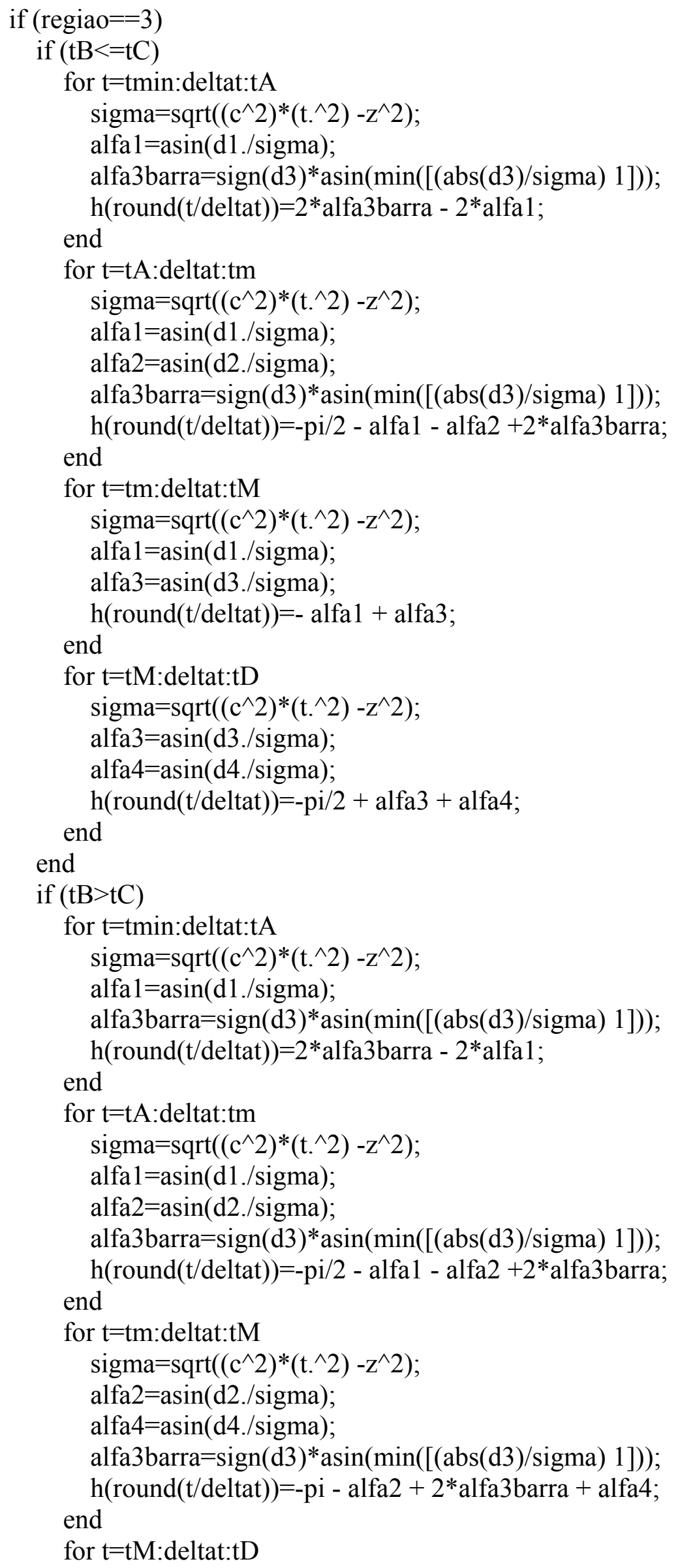




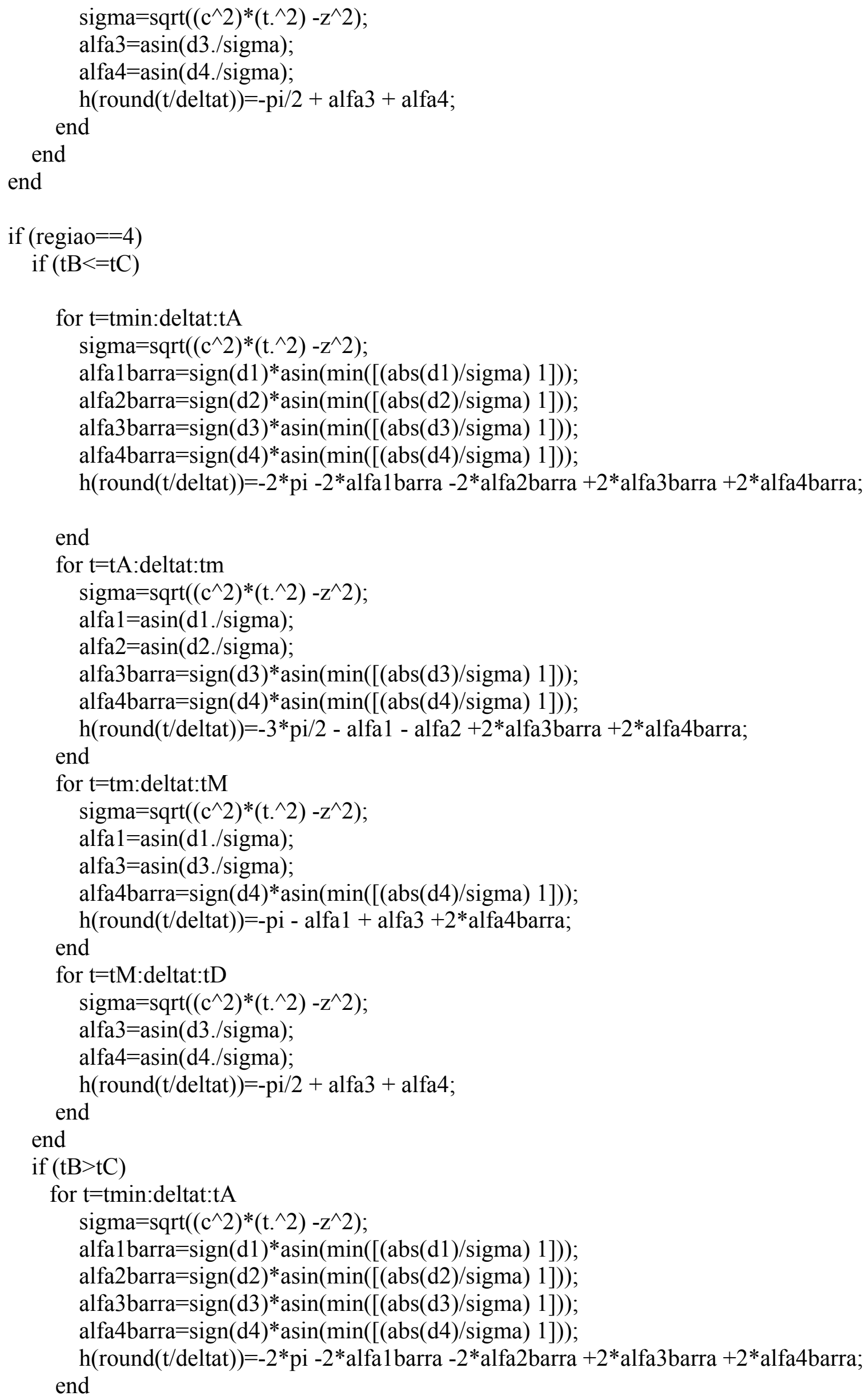




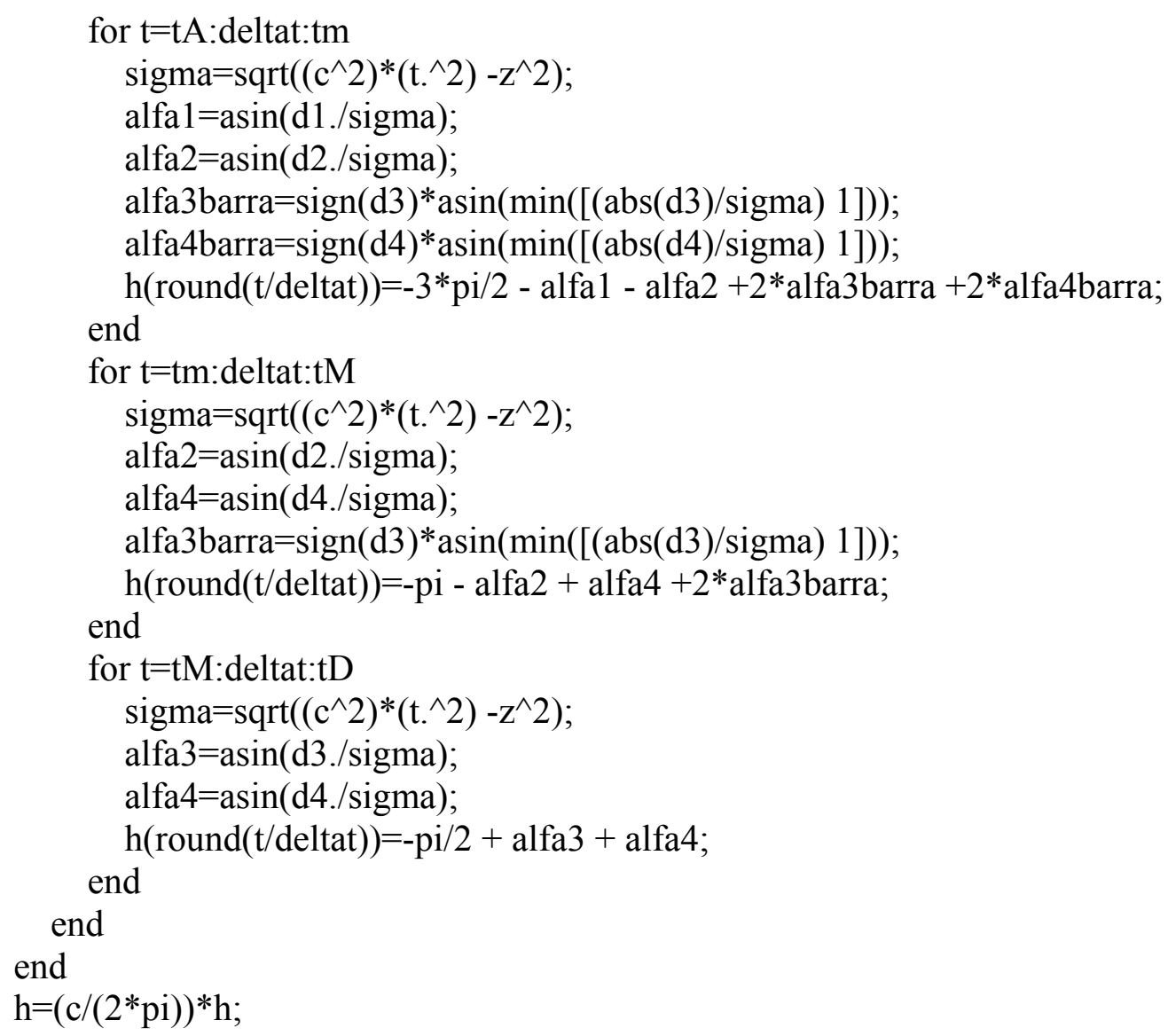

